University of Louisville

ThinkIR: The University of Louisville's Institutional Repository

Electronic Theses and Dissertations

$5-2017$

\title{
Embeddedness and commitment : tracing patterns of family instability and child wellbeing over time.
}

Heidi Michele Williams

University of Louisville

Follow this and additional works at: https://ir.library.louisville.edu/etd

Part of the Sociology Commons

\section{Recommended Citation}

Williams, Heidi Michele, "Embeddedness and commitment : tracing patterns of family instability and child wellbeing over time." (2017). Electronic Theses and Dissertations. Paper 2672.

https://doi.org/10.18297/etd/2672

This Doctoral Dissertation is brought to you for free and open access by ThinkIR: The University of Louisville's Institutional Repository. It has been accepted for inclusion in Electronic Theses and Dissertations by an authorized administrator of ThinkIR: The University of Louisville's Institutional Repository. This title appears here courtesy of the author, who has retained all other copyrights. For more information, please contact thinkir@louisville.edu. 
EMBEDDEDNESS AND COMMITMENT: TRACING PATTERNS OF FAMILY INSTABILITY AND CHILD WELLBEING OVER TIME

\author{
By \\ Heidi Michele Williams \\ M.A., Marshall University, 2003 \\ B.A., Marshall University, 2001 \\ A Dissertation \\ Submitted to the Faculty of the \\ College of Arts and Sciences of the University of Louisville \\ in Partial Fulfillment of the Requirements \\ for the Degree of \\ Doctor of Philosophy in Applied Sociology \\ Department of Sociology \\ University of Louisville \\ Louisville, Kentucky
}

May 2017 
(C) Copyright 2017 by Heidi Michele Williams

All rights reserved. 

EMBEDDEDNESS AND COMMITMENT: TRACING PATTERNS OF FAMILY INSTABILITY AND CHILD WELLBEING OVER TIME

\section{By}

Heidi Michele Williams

M.A., Marshall University, 2003

B.A., Marshall University, 2001

A Dissertation Approved on

April 19, 2017

by the following Dissertation Committee:

Robin Högnäs, PhD, Director

Robert Carini, $\mathrm{PhD}$

Karen Christopher, PhD

Lauren Heberle, $\mathrm{PhD}$

Armon Perry, PhD 


\section{DEDICATION}

This dissertation is dedicated to my grandmothers-Polly and Mary-who taught me early on the meaning of family. Neither of my grandmothers spent much time heading nuclear families; rather, they masterfully coordinated multigenerational households, concurrently caring for their own parents, their husbands and children, and even grandchildren. Growing up, I thought multigenerational households were the norm and always envied my two cousins who were lucky enough to live with my grandmothers. Now I realize how much effort and sacrifice (my word, certainly not theirs) it took for both of them to keep their households going.

To Grandma Polly, I am elated that you will share in my celebration of earning a $\mathrm{PhD}$ ! Thank you for teaching me that books are important and reading is an art. I have enjoyed our decades-long book club. I will always search for the red dot.

To Grandma Mary, I miss you every day. I promise to always, always insist that my guests drink coffee and eat something in your honor. Thank you for teaching me how to tell stories-you were the first sociologist I encountered, if only in practice and not in name.

In the words of Joni Mitchell, “'Love is touching souls.' Surely you touched mine 'cause part of you pours out of me in these lines from time to time."

Thank you both for inspiring me and my research. Don't these papers sound familiar? 


\section{ACKNOWLEGEMENTS}

I would like to thank my committee members-Drs. Robin Högnäs, Robert Carini, Karen Christopher, Lauren Heberle, and Armon Perry-for guiding me through the dissertation process.

To my chair, Robin Högnäs, thank you for introducing me to The Fragile Families and Child Wellbeing Study, for pushing me to explore statistical methods that terrify me, for insisting that I submit papers for presentation and publication, and for applying for workshops that I thought were out of my reach. You certainly pushed me well beyond my comfort zone and the limits I had imposed on my potential—for which I sincerely thank you.

To Bob and Karen, in addition to my dissertation committee, thank you for serving on my comprehensive exams and internship committees. You both stuck with me for three years - a commitment that spans the length of time it took the Fragile Families researchers to collect the first three waves of data. Thank you.

To Lauren and Armon, thank you for your feedback and guidance, particularly your useful comments at the proposal defense. And, Lauren, thank you for the continued reassurance (and hugs) that I would finish the dissertation.

Thank you to the Department of Sociology, the School of Interdisciplinary and Graduate Studies, and The Mary Craik Scholarship for funding my doctoral program. And, thank you to the Women's Center, the Graduate Student Council, the Graduate Student Union, and the Columbia Population Research Center for funding travel associated with my research.

I would be remiss if I did not also thank the countless people in my life who have supported me throughout my doctoral program. Where to begin?

Thank you Marcia Harrison for reporting to the National Science Foundation that an outcome of our ADVANCE Program was that the Program Coordinator (me!) would pursue a $\mathrm{PhD}$ in Sociology. No pressure!

To Jonetta Weber, thank you for always having (or finding) the answers. And, thank you for not yelling at me each time I forgot to do something (e.g., register for classes), which caused you more work. I appreciate you. 
To my peers, thank you for lending an ear and spending countless hours working on projects with me. In particular, I want to thank Cheryl Crane and Christa Moore, both of whom have not forgotten me, even after becoming doctors themselves. I have sincerely appreciated the phone calls, text messages, and emails over the past few months.

Cheryl, I will always think of you when I think of this program, as yours was the first face I remember seeing. In many ways, you were my motivating force throughout this program - thank you.

To my dedicated peer group — Katie Adamchik and Jennifer O. Rudy — I have a question? Have any of us made a decision over the past two years without consulting each other? I think not. I hope we continue to bounce ideas off of each other. Like Cheryl and Christa have done for me, I plan to encourage you both to the finish line.

To my friends, especially Susan Weinstein, Kelli Kerbawy, and Carol Johnson, thank you for continuously checking on me, visiting me in Louisville, sending food (mmm, cashews!), and simply being unconditional friends. I hope that I support you in similar ways.

To Ruby, thank you for keeping me healthy. It's a hard job, but you did it well.

To my family. Mom, thank you for being stronger than you know. Our late night phone conversations always kept me motivated. Dad, thank you for teaching me to stand up for what I believe in, even when it is not popular. To my brother, thank you for being constantly present during our own family structure transitions. I realize you were not in control of your living situation, but know your consistent presence mattered. To Mary and Sarah, my fearless cheerleaders! And, to Linda, thank you for always reading my academic books and chatting with me about them. I love you all.

To my partner, Jamie Lau, thank you for convincing me that I should pursue a $\mathrm{PhD}$ (and for pointing out that I would be 40 with or without one). I cannot thank you enough for the never-ending encouragement. Specifically, thank you for reading every page I wrote in this program to check for errors, listening to my research ideas (endlessly), sitting with me as I ran my statistical models, and pacing around the house with me as I fretted about every little thing. Thank you for believing in me, not only as a scholar, but as a human being. You are the kindest and most patient soul I know. I'm looking forward to our new adventure. All my love.

Thank you to the families who participated in The Fragile Families and Child Wellbeing Study. It is brave to share your life for the betterment of society.

Having nearly two pages of acknowledgements for one project is a testament to what Sociologists insist is true - nothing in life is ever accomplished alone or without help. We are all reliant on the kindness of others. May our society one day accept this as truth and find its way forward. 


\title{
ABSTRACT \\ EMBEDDEDNESS AND COMMITMENT: TRACING PATTERNS OF FAMILY INSTABILITY AND CHILD WELLBEING OVER TIME
}

\author{
Heidi Michele Williams
}

April 19, 2017

This dissertation consists of an introductory chapter; three quantitative papers, all using data from the Fragile Families and Child Wellbeing Study; and a discussion chapter. Chapter Two, "For us or the children: Exploring the association between coparenting trajectories and parental commitment," is situated in commitment theory and estimates latent growth curves. Findings suggest that coparenting relationships among unmarried parents are strong across the first five years of their children's lives. Further, coparenting relationships appear to influence parental commitment at year 5. Supportive coparenting among unmarried, cohabiting parents (i.e., less committed than married parents) increases the strength of parental relationships.

Chapter Three, titled "Maternal partnership transitions and coresidence with extended kin," is situated in life course theory and estimates fixed and random effects models. Findings suggest that unmarried mothers versus married mothers are significantly more likely to coreside with extended kin, especially early in their children's lives and following a partnership break up. Unmarried mothers, versus married mothers, are significantly more likely to live in extended kin homes than their own homes. By year 
9, unmarried mothers are significantly more likely to live elsewhere-either with friends or in temporary shelters. Reliance on extended kin appears to weaken over time, which may be associated with mothers experiencing more stress when living with family, or because mothers have exhausted the resources available to them from extended kin. Race is a more significant predictor of extended kin coresidence than socioeconomic status, with significant associations between Hispanic and mothers who self-identify as "other" races and extended kin coresidence. Importantly, this study found that money is not the only significant factor among families who double up; rather, mothers turn to family members during transitional times.

Chapter Four, "Nest effects: How children fare when changes occur within their mesosystems," is situated in ecological theory and estimates multilevel models. Findings suggest that extended kin mediate the association between mothers' relationship transitions when mothers consistently cohabit, when they transition from cohabiting relationships to being single, and when they are consistently single. Although extended kin coresidence appears to increase both internalizing and externalizing behaviors, they do buffer children from instability caused by fathers' incarceration or mothers' new multipartnered fertility. Extended kin may offer resources (e.g., attention) to children when their parents are distracted or absent. Children who visit fathers and who benefit from fathers' child support payments fare better than children who do not. Race and education appear to moderate the association between family structure transitions and child wellbeing. For nonwhite children, living with extended kin and mothers' relationship transitions increase children's internalizing and externalizing behaviors. On the other hand, if nonwhite children live with extended kin, but their parents do not 
experience a transition, extended kin do not influence externalizing behaviors. Mothers' education levels influence child wellbeing; however, for the lowest educated mothers with no transitions, extended kin coresidence appears to buffer children from externalizing, but not internalizing behaviors. Overall, children of mothers with less education, net of extended kin coresidence and transitions, are more likely than children with higher educated mothers to express internalizing and externalizing behaviors.

Chapter Five explores the connections between the three quantitative papers, discusses the contribution each makes to the literature, and highlights future research.

These three papers connect in that mothers' relationship status is an important factor in coparenting relationships (see Fagan and Palkovitz 2011) doubling up (Pilkauskas et al. 2014), and child outcomes (Lee and McLanahan 2015). There is evidence that a "new package deal" exists, suggesting that parents are initially committed to their shared children rather than to each other. However, if parental commitment (to each other) increases, parents may prioritize their relationship over their children (even briefly)—which may explain why mothers' reports of children's internalizing and externalizing behaviors increase when they move in with, or marry, biological fathers.

However, many mothers break up with both biological and social fathers over the first nine years of their children's lives. Relationship transitions may necessitate a period of coresidence with extended kin. Extended kin coresidence exacerbates maternal stress (Jackson 1998) and makes things worse for children — which may be why mothers tend to rely less on extended kin as their children age. Family members may interfere too much in mothers' lives, both to protect mothers (and their children) and themselves. In other words, extended kin may interfere in mothers' relationship decisions when mothers have 
supportive partners, as extended kin may benefit from mothers' partnerships (i.e., extended kin may not be providing support to mothers when they are partnered).

Although extended kin make things worse for mothers and their children, they do mediate the association between paternal incarceration and mothers' new multipartnered fertility. As focal children deal with changes in their mesosystems, extended kin may provide support (e.g., attention, financial support) that buffers children from change. 


\section{TABLE OF CONTENTS}

PAGE

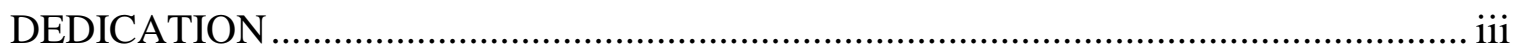

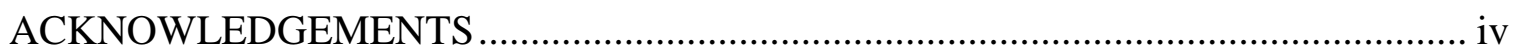

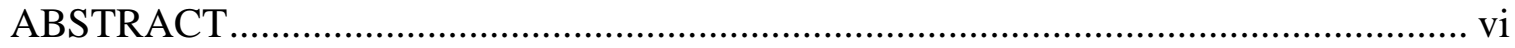

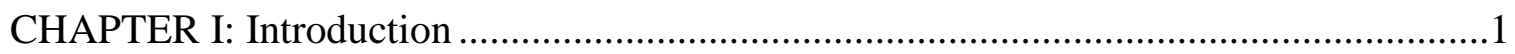

CHAPTER II: For Us or the Children?.................................................................12

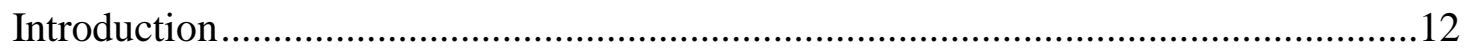

Theoretical Framework and Background...................................................................14

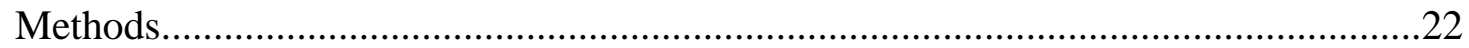

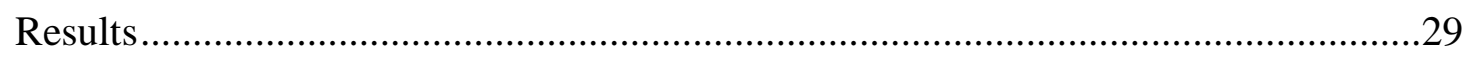

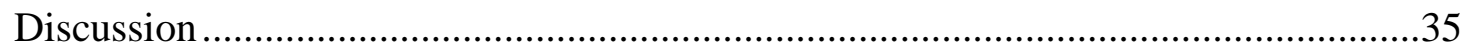

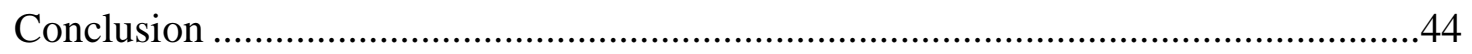

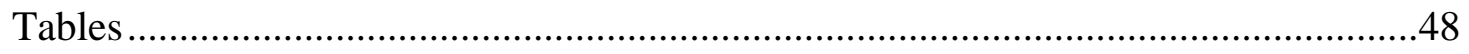

CHAPTER III: Transitions and Extended Kin Coresidence................................................54

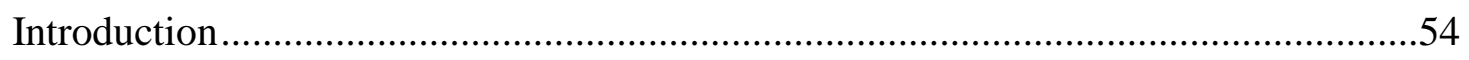

Theoretical Framework and Background.............................................................57

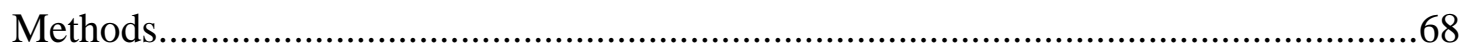

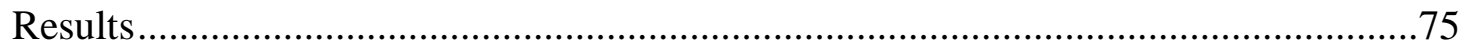

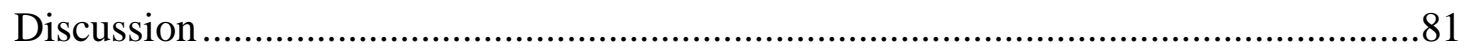


CHAPTER III continued

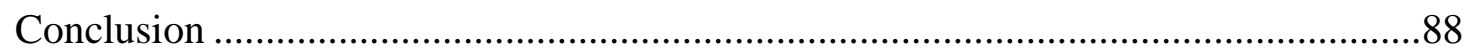

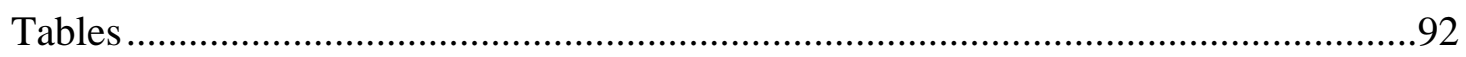

CHAPTER IV: Child Wellbeing within Mesosystems....................................................95

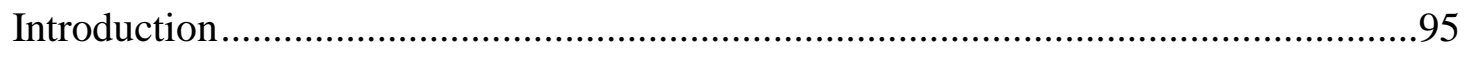

Theoretical Framework and Background...............................................................96

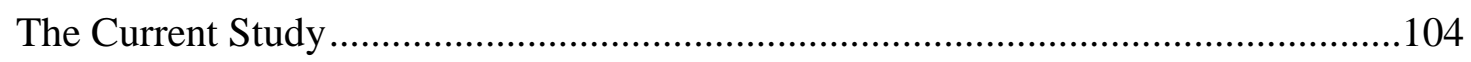

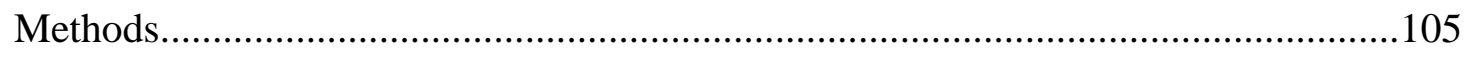

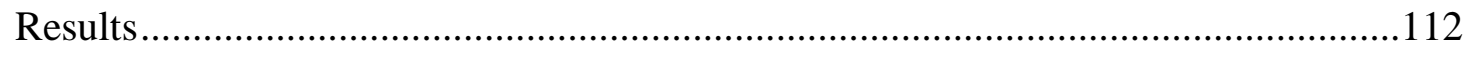

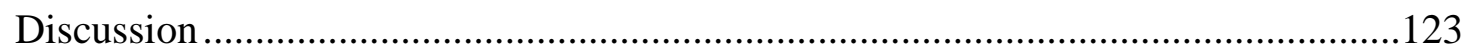

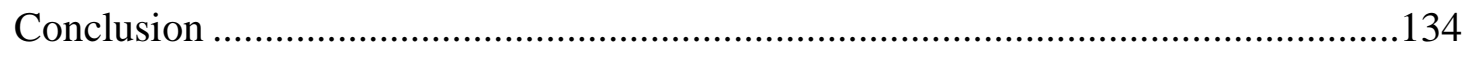

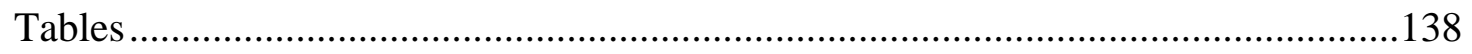

CHATPER V: Round and Round in the Family Game ……...........................................143

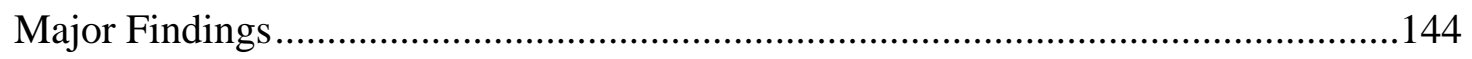

Connections between Chapters II through IV ........................................................148

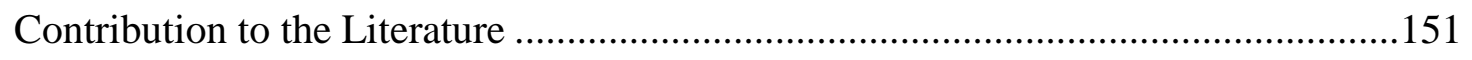

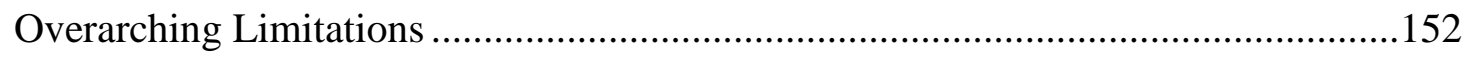

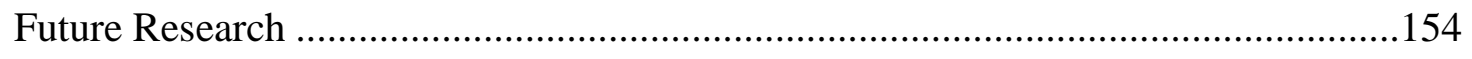

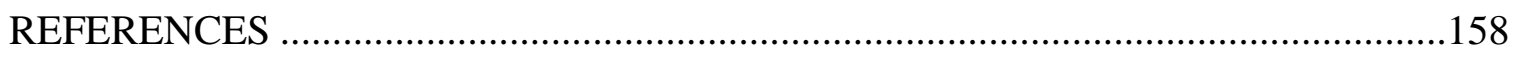

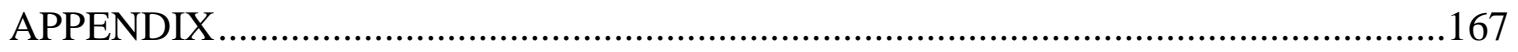

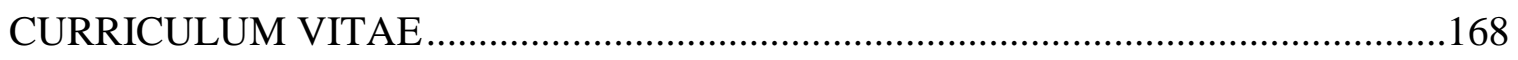




\section{CHAPTER I: \\ INTRODUCTION}

Over the past 50 years, the United States has witnessed dramatic changes in romantic partnering and parenting. Although marriage remains the most coveted and optimal family context for couples and children (Gibson-Davis et al. 2005; Cherlin 2009), economic changes, such as deindustrialization (Western et al. 2008), and differential educational attainment (Musick et al. 2010), have largely precluded low-income, lower educated men and women from the institution (Furstenberg 2003). Indeed, research suggests that there is an economic "marriage bar" among many low-income couples. For example, many low-income mothers believe that there is an (unattainable) optimal level of wealth accumulation necessary before marriage becomes an option (e.g., Edin and Kefalas 2005). Therefore, because children bring meaning and purpose to mothers' lives and mothers believe the marriage bar is often out of reach, marriage is no longer a required context for childbearing and childrearing (Edin and Kefalas 2005; McLanahan 2011). In fact, estimates show nonmarital childbearing has increased from $6 \%$ of all births in the early 1960s to $41 \%$ of all births in 2011(Martin et al. 2013), with lowincome couples overrepresented among this group (Carlson and England 2011).

Some scholars argue that shifts in cultural attitudes and the economy have unfettered sexual practices and childrearing from marriage. Research shows that many parents feel marriage requires more dedication to partners than is necessary prior to bearing children (Gibson et al. 2005; Reed 2006); therefore, cohabitation, particularly 
among low-income families, has surpassed marriage as the context for childbirth and childrearing (Bumpass 1990). In fact, Brown (2005) argues that over the past 40 years, cohabitation among the least educated and most financially stricken has increased by a factor of four. Undeniably, education now plays a salient role in who one marries, and when couples marry each other and have children. In general, scholars have found that college-educated couples tend to marry (albeit at later ages) and stay married (Mare 1991; Schwartz and Mare 2005; Brown 2005; Cherlin 2010), as their marriage protects their relationship from external influences such as extended family members who intervene on matters that do not directly concern them (Cherlin and Furstenberg 1986). So, education selection is important in determining who cohabits and who marries (SigleRushton and McLanahan 2004).

Further, those with more cultural and social capital (i.e., from education, employment, and personal networks) possess attributes that allow for entry into stable relationships, especially marriage (Carlson and Furstenberg 2006; Smeeding et al. 2011). The same factors contribute to child wellbeing (McLanahan 2004). Children reared in two-parent, low-conflict married households fare better than children raised in families outside of marriage (McLanahan 2004; Amato 2005). However, it appears that twoparent households only have salubrious effects on children if they are maintained throughout childhood. In fact, Lee and McLanahan (2015) found that transitions out of two-parent households cause both externalizing (e.g., fighting with other children) and internalizing (e.g., withdrawing socially) behaviors to spike among children. Moreover, the number and type of parental partnership changes (i.e., dating versus coresidential) 
affect outcomes such as children's cognitive functioning that may delay school readiness (Cooper et al. 2011).

Children born outside versus inside of marriage are more likely to experience parental and household transitions (Smock 2000) and an increased number of halfsiblings, all of which exacerbate parental stress and family instability (Fomby and Cherlin 2007; Smeeding et al. 2011). Multipartnered fertility (i.e., childbearing with more than one partner) generates family complexity. Around $33 \%$ of fragile families consist of one parent having a child with a partner who is not the focal child's parent (Carlson and Furstenberg 2006). For more than $10 \%$ of these families, both the mother and father have additional children with new partners (Carlson and Furstenberg 2006). Multipartnered fertility leads to an increase in the number of households and adults with which children interact. Further, multipartnered fertility, especially fathers', creates more economic hardships for focal children, as fathers' new fertility often means that they are more involved with their new children (Manning and Smock 2000; Uhlenberg and Mueller 2003) — as new children give fathers second chances at parenthood (Edin and Nelson 2013).

Although research suggests that partnerships that occur outside of marriage, or emerge from parenthood, tend to be precarious (Uhlenberg and Mueller 2003), scholars have reason to believe that ties with extended kin will remain strong. In fact, Bumpass (1990) argued that "the ascribed aspect of [intergenerational relationships] makes parents and children more permanent members of one's 'convoy' of social support over the life course. Friends and even spouses may come and go, but it is harder to trade in one's parents" (491). Intergenerational ties may become increasingly important as families 
negotiate new partnering paths (Cherlin 2010: 414) and as the economy continues to polarize, benefitting married, high-income earners (Western et al. 2008). Dunifon et al. (2014), for example, found that 1 in 10 grandchildren live with a grandparent, which was usually precipitated by financial need.

Although much of the research on extended kin involvement examines differences by race (e.g., Haxton and Harknett 2009; Radey and Padilla 2009), one study emphasizes family structure. Deleire and Kalil (2002) found that children who coreside with their single mothers and her parents fare as well, or even better, than children in two-parent households. However, this finding may be misleading, as only 30 families qualified for this classification (i.e., single mothers residing with extended kin). Further, the study was cross-sectional. More studies are needed that analyze whether extended kin relationships mediate the effects of instability on child wellbeing. Further, future studies should include longitudinal data to examine the effects of extended kin coresidence over time, as there are differences in how families change over time that may be related to varying outcomes. In other words, living with extended kin temporarily may not attenuate the association between parental relationship transitions and how well children fare; however, living with extended kin for longer periods of time or during each parental relationship transition may be more beneficial to children than living in temporary housing (i.e., homeless shelters) or with mothers' new partners, as these non-kin environments and people may be unfamiliar.

Nonmarital births will likely alter the life course of families; although Furstenberg (2003) found that teenage pregnancies did not significantly affect disadvantaged mothers' life chances, as their precarious financial situations had already limited their futures. Men 
who become fathers at young ages do not have promising job prospects, nor do they typically pursue educational attainment that could lead to better opportunities (Smeeding et al. 2011). Financial hardships may contribute to rising rates of cohabitation and impede the progression toward marriage (Smock and Manning 2010). In fact, estimates show that half of the $41 \%$ of children born to unmarried parents cohabit (Cherlin 2010). Increases in cohabitation provide evidence that couples are experimenting with their relationships. These trial and error attempts at partnerships highlight the notion that relationships have evolved into mechanisms for personal fulfillment, rather than as avenues toward lifelong commitment. Even the presence of children does not derail parents from seeking personal happiness. Reed (2006) found that "cohabitation among parents indicates they believe that children warrant a greater commitment to the relationship. Once couples begin cohabiting, however, children seem to lose their power to bring couples together" (1128). In fact, Reed's interviewees seemed comforted by the idea that cohabitation provided easy escape. One Hispanic mother commented, "Like if you're living together, you don't have to...think about it too much ... I feel like probably if we ever get married, I feel like I owe it to work on something like that [the relationship] ... I won't feel as free, like I do now" (Reed 2006: 1124). When parental commitment is low, scholars can speculate that the risk of instability and complexity increases, both of which increase the likelihood that children will experience considerable uncertainty within their formative years.

This dissertation consists of five chapters (including this introductory chapter), references, and my Curriculum Vitae. In this dissertation, I explore mothers' and children's trajectories from the births of children to their ninth year. To accomplish this, I used data from The Fragile Families and Child Wellbeing Study (defined below) to write 
three quantitative papers that investigate how mothers' relationship choices and changes both influence their life trajectories and those to whom they are linked. These three papers elucidate the interdependency of family members and provide evidence that social policy efforts should be broadened to include all members of a family system if child wellbeing is a national goal.

Chapter Two uses latent growth curving modeling to estimate coparental trajectories to predict parental commitment five years after the birth of focal children. Framed within commitment theory, this paper investigates whether parents who coreside are together for their children or for each other. No studies exist (to my knowledge) that model parental commitment, explicitly examining how their shared commitment to their children affects their commitment to each other over time. Specifically, this paper investigates the following question: Is there an association between coparenting and parental commitment (i.e., dedication to each other) five years after the focal child's birth?

Chapter Three uses random and fixed effects modeling to examine where mothers reside during periods of relationship changes, particularly during partnership break-ups. Framed within life course theory, this paper explores whether and how often mothers rely on extended kin during times of partnership change. No studies exist (to my knowledge) that examine whether extended family members coreside with their daughters (and their children) during transitional times. Therefore, this paper fills a gap in the literature by investigating the following questions: Are mothers' coresidential relationships with extended family members (either in mothers' homes or extended kin homes) formed by their changes in coresidential romantic partnership status? Do mothers' end coresidence 
with extended family members (either in mothers' homes or extended kin homes) when they form new coresidential romantic partnerships?

Chapter Four, using multilevel modeling, examines how mothers' relationship transition types and extended kin coresidence affect children's internalizing (e.g., anxiety) and externalizing (e.g., fighting) behaviors over the first nine years of their lives. No studies exist (to my knowledge) that examine whether the associations between mothers' transitions and childhood outcomes are mediated by extended kin coresidence. Specifically, this paper investigates the following questions: Does extended family coresidence mediate the association between family structure transitions and child wellbeing, internalizing (i.e., withdrawing from others) and externalizing (i.e., fighting, skipping school) behaviors? Do race and education moderate the association between family structure transitions, extended family coresidence, and child wellbeing?

These three papers contribute new knowledge to literature on families. Chapter Two, rather than examining what happens after parents break up, investigates why parents stay together. Findings from this paper show that the coparental relationship influences the parental bond and, therefore, could inform new policies (e.g., coparenting versus marriage incentives and promotion) related to families. Chapters Three and Four examine mothers' relationship changes and child wellbeing and how these associations are mediated by extended kin coresidence. Findings from both chapters suggest that mothers rely less and less on extended kin over the 9-year period, as extended kin appear to make things worse for families in many ways. Therefore, mothers' reliance on extended kin may not be the best solution to meet their needs. These findings are crucial 
because they are counterintuitive and show that policy efforts need to focus on the needs of families in ways that do not assume that each family has its own personal safety net.

Chapter Five, the last chapter, synthesizes the findings from chapters one, two, and three into a single, coherent argument. Further, this chapter discusses how the dissertation makes a contribution to the literature on fragile families and my future research goals. Both my references and Curriculum Vitae follow chapter five.

\section{The Fragile Families and Child Wellbeing Study}

The Fragile Families and Child Wellbeing Study is a nationally representative birth cohort study, initiated to examine the wellbeing trajectories of parents and children following a nonmarital birth. In 1998, researchers began collecting baseline data from predominantly heterosexual mothers and fathers (if present) at the births of their children (referred to as focal children in the literature) $(N=4898)$. Hoping to address the "missing fathers' problem" (McLanahan, personal communication), researchers decided to conduct baseline interviews in hospitals, as fathers were likely to be present. In fact, research has shown that the birth of a child sparks a "magic moment" (or a "magic nanosecond," as McLanahan refers to it) between parents, when hopes are high and futures certain (Edin and Kefalas 2005).

According to Reichman et al. (2001), the intentions of the study were to collect and provide data to policymakers on three issues that were contributing to great change within families in the United States: "non-marital childbearing, welfare reform, and the role of fathers" (304). Purposely by design, then, the study oversampled non-marital childbirth at a rate of 3 to 1 . Indeed, three-fourths of the participating families are 
considered "fragile," as their nonmarital status implies a precariousness not present in married families — which allowed researchers to address the following questions: “1) What are the conditions and capabilities of unmarried parents, especially fathers?; 2) What is the nature of the relationships between unmarried parents?; 3) How do children born into these families fare?; and 4) How do policies and environmental conditions affect families and children?” (http://www.fragilefamilies.princeton.edu/about). Specifically, data collection began shortly after the implementation of the Personal Responsibility and Work Opportunity Act (better known as welfare reform) to determine how changes in governmental assistance would influence family-level outcomes.

Using a stratified sample, the following cities were chosen for inclusion in the study: Oakland, California (CA); Santa Ana, CA; San Jose, CA; Jacksonville, Florida; Chicago, Illinois; Indianapolis, Indiana; Baltimore, Maryland; Boston, Massachusetts; Detroit, Michigan; Newark, New Jersey; New York, New York; Toledo, Ohio; Philadelphia, Pennsylvania (PA); Pittsburgh, PA; Nashville, Tennessee; Austin, Texas (TX); Corpus Christi, TX; San Antonio, TX; Norfolk, Virginia (VA); Richmond, VA; and, Milwaukee, Wisconsin. The research team then selected specific hospitals within each city and met with hospital administrators to gain entrée (Reichman et al. 2001). Once entrée was achieved, researchers randomly sampled hospital beds and asked mothers if they were willing to participate in the study.

Initial (and separate) interviews with both mothers and fathers (when present) lasted about 30 minutes. Follow-up interviews were conducted 1, 3, 5, 9 and 15 years after the births of focal children. Around $85 \%$ of all fathers have been interviewed in at least one wave. Data from baseline to year 9 are accessible (with permission) through the 
Office of Population Research at Princeton University. The 15-year data, which provides more extensive interviews with children, has been collected, but is still being prepared for public release.

In addition to mother and father interviews, researchers collected maternal medical data at the hospitals at the time of focal children's births. Further, beginning in year 3 , surveys were administered to primary caregivers and child care providers. An inhome assessment was conducted by interviewers during years $3,5,9$, and 15 . At years 5 and 9, teacher surveys were conducted; however, teachers were only sampled in half (or 10) of the participating cities. Children were interviewed in both the 9- and 15-year waves. In addition, at year 9, researchers began collecting saliva samples from the children for DNA analysis.

The primary caregiver survey, which was administered in homes, included questions that measure children's internalizing and externalizing behaviors and questions about the family in general (e.g., routines, nutrition, violence, etc.). During home visits, the interviewers also recorded data (subjective) about the appearance of the home (e.g., exposed wiring), the neighborhood (e.g., broken glass near the home), and the child. Further, the interviewers recorded how the parents and children interacted with each other. The in-home assessments also included an activity booklet that measured children's vocabulary via the Peebody Picture Vocabulary Test. For more information on the data and documentation, visit: http://www.fragilefamilies. princeton.edu/documentation/general.

The Fragile Families and Child Wellbeing Study is led by Principal Investigators Sara McLanahan (Princeton University) and Irwin Garfinkel (Columbia University) and 
is funded through a variety of government agencies (e.g., Eunice Kennedy Shriver National Institute of Child Health and Human Development and the National Science Foundation) and foundations (e.g., Ford, MacArthur, Public Policy Institute of California). For a complete list of funders, visit: http://fragilefamilies.princeton.edu/about/funders. 


\section{CHAPTER II: \\ FOR US OR THE CHILDREN?: EXPLORING THE ASSOCIATION BETWEEN COPARENTING TRAJECTORIES AND PARENTAL COMMITMENT ${ }^{1}$}

\section{Introduction}

Over the past several decades, the United States has witnessed a dramatic increase in nonmarital childbearing, from 6\% to $41 \%$ (Martin et al. 2013). Nonmarital childbearing often means parents negotiate parenting responsibilities outside of marriage and across households (Fomby and Cherlin 2007). At their child's birth, $80 \%$ of unmarried parents were romantically involved with hopes to eventually marry each other; however, five years later the majority had broken up (McLanahan 2011). Research shows that children living apart from their fathers (following a parental break up) experience diminished life chances due to lower educational attainment and early entrance into risky behaviors (e.g., sexual activity, substance abuse) (Sigle-Rushton and McLanahan 2004). Understanding the deleterious effects of absent fathers on children, researchers examine the quality of (Kamp Dush et al. 2011) and factors associated with coparenting relationships (see Goldberg and Carlson 2015) after parents break up. These studies aim to determine what influences continued paternal involvement (Carlson et al. 2008) and engagement (Fagan and Palkovitz 2011). However, little is known about how changes in coparenting affect the romantic attachments of parents. This paper, therefore, evaluates

\footnotetext{
${ }^{1}$ Acknowledgements/Funding: Thank you to the Columbia Population Research Center for its support of this study (FFCWS Study \# 5R01HD03699916, FFCWS Workshop \# 5R25HD074544; CPRC \# P2CHD058486).
} 
whether parents' coparenting relationships influence their commitment to each other five years after the birth of their child.

Determining whether an association exists between coparenting and parental commitment is important for several reasons. First, research has shown that coparenting relationships are dynamic, often contingent on parents' relationships with each other and new partners (Cooper et al. 2015). Second, research shows that family complexity increases substantially if parents are unmarried (McLanahan 2011), which affects the long-term wellbeing of children. For example, parents may "partner up" (Tach et al. 2010) or engage in multipartnered fertility (Carlson and Furstenberg 2006), both of which expose children to new adults and siblings and decrease the resources invested in each individual child (Cancian et al. 2011). Children exposed to multiple half-siblings and social fathers face significant instability and, subsequently, engage in negative externalizing (e.g., fighting with other children) and internalizing (e.g., withdrawing from others) behaviors (Lee and McLanahan 2015). However, research shows that children benefit from stable, two-parent families (e.g., McLanahan 2004); therefore, if supportive coparenting relationships encourage parental relationship stability, even among unmarried parents, then children stand to benefit.

Much of the research on coparenting focuses on how parents negotiate their parental roles after a break up (e.g., Goldberg and Carlson 2015), the factors that encourage father involvement (e.g., Carlson et al. 2008), and paternal engagement (Fagan and Palkovitz 2011) post-dissolution. This study extends literature on fragile families by focusing on parents who coparent within coresidential and relationship contexts to determine whether their coparenting relationships influence commitment to each other 
over time. Drawing from commitment theory, and using the Fragile Families and Child Wellbeing Study $(N=3,030)$, I examine the following research question: Is there an association between coparenting and parental commitment (i.e., dedication to each other) five years after the focal child's birth? Even though scholars argue that normative pressures encouraging parents to stay together for the children have decreased (Edin and Kafalas 2005), I posit that children still (potentially) influence parental commitment more than may be expected.

\section{Theoretical Framework and Background}

\section{Commitment Theory and Coparenting}

Commitment is defined as "the intention to maintain a relationship over time" (Stanley et al. 2010: 243). In other words, commitment theorists argue that couples who clearly articulate their long-term plans (e.g., marriage) to each other are more likely to be dedicated and stay together; whereas couples who "slide into" a relationship may acquire too many constraints (e.g., shared debt) to leave the relationship (Stanley et al. 2006). Although both scenarios—intentional versus unintentional—produce similar outcomes (i.e., relationship stability), the key difference is between dedication and constraint. Dedicated relationships are sustained out of desire, while constrained relationships out of obligation. Commitment theory focuses on the dyadic relationship between couples and presupposes that dedication and constraints are determined at the beginning of a relationship and are, therefore, static. But, even with the best intentions (i.e., dedication), relationship dynamics change over time (Schoppe-Sullivan et al. 2004) and couples face 
challenges that may produce constraints; whereas couples that are initially constrained may develop dedication.

Indeed, research on coparenting, defined as the shared responsibility of biological parents to rear their children (McHale and Irace 2011), among married couples shows that children affect the marital relationship (e.g., Schoppe-Sullivan et al. 2004). Within this context, the couple's adjustment to parenthood often decreases marital satisfaction (Christopher et al. 2015) — a finding that suggests children may constrain even the most committed couple's relationship. There is evidence, however, that dedicated couples can more easily transition into new roles, such as parenting, without significantly affecting the parental dyad. For instance, Bonds and Gondoli (2007) found that couples with strong marital baselines (prior to children) adapt to parenting through supportive coparenting. In other words, parents who have successfully supported each other through marriage can transfer the same prosocial behaviors- - "good teamwork [and] mutual support"- to parenting (Bonds and Gondoli 2007: 294); thus, a supportive coparenting relationship allows parents to cooperatively rear their children without weakening the parental dyad. There is reason to suspect, then, that if parental commitment is strong at the beginning of parenthood, subsequent coparenting may also be strong.

However, marital satisfaction is dynamic, as is coparental behavior (see SchoppeSullivan et al. 2004); therefore, using only baseline levels of marital satisfaction to predict subsequent coparental relationships may not capture the magnitude of their association over time (Lindahl et al. 1997; Schoppe-Sullivan et al. 2004), nor take into account factors (e.g., children) that may strain the parental dyad. In particular, marital satisfaction and coparenting interact and influence each other over different stages of 
child development (Schoppe-Sullivan et al. 2004), when parental duties and demands are subject to change. For example, mothers often assume more childrearing responsibilities throughout their lifetimes, but especially during the infant years (Lindahl et al. 1997), which may lead to marital dissatisfaction (Merrifield and Gamble 2012). The effects of these new responsibilities on maternal well-being are mitigated by "coparenting support" (Bonds and Gondoli 2007: 293). In other words, when mothers feel their parenting efforts are supported by fathers (even if fathers do not contribute as much to childcare), negative emotions related to coparenting may not "'spill over' and affect the marital relationship" (Schoppe-Sullivan et al. 2004: 203); therefore, parental dedication is possibly unaffected. A supportive coparental relationship may be a sign of parental dedication, which likely means that coparenting will be strong and positive and commitment high over time.

In contrast, mothers who feel constrained by increased childrearing (i.e., children as constraints), tend to report increases in marital conflict (Christopher et al. 2015) and undermining coparenting (i.e., parents disagreeing with each other on how to raise their child, competing for child's attention, etc.) (Belsky and Hsieh 1998)—all of which could be interpreted as decreased dedication. Although both fathers and mothers report significant negative changes in marital quality during the initial transition to parenthood, mothers experience longer periods of marital dissatisfaction (Christopher et al. 2015). Therefore, some parents may purposefully differentiate (rather than enmesh) the parental relationship from the coparental relationship as a way to "protect their children from repeated exposure to interparental conflict, [and] collaborate in child rearing regardless of their strong feelings of disdain and animosity toward each other" (Margolin et al. 2001: 
4). Parents, then, may stay together to fulfill parental obligations - which reinforces the argument that children may constrain parental relationships.

Further, research suggests that fathers' parenting is contingent on their relationships with mothers (Merrifield and Gamble 2012). In fact, when mothers report lower levels of marital satisfaction, fathers participate more in parenting as a way to "compensate for the poor marriage" (Merrifield and Gamble 2012: 528); whereas when fathers report higher levels of marital satisfaction, they participate less in parenting. Thus, if dedication weakens over time, constraints (i.e., children) may become more important, particularly for fathers. Indeed, when marital conflict cannot be positively negotiated, fathers (more so than mothers) form "crossgenerational alliances" with children (Lindahl et al. 1997: 148). These alliances indicate an elevation and strengthening of the parentchild dyad and subordination or weakening of the parental dyad. This shift, often referred to as triangulation (Margolin et al. 2001), points to transference of allegiance (or dedication) from the parental relationship to the parent-child relationship. The employment of triangulation negatively affects the other parent by undermining their parenting behavior (Margolin et al. 2001), often via "hostile-competitive coparenting" (Mangelsdorf et al. 2011: 42). If parents remain married under tenuous circumstances (i.e., constrained), their coparenting relationships will, arguably, be weak and commitment to each other low.

Interestingly, commitment theory suggests that the onset of the relationship determines a couple's level of dedication and constraint. But, studies investigating married couples show that children often dramatically (and sometimes negatively) alter marital satisfaction (see Shoppe-Sullive et al. 2004). Moreover, there is evidence that 
dedication shifts from the parental dyad to the parent-child dyad, especially when crossgenerational alliances are formed (Lindahl et al. 1997). Commitment scholarship, however, focuses on investments between partners, such as shared leases or pets, but not often children. Stanley and Markman (1992) ran a series of analyses to test commitment difference among five groups of partners-exclusively dating, engaged, married without children, married with some or all children under 21-years old, and married with all children over 21-years-old. They found that parents with children over 21-years-old reported the highest level of commitment. However, their longitudinal data collection only spanned an 8-month period — a length of time that does not allow for significant analysis of how children may affect the parental dyad. Further, knowing that different developmental stages influence the parental dyad (Schoppe-Sullivan et al. 2004), Stanley and Markman's (1992) study is limited by aggregating their analyses to children under and above the age of 21, as children's needs within these two categories are vastly different.

Another study examined commitment between dedicated partners (i.e., intentional) and constrained couples who were together due to a "life event" (e.g., pregnancy) (Surra and Hughes 1997). The authors found that commitment is lower for partners who were together because of a pregnancy. However, their sample was limited to 113 individuals and, though longitudinal, spanned only 12-months, also a period of time that limits the depth of investigation. There is a significant gap in the literature about the association between the coparental relationship and parental commitment over time (greater than one year), using a large dataset — a glaring omission, given that children often transform the parental dyad significantly. Further, this oversight supports the notion 
that commitment theory assumes that commitment is determined at the onset of a relationship and remains static over time — an assumption that is clearly debunked by what Cherlin (2009) refers to as the "Marriage-go-Round," where people, particularly couples in the United States, marry and re-marry in search of personal, rather than couple, fulfillment.

Further, Stanley et al. (2006) argue "commitment is an important aspect of relationship quality for adults and is, likewise, important for child well-being" (Stanley et al. 2006: 503). But, changes in partnering behavior (i.e., cohabitation before marriage) (Seltzer 2000) and expectations (i.e., marriage as individualized pursuits of happiness, rather than companionate unions) (Cherlin 2009) predict tenuous, rather than stable, longterm relationships (Rhoades et al. 2010); thus, children are often not reared in households with committed biological parents. In fact, much of the literature on coparenting examines how parents negotiate their parental roles after partnership dissolutions, especially studies on fragile families (see Carlson et al. 2008; Bronte-Tinkew and Horowitz 2010; Fagan and Palkovitz 2011; Kamp Dush et al. 2011; Waller 2012; Cooper et al. 2015; Goldberg 2015; Goldberg and Carlson 2015) —which substantiates the notion that a "new package deal" exists, where children now precede parental commitment (Tach et al. 2010; Edin and Nelson 2013). Ethnographic research shows that many lowincome couples "slide into" relationships, but intentionally have children to give their lives meaning (Edin and Kefalas 2005).

Understanding that children born to unmarried parents are the result of both intentional (see Edin and Kefalas 2005; Edin and Nelson 2013) and unintentional pregnancies (Musick et al. 2010), it is possible that the children influence parental 
commitment, rather than the couple's initial romantic attachment to each other. It seems reasonable to also consider children as forms of dedication and parental commitment a form of constraint among families engaging in the "new package deal." In other words, parental commitment may, for some parents, be an outcome of coparental dedication. Whereas coparenting may become more hostile among unhappily married couples, coparenting among fragile families may be supportive as a way for parents, especially fathers, to experience parenthood (Edin and Nelson 2013). Indeed, the coparental relationship may be more salient than the parental dyad because: 1) nonresident, nonromantic fathers are at the greatest risk of losing contact with their children (Fagan and Palkovitz 2011), especially when mothers repartner (Cooper et al. 2015); and 2) coparenting among uncommitted parents immediately suffers post-dissolution and continues to diminish over time (Goldberg and Carlson 2015). Therefore, the present study examines how changes in coparenting influences parental commitment among fragile families five years after the birth of a child. For families that are dedicated in the traditional sense (i.e., parents form dedicated unions with each other and children follow), coparenting will likely be supportive and parental commitment high over time. For families that are dedicated in the nontraditional sense (i.e., parents "slide into" relationships with each other, but are intentional [or dedicated] to their children), coparenting will likely be supportive and parental commitment low over time.

\section{Potential Confounding Factors}

Although the present study examines the association between coparenting and parental commitment, other factors will possibly contribute to this association. For 
example, mothers' new partnerships, both residential and nonresidential, affect fathers' ability to coparent (Cooper et al. 2015), especially if mothers' new partners act as social fathers to children (Kamp Dush et al. 2011). Further, fathers who had not formed strong romantic bonds with mothers experience the greatest decreases in coparenting (Martin et al. 2015) — which may mean that fathers will also invest in new relationships (BronteTinkew and Horowitz 2010). Investments in new partnerships may influence the coparental relationship and will likely diminish the likelihood that parental commitment will develop over time.

Moreover, the transition to parenthood constrains some partnerships (Bonds and Gondoli 2007); therefore, having more children (i.e., parity) may exacerbate this constraint. Indeed, the more children within a single family, the more likely parents will report less supportive coparenting — a finding that the authors speculate is linked to an increased amount of interaction between parents who do not share the same household (Bronte-Tinkew and Horowitz 2010). However, there is reason to speculate that more children will also place greater strain on coresiding parents, as carework will increase with the number of children; therefore, commitment between parents may decline. Other key maternal characteristics include mother's health, where mothers who report better health also report more supportive coparenting; and poverty status, where a negative relationship exists between father's financial contributions and mother's poverty status (Goldberg 2015). Thus, mother's relationship status, parity, poverty status, and health are included in this analysis as time-varying covariates to account for variation in coparenting and commitment. 
Research shows that some time-invariant factors influence coparenting and commitment. For example, race factors into commitment because black parents are much more likely to break up than other races (McLanahan 2011), but black parents are also more likely to maintain a coparenting relationship after a dissolution (Goldberg and Carlson 2015). Family background also contributes to parental commitment; parents who were reared outside a two-parent household are the most likely to break up (McLanahan 2011), increasing the likelihood that coparenting relationships will diminish over time (Goldberg and Carlson 2015). Age and education are held constant at the birth of the child to be consistent with other studies (Meadows 2011; Goldberg 2015). Mother's age at her child's birth is correlated with her ability to maintain a stable relationship, with younger mothers experiencing more relationship transitions than older mothers (Fomby and Cherlin 2007). Education also plays a role in the number of children women have and is also a determinant for intended versus unintended children (Musick et al. 2010). In fact, Musick et al. (2010) found that college educated women have fewer children than women with lower levels of education. Thus, race, family background, age, and education are included in this analysis as time-invariant covariates to account for variation in coparenting and commitment.

\section{Methods}

Dataset

This study uses data from the Fragile Families and Child Wellbeing Study (FFCWS), a longitudinal birth cohort study conducted in 20 cities with populations greater than 200,000, in 75 hospitals. Baseline data were collected between 1998 and 
2000 at the birth of the focal child, with follow-up surveys conducted at years 1, 3, 5 and 9 following the birth. The study oversampled nonmarital births, with a 3:1 ratio $(N=$ 4898, with 3,710 unmarried parents and 1,188 married parents). Both mothers and fathers were interviewed. By year 9, 76\% of mothers still participated in the study. Fathers were more difficult to locate at baseline, and their retention rates were not as high as mothers', but $88 \%$ of fathers participated in at least one survey wave. Mother reports are used to estimate the models in this study, as mothers are (usually) the custodial parent. However, to alleviate concerns related to using mother reports of fathers' coparenting and parental relationships, father reports are used in sensitivity analyses.

\section{Sample}

The number of mothers in this sample was restricted to those who responded to the coparenting questions at years 1,3, and 5 and the commitment questions at year 5 . Analyses did not include data from year 9 because the commitment measures (dependent variable) were only asked at year 5. Mothers who had never been in a relationship with the father since the birth of the focal child (asked in years 1 and 3) were not asked questions about coparenting, nor were mothers asked if the father was deceased or had no contact with the child (asked in year 5). Mothers who were not in a relationship with the biological father at year 5 were not asked the commitment questions. Further, both the coparenting and commitment measures were only asked in 18 of the 20 sampled cities. Taken together, and using full information maximum likelihood (FIML) to estimate the models, the final sample size was $N=3,030$. 
Scholars have argued that full information maximum likelihood estimation is the most appropriate method for handling missing data when using structural equation modeling (Allison 2003; Carlson et al. 2008; Kamp Dush et al. 2011). Schminkey et al. (2016) argue that FIML “calculates the parameter estimates by maximizing the likelihood function of the data directly, rather than from the covariance matrices, which is particularly useful when missing data are present. The FIML analysis produces one result, whereas multiple imputation produces a different result with each iteration of the analysis" (Schminkey et al. 2016: 289). Further, they argue that this function is the least biased in model estimations when compared to other methods (e.g., multiple imputation, listwise deletion) of handling missing data (Schminkey et al. 2016).

\section{Measures}

Dependent variable. An index of mothers' reported parental commitment at year 5 was generated by averaging the following six items, all of which were measured on a scale from 1 "strongly disagree" to 5 "strongly agree": "My relationship with father is more important than almost anything else, in my life," "I may not want to be with father a few years from now" (reverse coded to have higher numbers indicate more commitment), "I like to think of father and me as a couple than as two separate people," "I want this relationship [with father] to stay strong no matter what rough times we may encounter," "I am happy with my sexual relationship with father," and "I can trust that father will not cheat on me with other people." The commitment measures were constructed from Stanley and Markman's (1992) Commitment Inventory and, therefore, load well together with an alpha reliability score of .77 , with a mean score of 3.71 . 
Independent variable. Beginning at the year 1 follow-up, mothers were asked six attitudinal questions related to coparenting. Indices for coparenting at years 1,3 , and 5 were generated by averaging the following six items, all measured on a scale from 1 "rarely true" to 3 "always true," and all reverse coded so that a higher score would indicate higher levels of coparenting: "When current partner is with child, he acts like the kind of parent you want for your child," "You can trust [father] to take good care of child," "He respects the schedules and rules you make for child," "He supports you in the way you want to raise the child," "You and [father] talk about problems that come up with raising child," and "You can count on [father] for help when you need someone to look after child for a few hours." Alpha reliability scores were $.83, .86$, and .87 for years 1,3 , and 5 respectively. Their mean scores were $2.69,2.59$, and 2.53 for years 1,3 , and 5 respectively.

Time-varying covariates. A series of time-varying covariates were included in the coparenting analyses for years 1,3, and 5. A dummy variable for poverty was included; mothers who reported that they were at $99 \%$ or below the federal poverty line were coded as in poverty. A dummy variable for mothers' health was included; mothers who selfreported that they were in fair or poor health were coded as in poor health. A dummy variable was included to control for whether or not mothers had a child(ren) or were pregnant at every wave since baseline. Finally, three dummy variables were included to control for relationship status (married is the reference category). In particular, whether or not the mother was cohabiting with the biological father; in a romantic relationship with the biological father, but not cohabiting; or was not in a relationship at all with the biological father. 
Time-invariant covariates. A series of time-invariant covariates were included in the parental commitment analyses. Mothers' age at baseline (in years) was included. A dummy variable for whether or not the mothers lived with both her biological parents at age 15 was included. Further, four dummy variables for race (black, Hispanic, other, and white as reference) and four for education (high school, some college, college, and less than high school as reference) were included.

\section{Analytic Approach}

First, descriptive statistics for the independent, dependent, and control variables were conducted, using city sampling weights. Second, correlation matrices were completed to determine the following relationships: 1) the relationship between parental commitment at year 5 (DV) and coparenting (IV) at years 1, 3, and 5, all of which are composite variables, and 2) the relationship between parental commitment at year 5 (DV) and each of the six indicators (IVs) used to construct the coparenting composite variables at years 1, 3, and 5. Third, I estimated two latent growth curve models to determine whether an association exists between coparenting and parental commitment. The first model estimated coparenting trajectories and parental commitment at year 5. The coparenting trajectories provide an initial level of and changes in coparenting. The second model added time-varying covariates to the coparenting trajectories and timeinvariant covariates to parental commitment to control for these confounding factors (Figure 1).

Latent growth curve models were ideal for this study, as they rely on repeated measurements of the same sample over time to capture within-individual change. The 
FFCWS sample meets the criteria to estimate latent growth curve models as participants in the study were interviewed the same number of times and within the same timeframe. Further, the sample size exceeds the 200-observations minimum (Byrne 2010).

Latent growth curve models estimate group-level trajectories (fixed effects) by generating two unobserved latent constructs (independent variables), an intercept ( $\alpha$ ) and a slope $(\beta)$, to determine both mothers' initial attitudes about coparenting and subsequent changes in these attitudes over time (random effects)(Meadows 2011). In addition to $\alpha$ and $\beta$, three observed variables for each coparenting index were generated, each with an error term $(\varepsilon)$. Below is the equation, which includes the dependent variable $(y)$ for each individual $(i)$ at year $5(t)$, the intercept, slope, and error terms, representing withinindividual $(i)$ change in coparenting over the three time $(t)$ periods (Meadows 2011):

$$
y_{i t}=\alpha_{i}+\beta_{i} t+\varepsilon_{i t}
$$

The addition of time-varying covariates provided information on why some mothers' initial attitudes about coparenting may vary from the group-level means and slopes, and how these factors alter mothers' coparenting reports. The equation that includes the time-varying variables is as follows, where $\gamma_{i} w_{i t}$ accounts for how the change in time varies for each individual's coparenting trajectory (Meadows 2011):

$$
y_{i t}=\alpha_{i}+\beta_{i t}+\gamma_{i} w_{i t}+\varepsilon_{i t}
$$


Figure 1 represents the full model estimated in this paper. An intercept and slope first estimated the coparenting trajectory over years 1 (coparent1), 3 (coparent 3 ), and 5 (coparent5), followed by the prediction of parental commitment at year 5 (commit5). Time-varying covariates (time-vary 1-5) were regressed on the coparenting factors and time-invariant covariates (time-invar) were regressed on parental commitment at year 5. The time-varying covariates were regressed on the coparenting trajectories because these variables (mother's poverty status, number of children, health, and relationship status) have been linked to a mother's ability to maintain coparenting relationships with the biological father over time (see Bronte-Tinkew and Horowitz 2010; Kamp Dush et al. 2011). Time-invariant covariates were regressed on parental commitment, because research has shown these factors contribute to relationship stability. In other words, mother's race, age, education, and whether she lived with both biological parents at age 15, have been shown to influence her marital status (see "Potential Confounding Factors" section above).

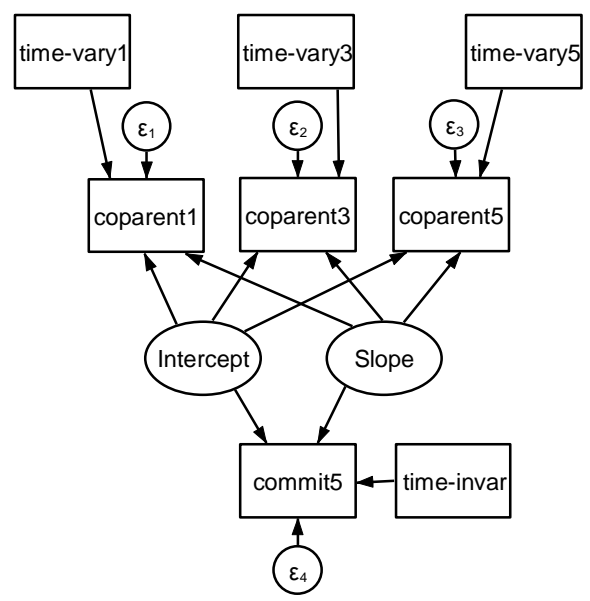

Figure 1. Full latent growth model of maternal reports of coparenting and parental commitment at Year 5, including time-varying and time-invariant covariates. The coparenting trajectory predicts parental commitment. If coparenting is high and commitment is high, then the model suggests that parents are dedicated. However, if coparenting is high and commitment is low, then the model suggests that parents are constrained. 
A chi-square analysis, the root mean square error of approximation (RMSEA), the comparative fix index (CFI), and the Tucker-Lewis index (TLI) were used to determine model fit. Chi-square results are usually significant when using large datasets $(>200$ cases) (Kamp Dush et al. 2011); therefore, other indicators of model fit were evaluated, such as the RMSEA, which adjusts for large sample sizes and estimates the error associated with degrees of freedom (Acock 2013). Further, both the CFI and TLI compare the model used in this study to a baseline model, which assumes that the observed variables are not correlated. The CFI determines how well my model fits compared to the baseline model, by examining the differences in chi-square results, while the TLI adjusts for bias within the models (Acock 2013). An RMSEA value below 0.05, a CFI value greater than 0.95 , and TLI value closer to 1.0 are considered good fit (Meadows 2011; Acock 2013). The latent growth curve models and models of fit were estimated using Stata 14.1.

\section{Results}

\section{Descriptive Statistics}

Table 1 shows weighted scores for the analytic sample.

Parental commitment (the DV). Mothers, on average, reported their relationships with fathers as committed. Mothers' mean commitment scores ranged from a low of 3.6 when responding to the question "my relationship with father is more important to me than almost anything else in my life," to a high of 4.6 when responding to the question, "I want this relationship [with father] to stay strong no matter what rough times we may encounter." 
Coparenting (the IV). Overall, the mean level of coparenting was greater than 2.5 (out of 3.0) for each of the six questions at years 1,3, and 5 (Table 1). Therefore, mothers, on average, reported their coparenting relationships with biological fathers as strong. In year 1, mothers' scores ranged from a low of 2.7 when responding to the questions "father respects mother's schedules/rules for child" and "mother can rely on father to watch child independently"; to a high of 2.9 when responding to the question "mother can trust dad to take care of child". In year 3, mothers' scores ranged from a low of 2.6 when responding to the question "father respects mother's schedules/rules for child," to a high of 2.8 when responding to the question "mother can trust dad to take care of child." In year 5, mothers' scores ranged from a low of 2.6 when responding to the questions "father acts like a father mother wants for child," "father respects mother's schedules/rules for child," "father supports mother in the way she wants to raise child," and "mother can rely on father to watch child independently"; to a high of 2.8 when responding to the question "mother can trust dad to take care of child."

\section{Time-varying variables}

Poverty. The percentage of mothers in poverty increased from 31.4 in year 1 to 33.3 in year 5. Health. The percentage of mothers who reported that their health was excellent declined from 33.5 in year 1 to 25.9 in year 5; whereas mothers who reported poor health increased from 1.0 in year 1 to 1.8 in year 5. Relationship status. The percentage of married mothers decreased over the four-year period from 62.8 in year 1 to 58.5 in year 5 . The percentage of cohabiting mothers decreased from 21.7 in year 1 to 11.7 in year 5. The percentage of mothers romantically involved with, but not cohabiting 
with, the biological father decreased from 4.0 in year 1 to 2.1 in year 5. And, the percentage of mothers and fathers not in relationships with each other increased from 11.5 in year 1 to 27.7 in year 5. Fertility. In terms of fertility, $10.9 \%$ of mothers had new child(ren) between the birth of the focal children and year 1, 33.7\% had a new child(ren) between year 1 and year 3, and 4.4\% had a new child(ren) between year 3 and year 5 .

\section{Time-invariant variables}

Age. Mothers were, on average, 27.4 years old. Family background. The majority of mothers, $55.8 \%$, lived with both biological parents at age 15 . Race. The analytic sample for this study includes $32.2 \%$ white mothers, $30.8 \%$ black mothers, $29.4 \%$ Hispanic mothers, and $7.5 \%$ mothers who identify as other. Socioeconomic status. In terms of education, $26.2 \%$ of mothers have less than a high school education, $30.5 \%$ have a high school diploma or equivalent, $19.7 \%$ have some college, and $23.6 \%$ have a college degree.

\section{Correlation Matrices}

Table 2 shows the correlations between parental commitment and coparenting at years 1,3 , and 5 .

Composite variables for coparenting at years 1,3 , and 5 were correlated with parental commitment (also a composite variable) at year 5. Results indicate that coparenting at years $1(\mathrm{r}=.17)$ and $3(\mathrm{r}=.21)$ were weakly related to parental commitment at year 5; whereas coparenting at year $5(\mathrm{r}=.34)$ was moderately related to parental commitment at year 5 . 
Shifting to the six individual indicators used to construct the coparenting measures, all of the individual indicators at years 1 and 3 were weakly $(r<.30)$ related to parental commitment at year 5. Examining year 1 alone, there were strong relationships between father is trustworthy and father acts like the kind of father mother wants for her child $(\mathrm{r}=.48)$, and between father is supportive and father acts like the kind of father mother wants for her child $(\mathrm{r}=.48)$. Examining year 3 alone, there were strong relationships between father is supportive and father is respectful of mother's schedules and rules for child $(r=.56)$, between father is supportive and father acts like the kind of father mother wants for her child $(r=.49)$, and between father is respectful of mother's schedules and rules for child and father acts like the kind of father mother wants for her child $(\mathrm{r}=.45)$. Turning to year 5 , two indicators, father acts like the kind of father mother wants for her child $(\mathrm{r}=.26)$, and fathers is supportive $(\mathrm{r}=.27)$, were moderately related to parental commitment at year 5. And, there were strong associations between father is supportive and father is respectful of mother's schedules and rules for child $(\mathrm{r}=.54)$, and between father is supportive and father acts like the kind of father mother wants for her child $(r=.45)$.

\section{Multivariate}

Table 3 reports the coparenting means for years 1, 3, and 5. Table 4 shows results from the coparenting growth models, and the time-varying and time-invariant covariates. Two latent growth curve models were estimated for this study. Model 1 examined the association between coparenting trajectories and parental commitment at year 5. Model 2 included the time-varying covariates to determine how these factors affect the starting 
points (at each wave) for individuals within the study, and the time-invariant covariates, which were regressed on parental commitment at year 5 .

Results from Model 1 suggest that mothers who report supportive coparenting at year 1 (or their starting point for commitment) $(\beta=2.68, \mathrm{p}<0.001)$ are committed to the biological father at year 5, albeit the commitment is low $(\beta=1.34, \mathrm{p}<0.001)$ - a finding that supports the hypothesis that parents may be dedicated to children and constrained by parental commitment. The coparenting trajectory decreased over time by 0.04 each year (from 2.68 to 2.52 ). The decreasing coparenting trajectory (or negative slope) was associated with positive commitment $(\beta=0.53, \mathrm{p}<.05)$. Although reports of coparenting were decreasing over time, coparenting remained relatively high over the four-year period. Together, these findings support the hypothesis that children are constraining the parental dyad.

The association between coparenting and parental commitment strengthened significantly after accounting for the time-varying and time-invariant covariates. Model 2 showed that mothers' initial reports of coparenting $(\beta=2.79, \mathrm{p}<0.001)$ and commitment at year $5(\beta=2.55, \mathrm{p}<0.001)$ were higher than estimated in Model 1. Model 2 also suggested that coparenting decreased $(\beta=-0.03, \mathrm{p}<0.001)$ and parental commitment increased $(\beta=2.56, \mathrm{p}<0.001)$ over time. However, the increase in commitment was much greater than predicted in Model 1. Of the time-varying covariates, relationship status significantly affected the coparenting relationship. Specifically, compared to being married (reference), not being in a relationship with the biological father greatly diminished the coparenting relationship by $27 \%$ at year $1,39 \%$ at year 3 , and $38 \%$ at year 5; whereas being romantically involved with the biological father at year 1 was 
equivalent to a $19 \%$ decrease in the coparenting relationship, according to the mother. Cohabiting, on the other hand, was associated with a slight, insignificant decrease in coparenting at years $1(-2 \%)$ and $3(-3 \%)$; however, by year 5 , cohabiting couples were $6 \%$ more likely to report significantly higher levels of coparenting $(\mathrm{p}<0.05)$. Compared to mothers who did not have another baby, having another child or being pregnant at the year 1 was associated with a $6 \%$ decrease in coparenting, which was moderately significant.

In terms of time-invariant covariates, race and education played significant roles in parental commitment by year 5 . Indeed, compared to being white (reference), being black was associated with a $16 \%$ decrease in mothers' reports of parental commitment (p $<0.001)$; whereas being Hispanic was associated with a $13 \%$ decrease $(\mathrm{p}<0.01)$. More educated mothers reported they were more committed to the biological father. Indeed, mothers with some college were $13 \%$ more likely to view their relationships with the biological father as committed $(\mathrm{p}<0.01)$, while mothers with college degrees were $12 \%$ more likely $(\mathrm{p}<0.05)$. Mothers with a high school degree or equivalent were $7 \%$ more likely to be committed to biological fathers as mothers with less than a high school diploma (reference), but only moderately. Mother's age had a significant $(p<0.05)$ effect on parental commitment, but the magnitude of the coefficient was small ( 1\%). And, compared to mothers who lived with both biological parents at age 15 , mothers who were not reared in a two-parent household by the age of 15 were $5 \%$ less likely to report their relationships with the biological father are committed; however, this association was only moderate. 
Sensitivity analyses.

The analyses for this paper rely on mother reports to estimate the coparenting trajectory from years 1-5 and parental commitment at year 5; thus, I re-estimated the models using father reports to examine consistency with mothers' reports, using full information maximum likelihood estimation. Consistent with maternal reports of coparenting, fathers' initial levels of supportive coparenting were high $(\beta=2.82, \mathrm{p}<$ $0.001)$ and decreased slightly over time $(\beta=-0.02, p<0.001)$. Fathers' reports of parental commitment were somewhat higher than mothers $(\beta=1.39, \mathrm{p}<0.001)$, but their rate of change was considerably higher $(\beta=6.12, \mathrm{p}<0.001)$. Research suggests (see Fagan and Palkovitz 2011) that fathers may report higher levels of commitment because they may feel their access to children is contingent on their dedication to the mothers of their children. Or, fathers may rate commitment higher than mothers, as mothers often assume more of the child-rearing responsibilities (e.g., bed time routine), and, subsequently, rate their relationship quality lower than fathers (Christopher et al. 2015). Overall, father reports corroborate, or somewhat augment, mothers' perceived coparenting and commitment reports.

\section{Discussion}

Previous research has shown that fragile families are dynamic, many of which are fraught with multiple transitions (McLanahan 2011) that often lead to deleterious effects on child wellbeing (Lee and McLanahan 2015). Therefore, the purpose of this study was to examine whether an association between coparenting - which is often correlated with marital satisfaction (Shoppe-Sullivan et al. 2004; Christopher et al. 2015) —and parental 
commitment exists. More specifically, does coparenting influence parental commitment over time? Evaluating whether an association exists between these two constructs may help us better understand and meet the needs of contemporary families.

Beginning with the descriptive statistics, mothers' reports of parental commitment at year 5 are high. Although mothers want to stay partnered with fathers no matter the circumstances (4.6 out of 5.0), interestingly, fathers do not appear to be the most important relationship in their lives (3.6 out of 5.0). Mothers' dedication to fathers may wax and wane over time as a result of other factors, such as childcare responsibility (Christopher et al. 2015); therefore, as mothers devote more time to childrearing, they may prioritize the parent-child dyad over the parental dyad, but maintain their dedication to fathers. Although childrearing responsibilities are beyond the scope of this paper, research does suggest that a relationship between supportive coparenting (even when shouldering much of the childrearing) and martial satisfaction exists (Bonds and Gondoli 2007). Thus, dedicated partners may be more likely to foster supportive coparenting, which may buffer the effects of role conflict on the parental dyad.

Turning to the independent variables, the means of the six indicators used to measure coparenting decreased between years 1 and 5, albeit slightly. Specifically, the questions, "father acts like father mother wants for her child," and "father supports mother in the way she wants to raise child" both decreased from 2.8 to 2.6 over four years. Perhaps the decrease in perceived coparenting is associated with parental commitment. In other words, as fathers become more committed to mothers, they may feel less inclined to fulfill their coparental roles. In fact, Fagan and Palkovitz (2011) found that being romantically tied to the mother appears to attenuate the importance of 
the coparenting relationship, as fathers do not have to negotiate access to their children. Therefore, as parents' commitment to each other increases, fathers may evade some of their parenting roles. Subsequently, mothers' evaluations of fathers and their associated support may be lower.

Bivariate results show a moderate association between coparenting and parental commitment at year 5, but strong associations between coparenting at years 1 and 3 and years 3 and 5. Thus, coparenting relationships appear to be contingent on previous coparenting relationships. Further, strong, positive associations exist across the three waves of data between fathers who are supportive to mothers and "father acts like father mother wants for her child," and between fathers who are supportive to mothers and "father respects the schedules and rules mothers make for child." These findings suggest that mothers in this study are similar to mothers in previous studies in that they evaluate fathers more positively when engaging in cooperative coparenting (Bonds and Gondoli 2007). Results from bivariate analyses suggest that parents are dedicated to their children, but not necessarily to each other. Indeed, results show that the associations between coparenting and parental commitment at years 1 and 3 are weak, but the relationship is getting stronger at year 5-which may substantiate the notion that parents' relationships are the constraints (see Fagan and Palkovitz 2011).

Moving to multivariate analyses, there is a significant association between coparenting and parental commitment at year 5; however, commitment is low, bolstering support for the argument that parents are more dedicated to their shared children than to each other. Further, net of covariates, the association between coparenting and parental commitment remains significant, but perceived commitment is significantly higher. 
Consistent with previous research, results from this study show that relationship status is important for coparenting relationships (Bonds and Gondoli 2007; Fagan and Palkovitz 2011; Christopher et al. 2015). Indeed, there was a sharp contrast in coparenting relationships between mothers living with or married to fathers and those who were not. In fact, 38 percent of mothers report diminished coparenting relationships with nonresident, nonromatic partners at year 5, a finding that supports previous research (Fagan and Palkovitz 2011; Goldberg and Carlson 2015). However, in contrast to Fagan and Palkovitz's (2011) research, results from this study suggest that cohabiting parents' coparenting relationships are getting stronger over time. Understanding that coparenting and parental commitment are weakly correlated at years 1 and 3, perhaps cohabiting fathers increased their participation in childrearing activities in an effort to "compensate" for their "poor" relationships with mothers (Merrifield and Gamble 2012: 528) and as a way to maintain their place in their child's life (Edin and Nelson 2013). Further, understanding that fathers' level of commitment is similar to mothers, but increasing more sharply, perhaps cohabiting fathers who feel supported in their coparenting roles subsequently feel more attached to mothers. This speculation is beyond the scope of this paper, but would support the notion that parents are initially together out of dedication to their children and develop dedication to each other over time. Regardless of the reasoning, it does seem possible that a bidirectional association between coparenting and parental commitment exists, where both the parental relationship influences coparenting, and coparenting influences the parental relationship.

Consistent with prior research, results from this study show that maternal background, education, and race significantly contribute to parental commitment 
(McLanahan 2011). Specifically, having been reared in a two-parent household is significantly correlated with mothers' subsequent commitment. This result suggests that individuals establish and emulate households similar to those that they experienced in childhood. Not surprisingly, mothers with more education are more committed to fathers than mothers with less education. Studies examining assortative mating show that women and men tend to partner based on similar attributes (e.g., educational attainment) (see Schwartz and Mare 2005). As a result, more educated parents tend to have access to better resources, marry later, and be more intentional with their fertility (Musick et al. 2010) —all of which increases their chances of establishing stable households and committed relationships (McLanahan 2011); whereas less educated parents are hopeful for marriage, but often lack the resources that would allow them to fulfill this dream (Gibson-Davis et al. 2005). These findings reinforce McLanahan's (2004) argument that children from different backgrounds have "diverging destinies," with children reared in stable, two-headed households faring better than children reared in other contexts.

In terms of the racial disparities in this study, research has consistently shown that race matters for parental commitment— due to resources (e.g., education and marriage) (see Gibson et al. 2005 and Western et al. 2008) and engagement in nonmarital childbearing (see $\mathrm{Wu}$ 2008). Indeed, white parents tend to have higher marriage rates (Gibson et al. 2005), more access to education (Western et al. 2008), and lower rates of nonmarital childbearing than black and Hispanic parents (Wu 2008). However, it is also important to note that low levels of parental commitment among black families may be attributed to their ability to maintain coparental relationships after a partnership 
dissolution (Goldberg and Carlson 2015); therefore, black men's dedication to their children may not be conditional on the parental dyad or a shared household.

Unlike other studies on coparenting (e.g., Carlson et al. 2008; Kamp Dush et al. 2011), the present study focuses on parents who remain in coresidential relationships and who indicate (using mother reports) that their relationships are committed five years after their child's birth. Knowing that around two-thirds of unmarried couples break up by the child's fifth birthday (see Carlson and McLanahan 2010)—which leads to greater instability and diminished life chances for children (McLanahan 2004) - it is important to question whether other relationships, such as the coparental relationship, could influence parental commitment. The results suggest that coparenting is significantly associated with parental commitment — a finding that could lead to salubrious benefits for children. Overall, the hypothesis that parents are dedicated to each other in a nontraditional sense, indicating that they are dedicated to their children first and each other second, is supported. Although commitment theorists might argue that children are constraints, I argue that the parental relationship is the constraint. Knowing that maternal reports of coparenting are consistently high over time, but parental commitment low (although significantly higher net of covariates), the findings support the argument that a "new package deal" exists (Tach et al. 2010; Edin and Nelson 2013). Parents, then, are dedicated to their children.

Turning to commitment theory, results from this study suggest that baseline relationship status may not be the best long-term predictor of dedication and constraints. In other words, dedication and constraints are not static, each are dynamic over time. In previous studies on married couples, undermining coparenting has been shown to strain 
the parental dyad, but also exposes children to negative behaviors (Belsky and Hsieh 1998). In these situations, children's lives remain stable, but may not necessarily be healthy. In fact, the formation of crossgenerational alliances could be detrimental to children, as they foster anti-social behaviors that often alienate, or marginalize, one parent in the family. Therefore, dedicated parents, or those who intentionally form unions, may maintain unhappy relationships to fulfill obligations - a finding that contradicts commitment theory. In contrast, findings from the present study, even for cohabiting couples (i.e., unintentional relationships), suggest that families maintained by constraints (i.e., children) often display pro-social behaviors (i.e., supportive coparenting) that may, in turn, foster dedication between parents over time - a finding that also contradicts commitment theory. Supportive coparenting centralizes the child, ensuring that their needs are met; whereas undermining coparenting appears to centralize the parents' needs to the detriment of the child. Arguably, then, the coparental relationship matters for commitment and childhood outcomes. If this pattern is true, scholars may need to look beyond the initial relationship status of parents to predict familial commitment.

Indeed, given the rise in nonmarital childrearing, forecasting commitment based on baseline parental relationship statuses may overlook other (e.g., coparental) family processes at play that could influence childhood outcomes. Therefore, this study contributes new information to both coparenting and parental commitment, suggesting that parents can (and often do) develop supportive coparenting relationships, despite low levels of initial dedication to each other. Research on commitment, then, should not solely be predicated on or defined by the parental relationship, but should include studies 
examining the interaction between family processes (i.e., coparental relationships) over time. Just as parental dedication has been shown to influence subsequent coparenting relationships among married couples (Schoppe-Sullivan et al. 2004; Bonds and Gondoli 2007), coparenting appears to influence subsequent parental commitment among fragile families.

This study provides new evidence that coparental relationships do contribute to parental commitment five years after the birth of the focal child. However, these findings may be upwardly biased, as the study represented a more advantaged group of families. First, when comparing the relationship statuses of the families represented in this study to the families who were not in the sample, mothers in this study are married at higher rates (58.5\% versus $31.3 \%)$, cohabiting less (11.7\% versus $14.3 \%)$, and more likely to be in a relationship with the father $(2.1 \%$ versus $1.9 \%$ are romantically involved and $27.7 \%$ versus $52.5 \%$ are not in any relationship with the father). The mothers in this sample are more educated, with only $26.2 \%$ having less than a high school diploma (versus $34.7 \%$ of the full sample) and $23.6 \%$ having a college degree (versus $10.7 \%$ of the full sample). One third (33.3\%) of the mothers in this study are in poverty at year 5, compared to $41 \%$ of the full sample. In both samples, $\sim 86 \%$ of mothers report that their health is at least good. Moreover, mothers in the full sample have more children at year 5 than mothers in this study (10.1\% versus $4.4 \%)$. Lastly, mothers in this study who are reporting parental commitment at year 5 are older (27.4 versus 25.3 ) and more likely to be white (32.2\% versus $21 \%$ ), Hispanic (29.4\% versus $27 \%$ ), other ( $7.5 \%$ versus $4 \%$ ), and less likely to be black (30.8\% versus $48 \%)$ than the full sample. 


\section{Limitations}

This study relies on mother reports of coparenting and parental commitment. Although sensitivity analyses using father data were conducted (with consistent results), only mothers whose children had seen their fathers in the past year were asked the coparenting questions; therefore, the coparenting trajectories may automatically produce more positive results. Further, because the analyses are based on coresiding parents, the coparenting results may be upwardly biased, as residency ensures some contact between parents and children and likely influences the coparenting relationship between parents (Martin et al. 2015).

Coparenting in reality, however, is not confined to the biological parents. In fact, racial minorities are often linked to extended kin and fictive networks, where coparenting is more communal in structure (Jones and Lindahl 2011). Black extended families, especially maternal kin, often provide significant resources to family members, including caregiving (Stack 1974; Martin and Martin 1978; Haxton and Harknett 2009). In fact, Martin and Martin (1978) argue that "the black extended family has been the institution most significant to black survival” (95). They argue that researchers cannot understand the lived experiences of black families without including the extended family in empirical analyses (Martin and Martin 1978). Understanding that a significant portion of urban black families will contend with the incarceration of young, black fathers, it is likely that extended kin will serve as coparents. Hispanic families also activate extended kin networks, with both maternal and paternal kin providing support to family members in need (Haxton and Harknett 2009), usually in the form of coparenting (Jones and Lindahl 2011). Indeed, grand-coparenting is rooted in Hispanic culture and offers the caregivers 
salubrious health benefits and general happiness (Jones and Lindahl 2011). It is unfortunate that the coparenting questions in the Fragile Families and Child Wellbeing Study are limited to the biological mother and father and, therefore, do not capture the extent to which extended kin fill these roles.

This study is further limited by the fact that the commitment measures were only collected at year 5, a time when the majority of unmarried parents have broken-up or have engaged in bouts of relationship churning (breaking up with each other and, subsequently, reuniting) (Nepomnyaschy and Teitler 2013). Although longitudinal data allows researchers to estimate change over time, it is not possible to capture the causal, nor potentially bidirectional, relationship between coparenting and parental commitment. Further, I used a blunt measure of poverty (e.g., families living at or below $99 \%$ of the federal poverty line) to be consistent with other research (Meadows 2011); however, families living at or above the federal poverty line may also struggle to make ends meet. Lastly, the sample is limited to urban families. Without data on rural areas, we cannot evaluate how fragile families in these unexplored areas experience coparenting and commitment, nor can we assess how they differ from the urban families presented here.

\section{Conclusion}

Despite these limitations, the Fragile Families and Child Wellbeing Study, given its oversampling of nonmarital births, allows me to estimate the association between coparenting trajectories and parental commitment among a nationally representative sample of urban married and unmarried parents. This study provides new evidence that there is a link between levels of coparenting and parental commitment five years after the 
birth of the focal child. If mothers and fathers can support each other's coparenting goals, children stand to benefit. In fact, when parents can stay together, resources are more likely invested into one household, rather than diverted to new partners and/or new children (Kamp Dush et al. 2011).

Findings from this study indicate that mothers believe they have good coparenting relationships with fathers. And, despite reports of low commitment to each other, it is necessary to highlight the fact that commitment is increasing. Thus, supportive coparenting and low to moderate levels of commitment suggest that parents are primarily bound to each other because of their shared children, but may foster a relationship with each other over time. These findings strengthen support for the "new package deal," where dedication to jointly raise a child comes before the parents have firmly committed to each other (Tach et al. 2010; Edin and Nelson 2013). But, as previously stated, this study's sample was more advantaged than the families that were not included in the analyses due to attrition and skip patterns (i.e., participants were not asked questions that did not pertain to them).

In terms of future studies, I plan to include analyses of social support and neighborhood characteristics. In subsequent studies, I will examine the association between social support and coparenting trajectories on parental commitment. In other words, do perceptions of social support from others (e.g., extended kin) affect the coparenting relationship with the biological father and, subsequently, the parental dyad? Evidence suggests that black families are more likely to maintain coparental relationships after a dissolution (Goldberg and Carlson 2015). Black families have historically been more embedded in extended family networks; therefore, coparenting does not exist 
exclusively between the biological mother and father, but extends beyond households (Martin and Martin 1978). Further, neighborhood characteristics have been linked to father involvement, with more crime ridden areas deterring fathers from being involved with their children (Choi and Pyun 2013). It is important, then, to ask if neighborhood characteristics are associated with parental commitment. The Fragile Families and Child Wellbeing Study includes observational data (data collected by an interviewer) that may provide more information about household (e.g., exposed wiring) and neighborhood characteristics (e.g., litter in the street), which may broaden our understanding of how contextual factors influence coparenting and commitment over time.

If parents truly do feel constrained to each other due to shared children, social policies that provide parents, especially fathers who fear losing access to their children, with legal access to their children need to be explored. Scholarship has noted that women and men partner based on assortative mating (Schwartz and Mare 2005) and commitment theorists have found that couples who intentionally partner have better long-term outcomes (Stanley and Markman 1992; Stanley et al. 2010). These arguments have been corroborated by demographers who have found that college-educated (assortative mating), married parents (dedicated) tend to have more stable relationships in which to raise children (McLanahan 2004). Indeed, findings from this study suggest that relationship status and education are important factors in parental commitment. Parents who are not married may be trying to navigate an "incomplete institution," where they may be making decisions through trial and error rather than through socially-defined, normative expectations (Cherlin 2010). Policies directed at coparenting, rather than marriage incentives and promotion, could help parents learn to negotiate their parental 
duties with each other to ensure that both parents are vested in their children's lives.

Further, education programs could help parents obtain the resources (e.g., credentials and access to networks, both of which could lead to jobs) that are necessary to raise a child. 
Table 1. Weighted Means/Percentages and Standard Deviations of the Analytic Sample $(N=3,030)$

\begin{tabular}{|c|c|c|c|c|c|c|c|}
\hline & Baseline & \multicolumn{2}{|c|}{ Year 1} & \multicolumn{2}{|c|}{ Year 3} & \multicolumn{2}{|c|}{ Year 5} \\
\hline & \multirow{2}{*}{\multicolumn{2}{|c|}{$\frac{\text { Means/\% }}{\text { glv agree) }}$}} & $(\mathrm{SD})$ & Means/\% & (SD) & Means $/ \%$ & $(\mathrm{SD})$ \\
\hline \multicolumn{7}{|c|}{ Parental Commitment (1 strongly disagree - 5 strongly agree) } & \\
\hline Father important to mother & & & & & & 3.6 & $(1.3)$ \\
\hline future* & & & & & & 4.2 & $(0.03)$ \\
\hline Mother thinks of father and mother as one & & & & & & 4.2 & $(1.1)$ \\
\hline $\begin{array}{l}\text { Mother wants relationship to stay strong, even } \\
\text { through rough times }\end{array}$ & & & & & & 4.6 & $(0.8)$ \\
\hline $\begin{array}{l}\text { Mother satisfied with sexual relationship with } \\
\text { father }\end{array}$ & & & & & & 4.3 & $(0.9)$ \\
\hline Mother trusts dad won't cheat on her & & & & & & 4.3 & $(1.0)$ \\
\hline Parental Commitment Index & & & & & & 4.1 & $(0.02)$ \\
\hline \multicolumn{8}{|l|}{ Coparenting ( 1 rarely true -3 always true) } \\
\hline Father acts like father mother wants for child & & 2.8 & $(0.5)$ & 2.7 & $(0.6)$ & 2.6 & $(0.6)$ \\
\hline Mother can trust dad to take care of child & & 2.9 & $(0.4)$ & 2.8 & $(0.5)$ & 2.8 & $(0.5)$ \\
\hline Father respects mother's schedules/rules for child & & 2.7 & $(0.5)$ & 2.6 & $(0.6)$ & 2.6 & $(0.7)$ \\
\hline $\begin{array}{l}\text { Father supports mother in the way she wants to } \\
\text { raise child }\end{array}$ & & 2.8 & $(0.5)$ & 2.7 & $(0.6)$ & 2.6 & $(0.6)$ \\
\hline $\begin{array}{l}\text { Mother and father discuss problems related to } \\
\text { child }\end{array}$ & & 2.8 & $(0.5)$ & 2.7 & $(0.6)$ & 2.7 & $(0.6)$ \\
\hline $\begin{array}{l}\text { Mother can rely on father to watch child } \\
\text { independently }\end{array}$ & & 2.7 & $(0.6)$ & 2.6 & $(0.6)$ & 2.6 & $(0.7)$ \\
\hline Coparenting Indices & & 2.7 & $(0.01)$ & 2.5 & $(0.01)$ & 2.5 & $(0.01)$ \\
\hline
\end{tabular}

\section{Time-Varying Covariates}

Poverty $100 \%$ of the federal poverty line (yes/no)

Yes

$31.4 \quad 30.6$

33.3

No (ref)

Self-Reported Health

Excellent

33.5

30.2

25.9

Very Good

32.3

39.1

37.2

Good

Fair

Poor

Relationship Characteristics

Married

62.8

63.6

58.5

Cohabiting

21.7

16.4

11.7

Romantically involved

4.0

1.7

2.1

Mother and father not in a relationship

11.5

18.3

27.7

New fertility since baseline (yes/no)

Yes

10.9

33.7

4.4 
Table 1. (Continued)

\begin{tabular}{|c|c|c|c|c|c|c|c|}
\hline & \multirow{2}{*}{$\begin{array}{l}\text { Baseline } \\
\text { Means/\% }\end{array}$} & \multicolumn{2}{|c|}{ Year 1} & \multicolumn{2}{|c|}{ Year 3} & \multicolumn{2}{|c|}{ Year 5} \\
\hline & & Means/\% & SD & Means $/ \%$ & SD & Means $/ \%$ & $\mathrm{SD}$ \\
\hline \multicolumn{8}{|l|}{ Time Invariant Covariates } \\
\hline \multicolumn{8}{|l|}{ Mothers' age } \\
\hline In years & & 27.4 & $(6.2)$ & & & & \\
\hline \multicolumn{8}{|c|}{ Mothers lived with biological parents at age 15} \\
\hline Yes & 55.8 & & & & & & \\
\hline No & 44.2 & & & & & & \\
\hline \multicolumn{8}{|l|}{ Demographics } \\
\hline White & 32.2 & & & & & & \\
\hline Black & 30.8 & & & & & & \\
\hline Hispanic & 29.4 & & & & & & \\
\hline Other & 7.5 & & & & & & \\
\hline \multicolumn{8}{|l|}{ Education } \\
\hline Less than high school & 26.2 & & & & & & \\
\hline High school & 30.5 & & & & & & \\
\hline Some college & 19.7 & & & & & & \\
\hline College & 23.6 & & & & & & \\
\hline
\end{tabular}


Table 2. Correlations for Coparenting at Years 1, 3, and 5 and Parental Commitment at Year 5.

\begin{tabular}{|c|c|c|c|c|c|c|c|}
\hline & $\mathrm{C} 5$ & $\mathrm{C} 1$ & $\mathrm{C} 3$ & $\mathrm{C} 5$ & & & \\
\hline Commitment Year 5 (C5) & 1.0 & & & & & & \\
\hline Coparenting Year $1(\mathrm{C} 1)$ & .17 & 1.0 & & & & & \\
\hline Coparenting Year 3 (C3) & .21 & .53 & 1.0 & & & & \\
\hline \multirow[t]{2}{*}{ Coparenting Year 5 (C5) } & .34 & .39 & .51 & 1.0 & & & \\
\hline & $\mathrm{C} 5$ & I1 & $\mathrm{I} 2$ & I3 & $\mathrm{I} 4$ & I5 & I6 \\
\hline Commitment Year 5 (C5) & 1.0 & & & & & & \\
\hline Father Want Year 1 (I1) & .13 & 1.0 & & & & & \\
\hline Father Trustworthy Year 1 (12) & .08 & .48 & 1.0 & & & & \\
\hline Father Respectful Year 1 (13) & .1 & .43 & .32 & 1.0 & & & \\
\hline Father Supportive Year 1 (I4) & .14 & .48 & .35 & .44 & 1.0 & & \\
\hline Father Communicative Year 1 (I5) & .08 & .28 & .31 & .25 & .29 & 1.0 & \\
\hline \multirow[t]{2}{*}{ Father Reliable Year 1 (I6) } & .12 & .42 & .38 & .35 & .34 & .28 & 1.0 \\
\hline & $\mathrm{C} 5$ & I1 & $\mathrm{I} 2$ & $\mathrm{I} 3$ & $\mathrm{I} 4$ & I5 & I6 \\
\hline Commitment Year 5 (C5) & 1.0 & & & & & & \\
\hline Father Want Year 3 (I1) & .16 & 1.0 & & & & & \\
\hline Father Trustworthy Year 3 (12) & .15 & .41 & 1.0 & & & & \\
\hline Father Respectful Year 3 (13) & .14 & .45 & .32 & 1.0 & & & \\
\hline Father Supportive Year 3 (I4) & .16 & .49 & .37 & .56 & 1.0 & & \\
\hline Father Communicative Year 3 (I5) & .16 & .29 & .28 & .29 & .34 & 1.0 & \\
\hline \multirow[t]{2}{*}{ Father Reliable Year 3 (I6) } & .15 & .42 & .42 & .33 & .42 & .34 & 1.0 \\
\hline & $\mathrm{C} 5$ & I1 & $\mathrm{I} 2$ & I3 & $\mathrm{I} 4$ & I5 & I6 \\
\hline Commitment Year 5 (C5) & 1.0 & & & & & & \\
\hline Father Want Year 5 (I1) & .26 & 1.0 & & & & & \\
\hline Father Trustworthy Year 5 (I2) & .22 & .42 & 1.0 & & & & \\
\hline Father Respectful Year 5 (I3) & .19 & .38 & .33 & 1.0 & & & \\
\hline Father Supportive Year 5 (I4) & .27 & .45 & .35 & .54 & 1.0 & & \\
\hline Father Communicative Year 5 (I5) & .22 & .34 & .27 & .30 & .41 & 1.0 & \\
\hline Father Reliable Year 5 (I6) & .23 & .35 & .34 & .31 & .33 & .28 & 1.0 \\
\hline
\end{tabular}

Notes: Commitment Year 5 and Coparennting Years 1, 3, and 5 are composite variables.

The six indicators (I1-I6) for coparenting were separately correlated with commitment at year 5 . 
Table 3. Coparenting Trajectory Means $(N=3,030)$.

Year $1 \quad$ Year $3 \quad$ Year 5

\begin{tabular}{llll}
\hline Coparenting trajectories without covariates & $2.68 * * *$ & $2.60 * * *$ & $2.52 * * *$
\end{tabular}

\begin{tabular}{llll} 
Coparenting trajectories with covariates $\quad 2.79 * * *$ & $2.73 * * *$ & $2.67 * * *$ \\
\hline
\end{tabular}

$+p<.10 * p<.05 * * p<.01 * * * p<.001$

Note. The coparenting trajectory mean without covariates decreases by .04

per year; whereas the mean for coparenting with time-varying covariates decreases by .03 per year. 
Table 4. Latent Growth Curve Model of Mothers' Coparenting Trajectories on Parental Commitment at Year $5(N=3,030)$.

\begin{tabular}{|c|c|c|c|c|}
\hline & \multicolumn{2}{|c|}{ Model 1} & \multicolumn{2}{|c|}{ Model 2} \\
\hline & $\beta$ & $S E$ & $\beta$ & $S E$ \\
\hline \multicolumn{5}{|l|}{ Parental Commitment Year 5} \\
\hline \multicolumn{5}{|l|}{ Coparenting } \\
\hline Intercept & $1.34 * * *$ & .01 & $2.55 * * *$ & .31 \\
\hline Slope & $.53 *$ & .21 & $2.56 * * *$ & .31 \\
\hline \multicolumn{5}{|l|}{ Time-varying covariates } \\
\hline \multicolumn{5}{|l|}{ Year 1 Coparenting } \\
\hline Poverty & & & -.04 & .03 \\
\hline Self-reported poor health & & & -.02 & .04 \\
\hline \multicolumn{5}{|l|}{ Married (ref) } \\
\hline Cohabiting & & & -.03 & .04 \\
\hline Romantically Involved & & & $-.20 * *$ & .06 \\
\hline No relationship w/father & & & $-.27 * * *$ & .05 \\
\hline New child(ren) & & & $-.06 \dagger$ & .03 \\
\hline \multicolumn{5}{|l|}{ Year 3 Coparenting } \\
\hline Poverty & & & -.01 & .02 \\
\hline Self-reported poor health & & & -.03 & .02 \\
\hline \multicolumn{5}{|l|}{ Married (ref) } \\
\hline Cohabiting & & & -.02 & .03 \\
\hline Romantically Involved & & & -.06 & .05 \\
\hline No relationship w/father & & & $-.39 * * *$ & .03 \\
\hline New child(ren) & & & -.02 & .01 \\
\hline \multicolumn{5}{|l|}{ Year 5 Coparenting } \\
\hline Poverty & & & .00 & .02 \\
\hline Self-reported poor health & & & -.01 & .03 \\
\hline \multicolumn{5}{|l|}{ Married (ref) } \\
\hline Cohabiting & & & $.06 *$ & .03 \\
\hline Romantically Involved & & & .06 & .06 \\
\hline No relationship w/father & & & $-.38 * * *$ & \\
\hline New child(ren) & & & .05 & .05 \\
\hline
\end{tabular}


Table 4. (continued)

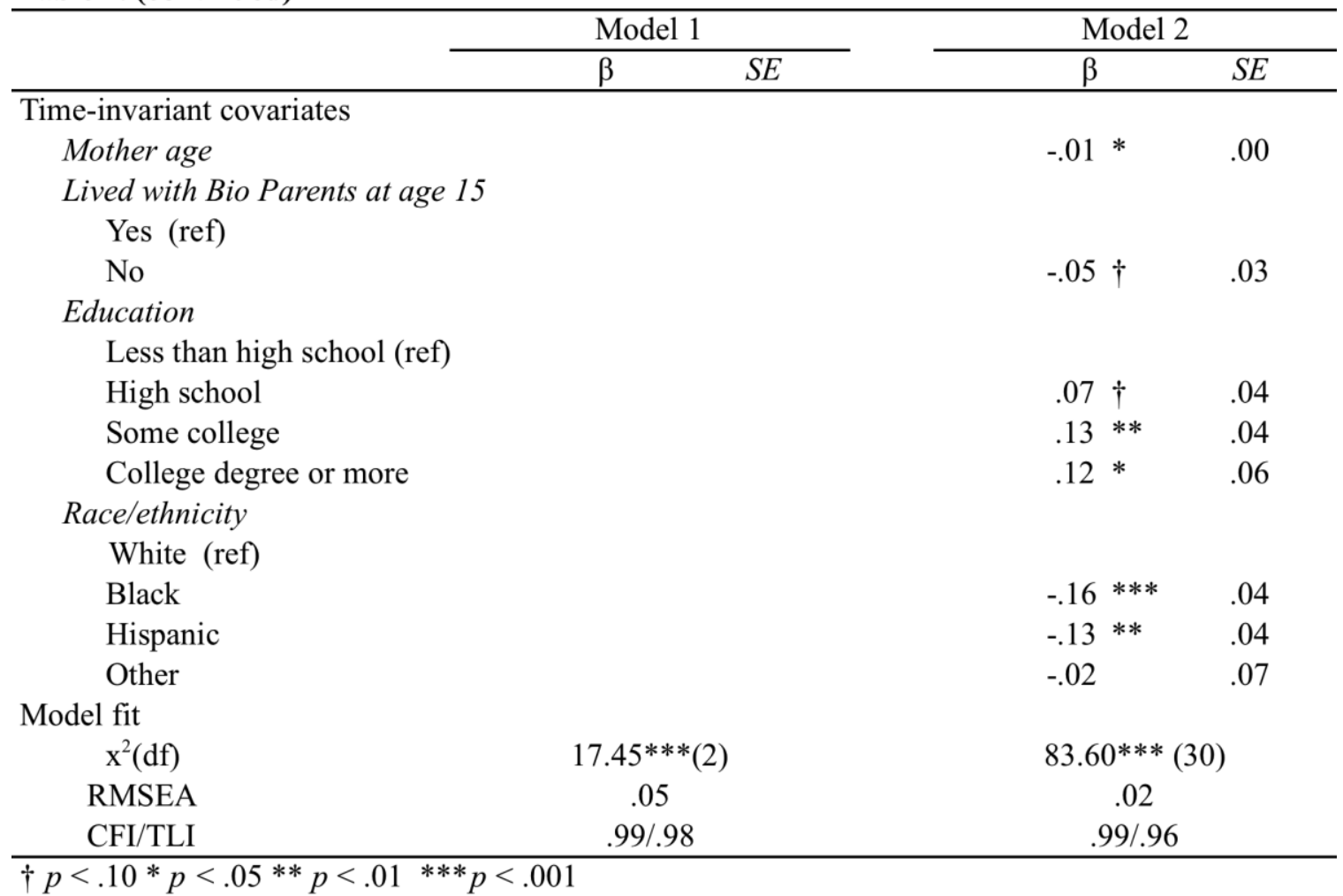

Note. Model 1 estimates the coparenting trajectory over years 1-5 after the birth of the focal child, predicting parental commitment at year 5. Model 2 adds in time-varying covariates predicting the coparenting trajectory and time-invariant covariates are regressed on parental commitment. Model fit is determined by the RMSEA (root mean square error of approximation), where values of 0.05 or less are considered good; CFI (comparative fit index), where values closer to 1.0 are considered good; and the TLI (Tucker-Lewis Index), where values closer to 1.0 are considered good. 


\section{CHAPTER III: \\ MATERNAL PARTNERSHIP TRANSITIONS AND CORESIDENCE WITH EXTENDED KIN ${ }^{2}$}

\section{Introduction}

The rise in family instability, i.e., increasing dissolution of parental relationships, over the past half century has often raised questions about how children fare amid these changes. For example, increasingly scholars are interested in the role of extended family members in the lives of their children and grandchildren. Research has shown that a significant proportion of unmarried mothers live with and have close relationships with their mothers (Högnäs and Carlson 2010). Evidence further suggests that multigenerational households are established to fulfill the needs of the younger, rather than elder generation (Aquilino 1990). Strong familial ties may be needed during times of distress, as extended families may serve as protective barriers against potentially negative consequences of family change (Wilson 2000).

Much of family change has included the context in which children are born and reared. In terms of single-parenthood, more mothers cohabit with their partners than was true in the past (Smock and Manning 2010), but cohabiting versus martial partnerships are significantly less stable (Seltzer 2000), and the challenges of single parenthood remains. Often, single mothers "double up" with extended family out of financial

\footnotetext{
${ }^{2}$ Acknowledgements/Funding: Thank you to the Columbia Population Research Center for its support of this study (FFCWS Study \# 5R01HD03699916, FFCWS Workshop \# 5R25HD074544; CPRC \# P2CHD058486).
} 
necessity (Pilkauskas et al. 2014), as they are at a greater risk of being unemployed, lesseducated, depressed, and stressed (Jackson 1998; Jackson et al. 2013). Indeed, “60 percent of white and 72 percent of black single mothers who had a child before marrying resided at some point with their parent(s)" (Casper and Bianchi 2002: 158) - a

phenomenon that does not wane across the life course. In fact, Pilkauskas (2012) found that single mothers often experience "on again, off again" coresidential relationships with kin, particularly following nonmarital births and subsequent breakups with fathers.

Studies have explored associations between parental relationships and financial support from kin (see Mazelis and Mykyta 2011; Pilkauskas, Garfinkel, and McLanahan 2014); however, the literature does not specifically examine the association between relationship status changes and extended kin coresidence over a nine-year period following the birth of a child. One study does examine multigenerational households by relationship status at the birth of focal children-a study the author refers to as “descriptive in nature" (Pilkauskas 2012: 934) and restricts extended kin coresidence to grandfathers, grandmothers, or both. My study, therefore, extends the literature in three ways: 1) by including a broader definition of extended kin in the models (e.g., aunts and uncles, grandparents, parents-in-law versus maternal parents); 2) by modeling where mothers live with extended kin (e.g., their own homes versus extended kin homes); and 3) by accounting for relationship status changes over a nine-year period, rather than holding relationship status constant at the birth of the focal child. Analyses focused only on the coresidence between mothers and their parents may limit our understanding of the breadth of extended kin involvement. Although from a life course perspective, I suspect mothers are more likely to move in with extended kin than the other way around given 
that base households (or the elder generations' households) are generally considered stable, there is evidence that "many mothers (56\%) bring others into their homes" (Pilkauskas et al. 2014). Lastly, it seems an odd methodological choice to hold relationship status constant, given that there are numerous studies that demonstrate that relationship status changes are frequent among fragile families, or families formed outside of marriage (see McLanahan 2011).

Whereas research has emphasized "activated support," which occurs when parents receive financial support from kin (Mazelis and Mykyta 2011), the present study investigates the association between relationship status change and residential supporteither mothers moving in with extended kin or extended kin coresiding with mothers. This is important because research suggests that mothers sometimes seek "temporary refuge" (Edin and Kefalas 2005: 67) with extended kin during times of crisis (e.g., relationship dissolution) (Martin and Martin 1978). The fragile family scholarship shows that unmarried parents often break up soon after the birth of their children and that repartnering is common (McLanahan 2011). Indeed, only around a third of children born to unmarried parents will be part of the quintessential, two-parent family by age 5 (McLanahan 2011) — what Edin and Kefalas (2005) have referred to as a "family-goround" (xi). Although a change in relationship status often means a change in financial resources (Tach et al. 2010), these changes may also necessitate a residential change. Temporary housing, unlike economic support, may put less strain on extended family members and, therefore, may be more manageable (Harknett and Hartnett 2011). Specifically, this paper examines the extent to which mothers coreside with extended kin, either in mothers' homes or the homes of extended family members, in 
response to relationship status change. Although place of residence (mothers' versus extended kin households) is included in the analyses, an examination as to why extended kin may move into mothers' homes is not possible due to data limitations. Extended kin may move in with mothers to offer child care assistance or as emotional support mechanisms - both of which I hope to explore once more data become available. This paper uses data from the Fragile Families and Child Wellbeing Study $(N=2,886)$ to examine the following questions: Are mothers' coresidential relationships with extended family members (either in mothers' homes or extended kin homes) formed by their changes in coresidential romantic partnership status? Do mothers' end coresidence with extended family members (either in mothers' homes or extended kin homes) when they form new coresidential romantic partnerships?

\section{Theoretical Framework and Background}

\section{Life Course Theory}

Life course theory approaches the family as a dynamic institution, and within particular historical contexts (Elder 1977; Elder 1998). Life course theorists argue that changes in the family result from newer generations 1) developing and enacting behaviors that produce cultural changes, and 2) embracing technological developments (Bengston and Allen: 1993) - both of which may spark "rapid change" in the developmental stages of the next generation (Elder 1977). Indeed, one argument suggests that new birth control methods, and changing societal attitudes about premarital sex and marriage in general, promoted cohabitation as an alternative to marriage (and possibly contributed to a $41 \%$ increase in cohabitation in less than two decades) (Smock 2000; 
Brown 2005; Cherlin 2009). Persistent fear of divorce among the unmarried (due to rising rates of marriage dissolution and personal fear of failure) (Bumpass 1990) and increased social acceptance of nonmarital childbearing (e.g., Edin and Kefalas 2005) also contributed to rising rates of cohabitation. Some scholars argue that changes in attitudes about cohabitation and nonmarital childbearing have been evolving for 50 years (Edin and Kefalas 2005). These shifts, then, may influence the next generation in terms of when and how they form families.

Family systems are comprised of individuals whose lives are linked and interdependent (Crosnoe and Elder 2002), and thus, the potential consequences of personal choices are not isolated to the individual, but tend to affect other members of a family system (Elder 1998). Therefore, the "timing and sequence of family events" may interfere with the development of subsystems (Bengston and Allen 1993: 482) and alter the life courses of those involved. For example, the marital context in which children are born affects family systems. One study, for example, shows that nearly half of all single mothers and nearly $20 \%$ of cohabiting couples coresided with extended kin at the time of their child's birth, compared to less than $10 \%$ of married couples (Pilkauskas 2012). Hence, relationship status matters. Nonmarital childbearing often does not allow mothers much time to acquire resources to sustain their own family system. In fact, unmarried mothers, both single and cohabiting, are more likely to depend on extended kin than married mothers (Mazelis and Mykyta 2011), as fragile families are often more transitory (Pilkauskas 2012).

Nonmartial childbearing may be considered a "deviant sequence," or a decision that diverts a person from what is considered a normative trajectory, e.g., education 
before marriage and marriage before childbearing. Moreover, nonmarital childbearing is often associated with relationship instability and economic hardship, particularly housing insecurity (Desmond 2016), both of which increase the likelihood that mothers' living situations are unstable (Park et al. 2015).The consequences of parental separation and often repartnering, subsequently, increase the likelihood that mothers experience spell/s of coresidence with extended kin (Elder 1977). Indeed, ethnographic data suggest that "a mother's parental or grandparental home...serves as a haven when relationships go bad" (Edin and Kefalas 2005: 66). On the other hand, the extant literature has not yet corroborated this finding using nationally representative, longitudinal data, which would help us to better understand the frequency and duration of extended family support/coresidence during periods when mothers' transition in and out of romantic partnerships.

Again, nonmarital childbearing, overall, has become more normative in many Western countries, including the United States (e.g., Edin and Kefalas 2005). These changing norms, compounded by the finding that many low-income women view motherhood before marriage as their only viable option, may mean that having a baby "out of order" disappoints extended kin, but will not likely dramatically change their life trajectories, as their life chances were limited to begin with (Collins 2000; Edin and Kefalas 2005: 65). In fact, Bengston and Allen (1993) argue that "the location of families in the broader social structure influences the events family members experience with the passage of time" (482). Therefore, structural barriers (e.g., limited access to jobs and education) may prevent couples from marrying (Smock et al. 2005; Sweeney 2012) and encourage nonmarital childbearing (Edin and Kefalas 2005) - a family formation practice 
that life course theorists argue has long-term ramifications for both individual and family trajectories (Elder 1977).

As life course theory underscores, parents' and children's lives are linked, suggesting that parental relationship changes may disturb the equilibrium of family systems, and thus affect all members of the family. Indeed, when mothers break-up or establish new partnerships, they not only transform their lives, but the lives of others (e.g., children, extended kin) living or interacting with them (Osborne et al. 2012). In fact, family structure transitions mean changes in resources for mothers and their children, and in some cases, affect maternal health (Osborne et al. 2012). Indeed, research suggests that mothers tend to "partner-up" after a break-up, meaning that they re-partner with men with greater resources than previous partners (Tach et al. 2010: 200; Bzostek et al. 2012); thus, entering a new union for mothers sometimes means more financial stability; whereas mothers who end a partnership often experience financial and psychological instability (Osborne et al. 2012). Mothers who experience a break-up may coreside with extended kin, particularly their parents, even if temporarily (Dunifon et al. 2014). Research on multigenerational households does suggest that mothers who, after establishing their own homes, take up coresidency with extended family "may have experienced a shock of some sort that led them to do so" (Pilkauskas 2012: 939).

Knowing that family structure transitions initiate changes in material and psychological stability, it is plausible that the "shock" that precipitated a move into a multigenerational household is a change in partnership status. Pilkauskas (2012) found that mothers' coresidential relationships with extended kin were ephemeral. Further, she found that "economic factors did not play a role among single mothers," in terms of their 
decisions to coreside with kin. Perhaps predicting the establishment of multigenerational households by mothers' relationship statuses at the birth of their children, rather than accounting for relationship changes over time, put too much emphasis on economic need and underestimated the need for temporary housing.

One limitation of life course theory is that it frames individual and family trajectories as a linear problem. For example, Elder (1977) argues that families are established when a man and woman marry. Children who are born into these unions are likely to grow up and do the same. Elder discusses the departures of adult children from their family-of-origin homes as permanent - what he refers to as "role sequences" (Elder 1977: 294). He argues that family cycling follows a sequence of events, which begin with "the marriage of two individuals through the postparental/postretirement/aging phase" (Elder 1977: 294). Today, Elder's conception of "family cycling” may be thought of differently. That is, children may revolve in and out of their parents' households. In other words, children may form families of their own and distance themselves from their family system of origin (at least temporarily); however, adult children may be more likely to return to their parents' homes for support if and when they experience hardship (i.e., partnership dissolves). For example, given the fragility of cohabiting relationships (Brown 2005), transitions from the family system of origin into a cohabiting union may indicate the impermanence of an adult child's exit. Therefore, the returns home may be considered developmental regressions, as the adult child's independence is held in abeyance until they "regroup" and "figure out a way to reestablish their own independent households" (Edin and Kefalas 2005: 67). The erosion of new partnerships, then, may be considered "turning points" for unwed mothers and fathers, yet life course theory 
presents these points as path diversions. If life course theory frames human development through role sequences (i.e., ordered paths), returns home could be viewed as impediments to development (i.e., the natural progression through life course stages). Family cycling, as theorized in the 1970s, acknowledged that parental duties within the main family system may change over time (i.e., as children age, they need different types of parenting); however, the notion that changes occur within a sequence suggests that the establishment and maintenance of children's independent households (i.e., subsystems) are permanent.

Elder et al. (2003) argue that individual agency tends to be consistent with the ebbs and flows of social structures. For example, mothers who return to their family system of origin may do so as a result of partnership dissolutions (or ebbing relationship structures). Because many families formed outside of marriage are more susceptible to break-ups (compared to families formed within marriages), analyses on families must span time. Examining families at one point in time fails to capture the prevalence of change within families that may be continuously adapting to societal and family-level changes (Bengston and Allen 1993; Elder 1998). Further, it could be argued that life course theory itself is biased toward the modern, normative behaviors of socioeconomically advantaged, white families and presupposes that the establishment of nuclear subsystems is permanent. In fact, Collins (2000) argues that "everything the imagined traditional family ideal is thought to be, African-American families are not" (53). Examining the life courses of minorities suggests that membership within a network, historically, was common and often necessary for survival (e.g., see Martin and Martin 1978). Whereas life course theory suggests a linear path from childhood to 
adulthood for white families (Roschelle 1997), studies focused on minority families show that diversions back to the "'family base' household" are not uncommon for a variety of personal (e.g., divorce) and structural (e.g., Great Recession) reasons (Martin and Martin 1978). Much like white families, black families establish "sub-extended families," or their own nuclear family households (Martin and Martin 1978: 8); however, these newly established households often remain connected to the base household in a system of "mutual aid," where they each operate under what Stack (1974) refers to as "norms of reciprocity" - which make it difficult to achieve and maintain independent, autonomous lives (Martin and Martin 1978: 8).

Race differences in terms of reciprocal supportive relationships have been noted in the literature (Stack 1974; Sarkisian and Gerstel 2004). Some evidence suggests that disadvantaged black women are more likely to live close to and engage in "balanced exchanges" (e.g., transportation exchanged for transportation) with extended kin than are white women (see Högnäs 2010 for an exception); therefore, black women are embedded in an ongoing exchange relationship, whether they can afford to be or not (Radey and Padilla 2009). Although reciprocal relationships are often viewed as survival mechanisms, they do "not even come close to compensating for the disadvantages of being poor, or a minority, or both" (Sarkisian and Gerstel 2004: 829). In other words, the intersection of race and class works against, rather than for, those most involved in exchange relationships (Martin and Martin 1978).

Other research, however, suggests extended family networks among blacks have deteriorated, with whites now offering more assistance to family members than blacks (Roschelle 1997; Collins 2000; McDonald and Armstrong 2001). Some argue that 
prevalent social problems (e.g., unemployment, drugs, segregation) within urban areas (Roschelle 1997) led to the breakdown of communal aspects of the black extended family, including othermothering (Collins 2000). Collins (2000) defines othermothers as "women who assist bloodmothers by sharing mothering responsibilities" (178).

Othermothers, who once offset the demands of biological motherhood (Collins 2000), are now less prominent. Some research points to self-sufficiency programs (e.g., TANF programs) for the marginalization of othermothers, which, consequently, contributed to the weakening of extended kin networks (McDonald and Armstrong 2001) and the “overstretch[ing] of black mothers (Collins 2000). Indeed, inundated black women may offer less support to new mothers, including their own daughters, which in turn may encourage the latter to seek assistance elsewhere (e.g., government programs, friends) (McDonald and Armstrong 2001). However, reliance on government support does not appear to weaken extended kin networks (Sarkisian and Gerstel 2004). Indeed, Edin and Kefalas (2005) found that low-income, urban mothers_-black, white, and Hispanic — are significantly reliant upon their own mothers and grandmothers; thus, both race (Stack 1974) and class (Edin and Kefalas 2005) may contribute to extended kin involvement.

Drawing on life course theory, this study fills a gap in the literature by examining the role of extended kin, specifically in terms of coresidency with mothers (and children), before and after a mother's romantic partnership dissolves. Because the links between parents and children are strong and interdependent, I hypothesize that during break-ups, mothers will coreside with extended family members. Importantly, mothers may live in extended family members' homes or extended kin may move into the mothers' homes. 


\section{Potential Confounding Factors}

Although the present study examines the association between relationship status change and extended kin coresidence, other factors may possibly contribute to this association. For example, the extent to which relationship changes are associated with extended kin coresidence may vary by mothers' age. Younger mothers are more likely to turn to family for financial support (Mazelis and Mykyta 2011) or housing (Pilkauskas 2012; Pilkauskas et al. 2014). On the other hand, there is evidence that older black women are withholding help to younger mothers, whom they view as placing more faith in the welfare system than extended kin networks (McDonald and Armstrong 2001). In other words, there is some sentiment among elder black women that younger mothers feel they can, via governmental assistance, make it on their own. Young, Hispanic mothers also coreside with extended kin at greater rates, as Hispanic families are more integrated than families of other races (Roschelle 1997; Pilkauskas et al. 2014).

Another potential confounding factor is mothers' parity. As mothers have more children, they may feel less supported, especially if new children are born within new romantic partnerships - research suggests, for example, that multipartnered fertility may lead to "network fatigue" (Harknett and Knab 2007: 246). In other words, mothers who have relied too heavily on their support networks with previous children may have,

consequently, drained their resource supply; thus, mothers with fewer children may feel they have greater access to extended kin support (Harkentt and Knab 2007).

Turning to economic necessity, mothers who experience material hardship have a greater propensity to seek help from extended kin than their more advantaged counterparts (Mazelis and Mykyta 2011). When examining the giving and receiving 
behaviors of mothers, Radey and Padilla (2009) found that disadvantaged mothers were more likely to receive help than to provide it. However, given the likelihood that disadvantaged mothers are connected to networks that are also disadvantaged, these support mechanisms may not always be dependable and steady; thus, more advantaged mothers tend to receive more consistent support (Radey and Padilla 2009). As Harknett and Hartnett (2011) argue, housing support may be "less of an impediment than...financial support"; therefore, mothers experiencing relationship transitions, regardless of their and their extended kin's financial situations, may be better able to access temporary housing support (863). Thus, age, parity, multipartnered fertility, and an income-to-poverty ratio are included as time-varying covariates in appropriate analyses.

Race is also a potentially confounding factor to consider in the association between partnership changes and extended coresidence. Whereas white and Hispanic families are able to access more support in desperate times, regardless of the severity of need, black families' receipt of aid does not waver during similar times (Radey and Padilla 2009). In fact, black families remain engaged in high levels of exchange, meaning that they are expected to provide aid to others even during their own troubled times (Radey and Padilla 2009).

Despite some evidence to the contrary, reciprocal relationships among black families, especially female kin (Haxton and Harknett 2009), seem to have endured over time (Stack 1974; Sarkisian and Gerstel 2004; Radey and Padilla 2009). Indeed, black families engage in "balanced exchanges," or the giving and receiving of "practical support, including transportation, household help, and child care"-a practice scholars argue is directly linked to structural issues (e.g., discrepancies in educational attainment 
between blacks and whites) that limit black families from getting ahead, but keep them reliant on each other (Sarkisian and Gerstel 2004: 823). Hispanic families also rely heavily on exchange networks, but tend to be more inclusive, meaning that they seek support from both female and male kin in times of need (Haxton and Harknett 2009). Hispanic families are also more likely to double-up with kin (Pilkauskas et al. 2014), a practice that research shows is also common for both black and Asian families (Dunifon et al. 2014). Sarkisian and Gerstel (2004) found that while white families engage in balanced exchanges, theirs typically are more emotional than financial (Sarkisian and Gerstel 2004). Given this study is investigating the link between relationship status changes (i.e., the emotional and physical severing of partnerships) and extended kin coresidence, it is likely that all mothers will turn to family members during transitional times.

Education may also play a role in extended kin coresidence following a partnership change. Research suggests that less education among the elder generation is indicative of lower levels of monetary support—which is particularly true for black and Hispanic families (Radey and Padilla 2009). The opposite relationship may be true for white families, where "low[er] parental education levels are related to higher levels of participation in financial transfers" (Radey and Padilla 2009: 348). Harknett and Hartnett (2011) found that "personal safety nets" are positively influenced by education and employment and are more common among whites (870). However, other research shows that mothers with less educational attainment, regardless of race, tend to double up (Pilkauskas et al. 2014), particularly in multigenerational households (Pilkauskas 2012). Only mothers who "self-identified as being in the 'other' race" category were 
significantly more likely to live with extended kin (937). This finding suggests that housing support may truly be "less of an impediment" than monetary support for families (Radey and Padilla 2009). Thus, because coresidence with extended kin during relationship status changes is presumed temporary, the education level of mothers may not matter as much as if they were seeking financial assistance.

Lastly, whether a mother lived with both biological parents at age 15 may matter. Indeed, research suggests that mothers who were reared in two-parent households feel more supported than mothers who were not (Harknett and Knab 2007). Thus, race, education, and whether mothers lived with both biological parents at age 15 are included as time-invariant covariates in appropriate analyses.

\section{Methods}

\section{Dataset}

The study employs a quantitative, deductive approach, using data from the Fragile Families and Child Wellbeing Study (FFCWS). The FFCWS is a longitudinal birth cohort study, conducted in 20 cities (with populations $>200,000$ ) in 75 hospitals. Baseline data were collected between 1998 and 2000 at the birth of the focal child, with follow-up surveys conducted at years $1,3,5$, and 9 following birth. The study oversampled nonmarital births $(N=4,897$ total 3,710 to unmarried parents and 1,187 to married parents). Both mothers and fathers were interviewed. By year 9, $76 \%$ of mothers still participated. Fathers were more difficult to locate at baseline, and retention rates were not as high as mothers', but $88 \%$ of fathers participated at least once. Because I am 
interested in mothers' residential patterns, reports from mothers will be used for this study.

\section{Measures}

Dependent variables for logistic regression, random effects, and fixed effects models. To determine whether mothers oscillate into and out of extended family members' houses (dependent variable) during break-ups, I began by using mothers' baseline responses to the following two questions, and then accounted for their living situations at years 1, 3, 5, and 9: At all waves, mothers were asked 'Are you and baby's father living together now?" This is a dichotomous variable, with yes or no responses. Also, mothers were asked to indicate who lives in the household in which they lived. Categories at baseline include mothers' parent(s), partner, friend, child, other child, and other. Mothers were coded as living with extended kin if they lived with their parents at baseline.

Beginning in year 1, mothers were also asked "how many people are currently living with you?" Subsequently, mothers were asked to identify with whom they coreside. I created a dummy variable to distinguish between mothers who lived with extended kin and mothers who did not. Mothers were coded as living with extended kin if they responded with one of the following categories: parent(s), grandparent(s), aunt(s)/uncle(s), partner's parent(s). Other categories, which were coded as zero, include: spouse, partner, bio/adopted child, stepchild, foster child, sibling, cousin, not-related adult, not-related child, niece/nephew, grandchild, new partner, new spouse, unknown 
related adult, and unknown related child. I recoded each of these as "others in household."

Dependent variables for multinomial regression models. Beginning in year 1 , mothers were asked “What is your current living situation?” In order to determine if, during transitional times, mothers moved in with extended kin or extended kin moved in with them, I coded mothers living in their own homes if they responded with "rent your own apartment or house" or "own your own home"; whereas, I coded mothers living in extended kin homes if they responded with "live with family or friends and contribute part of the rent," "live with family or friends and not pay rent," and "live in a house or condo owned by another family member.” All other response categories (temporary housing, halfway house, jail, homeless, mobile home, military base/dorm, motel, and other) were coded as other. In order to estimate multinomial regression models for years $1,3,5$, and 9 , I created a variable with four categories to determine where mothers were living, mothers live with extended kin in mothers' homes $=1$, mothers live with extended kin in extended kin homes $=2$, mothers do not live with extended kin, but live in their own homes $=3$, and mothers do not live with extended kin or in mothers' own homes $=4$. In order to capture only extended kin living in these households (and to also eliminate living with friends from the original response categories), I included only extended kin from the household roster in the four categories measuring where mothers lived at years 1-9.

Independent variables for all models (logistic regression, random effects, and fixed effects models and multinomial regression models). Mothers' relationship status changes with the focal child's biological father and subsequent other romantic partners were used as the independent variables. While this study is primarily interested in 
transitions among unmarried mothers, married mothers (and transitions) were included as a comparison group. The purpose of this comparison was to determine the frequency and likelihood that each group coresides with extended kin over the 9-year period. At baseline, mothers were asked if they were married to the biological father. For those who answered no, they were asked the follow-up question: "which of the following statements best describes your current relationship with baby's father?" The following were response options: "we are romantically involved on a steady basis," "we are involved in an on-again and off-again relationship," "just friends," "we hardly ever talk to each other," and "we never talk to each other." Follow-up surveys (years 1, 3, 5, and 9) asked mothers to define their relationship with the fathers. For my analysis, I used the constructed variable examining mothers' relationship status with biological fathers, which includes the following options: "married," "romantically involved," "separated," "divorced," "just friends," or "not in any kind of a relationship." I created a dummy variable from the constructed variable to distinguish mothers who are married (coded as 0 , reference category) to those who are not (all other categories coded as 1).

To determine whether mothers were living with biological fathers or new partners between years 1-9, I used the following constructed variables: "Is mother cohabiting with baby's father, " coded as yes $=1$ or no $=0$; "Is mother cohabiting with a new partner," coded as yes $=1$ or no $=0$; and "Is mother married to a new partner," coded as yes $=1$ or no $=0$. 


\section{Covariates}

I controlled for a host of covariates that likely affect both partnership transitions and extended kin coresidence. I included both time-varying and time-invariant measures. Time-invariant covariates included a dummy variable to determine whether the mother lived with both biological parents at age 15. Dummy variables were also constructed for Whites (reference category), African-Americans, Hispanics, and others, as race is likely an important factor (Lee and McLanahan 2015). Understanding that education is strongly associated with nonmarital births (e.g., Musick et al. 2010), I included mothers' education. I constructed four dummy variables, less than high school (reference), high school, some college, and a college degree or more. Education is included as a timeinvariant control because mothers' education levels did not change significantly over the survey waves. I also included mother's age (measured in years), as age is likely associated with both partnership transitions and extended kin coresidence (Herzog et al. 2007).

Time-varying covariates included mother's income-to-poverty ratio, measured at all waves. This ratio is calculated based on an income threshold (determined by the US Census Bureau) according to family size. The household's total income is divided by the threshold to generate a classification. In other words, a family of three with one minor child would be considered in poverty if their income was at or less than $\$ 19,055$ per year (https://www.census.gov/hhes/www/poverty/about/overview/measure.html). In addition, I controlled for mothers' parity (additional children, measured at all waves) and multipartnered fertility. Beginning at baseline, mothers were asked to numerically report their total number of biological children. Beginning in year 1, mothers were asked if they 
"had another baby, adopted a child, or pregnant now"? Dummy variables were included for mothers who have had (one or more children) or were expecting a new baby versus those who have not had more children, have adopted, or have had a miscarriage/stillbirth/abortion (reference category). To determine multipartnered fertility, I constructed a variable from the following questions: "Do you have any children by someone other than the father," measured as yes $=1$ or no $=0$; and "How many different fathers do these children have," reported numerically. More children may decrease the likelihood of extended kin coresidence due to resource dilution.

Analytic Strategy

In addition to univariate, descriptive analyses of all variables included in analyses, I estimated bivariate multinomial, logistic regression, random effects, and fixed effects models across 20 imputed data sets. All statistical analyses were conducted in STATA/SE 14.1. Missing values were imputed using the ICE command in Stata for only independent variables; only observed values were included for dependent variables. Coefficients were averaged across the 20 imputed datasets using the MIM command in Stata. My objective was to estimate extended family coresidence as a function of mothers' relationship status changes net of all covariates across five survey waves (baseline - year 9). I took advantage of the longitudinal design of the FFCWS and pooled the data across the waves to estimate both random and fixed effects models, with logistic regression.

First, to determine where mothers lived between years 1 and 9 , multinomial logistic regression models were estimated to explore the effects of mothers' relationship 
statuses on where and with whom mothers lived. Specifically, four relationship status dummy variables (mothers who were not married to biological fathers versus mothers who were married to biological fathers, mothers who cohabited with biological father versus those who did not, mothers who cohabited with a new partner versus those who did not, and mothers who were married to a new partner versus those who were not) predicted whether mothers lived with extended kin at each wave and where (mothers' homes, extended kin homes, or neither).

In terms of multivariate analyses, I begin by estimating logistic regression models. However, because these models do not address bias associated with potential unobserved differences in mothers' relationships and resident statuses, I also estimate random effects models. These models account for how the change in relationship status influences extended kin residence both within and between mothers. Below is the equation, which includes the dependent variable $(y)$ for each individual $(i)$ from baseline to year $9(t)$; the intercept $\left(\mu_{t}\right)$; a vector of independent variables $\left(\beta X_{i t}\right)$; a vector of timeinvariant covariates $\left(\gamma Z_{i}\right)$; a vector of time-varying covariates $\left(\delta W_{i t}\right)$; a set of random variables, each with a mean of zero and constant variance $\left(\alpha_{i}\right)$; and random error across time and observations $\left(\varepsilon_{i t}\right)$ :

$$
y_{i t}=\mu_{t}+\beta X_{i t}+\gamma Z_{i}+\delta W_{i t}+\alpha_{i}+\varepsilon_{i t}(1)
$$

Although random effects models control for unobserved heterogeneity, they assume these unmeasured variables are not associated with measured variables. Thus, fixed effects models were used to better control for unmeasured variables. These models 
estimate within-individual change and control for unobserved heterogeneity by treating these unobserved measures as factors that do influence outcomes. In order to run fixed effects models, the independent variables must change over time; cases where there was either no change in relationship status or no change in residence were automatically dropped from the analysis. Thus, fixed effects models produce more conservative estimates, include only time-varying covariates, and are appropriate to estimate the effects of mothers' relationships status changes (IVs) on extended kin coresidence (DV) over time. Below is the equation for the fixed effects model, which includes the dependent variable $(y)$ for each individual $(i)$ across baseline to year $9(t)$, a vector of independent variables $\left(\beta X_{i t}\right)$; a vector of time-varying covariates $\left(\delta W_{i t}\right)$; and a set of random variables, each with a mean of zero and constant variance $\left(\alpha_{i}\right)$ :

$$
y_{i t}=\beta X_{i t}+\delta W_{i t}+\alpha_{i}(2)
$$

\section{Results}

\section{Descriptive Statistics}

Table 1 shows weighted descriptive statistics for the analytic sample. Extended kin coresidence, in mothers' homes or extended kin homes (DVs). At baseline, $18.4 \%$ of mothers lived with extended kin. This number increased to $21.2 \%$ in year 1 , but decreased in years $3(15.6 \%), 5(11.1 \%)$, and $9(11.8 \%)$. Although the number of mothers living with extended kin decreased from years 1 to 9, a significant proportion $(11.1 \%)$ remained living with extended kin by the time their children were age 9 . Over time, the number of mothers living in their own homes increased from $77.5 \%$ in year 1 to $90.5 \%$ 
by year 9. Conversely, the number of mothers living in extended kin homes decreased from $21.1 \%$ in year 1 to $8.8 \%$ by year 9 , suggesting an overall decrease in extended kin coresidence (in the analytic sample) before accounting for partnership changes.

Relationship status changes (IVs): More than half (52.3\%) of mothers in the analytic sample were married to the biological fathers at baseline. This number increased to $54.8 \%$ in year 1 , increased to $55.5 \%$ in year 3 , but then decreased in years $5(51.1 \%)$ and $9(50.3 \%)$. Of the mothers who were not married to biological fathers, $22.9 \%$ cohabited at baseline. The number of mothers cohabiting with biological fathers decreased between baseline and year $9(22.9 \%$ to 5.5\%). Many of these mothers were no longer with, and some went on to marry, the biological fathers, particularly in years 5 and 9. The number of mothers reporting relationships with new partners increased dramatically between years 1 and 9 . For mothers cohabiting with a new partner, the percentage point increase was $2.0 \%$ in year 1 to $9.1 \%$ in year 9 ; whereas the percentage of mothers reporting a marriage to a new partner increased from .3\% in year 1 to $6.7 \%$ in year 9.

Time-varying covariates. Mothers, on average, reported an increase of two children over the 9-year period, from 1.1 children at baseline to 3.0 children in year 9 . Multipartnered fertility increased substantially from $1.3 \%$ of mothers reporting having children with new partners in year 1 to $7 \%$ in year 9. Mothers' average income-topoverty ratio was consistently around 3 from baseline to year 9 , suggesting that this was a sample of low-income mothers.

Time-invariant covariates. More than half of the mothers had a high school degree or less (61\%), while $19.4 \%$ had some college, and $19.7 \%$ had a college degree or 
more. Combining mothers' educational attainment with their poverty status, the sample, overall, is disadvantaged. The sample is fairly equally distributed in terms of race. Black mothers make-up the majority of the sample (34.4\%), followed by Hispanics (29.6\%), whites (29.3\%), and mothers who self-identify as other (6.4\%). At baseline, mothers were on average 27-years-old. And, more than half (53.3\%) of mothers lived with both biological parents at age 15 .

\section{Bivariate}

Table 2 shows the results from multinomial regression models predicting where mothers live by their relationship statuses at years 1,3,5, and 9. Mothers were not asked at baseline where they lived specifically; therefore, the models are based on the subsequent four waves of data. The three contrasts include mothers live with extended kin in mothers' homes, mothers live with extended kin in extended kin homes, and mothers do not live with extended kin or in mothers' own homes. The contrast outcome category for each of these contrasts is mothers who do not live with extended kin, but live in their own homes. Each was estimated separately for each wave.

As the odds ratios (OR) show, mothers' relationship statuses were associated with where and with whom they live. The effects are especially salient for unmarried mothers (versus mothers married to biological fathers). Indeed, beginning with Year 1, compared to mothers married to biological fathers, the odds of unmarried mothers living with extended kin in mothers' own homes (Panel 1) increased by 2.06 in year $1(p<0.001)$ and 1.71 in year $3(p<0.001)$. However, by year 9 , the odds of unmarried mothers living with extended kin in their own homes had decreased substantially, changing the direction 
of the OR (.86). Further, the association was no longer significant. Turning to Panel 2, mothers living with extended kin in extend kin homes, unmarried mothers were significantly more likely than married mothers to live with extended kin in extended kin households (versus living with extended kin, but in their own home) — a finding that was consistent from year 1 to year 9; the magnitude of the OR (but not the significance) for this association, however, decreased substantially from year 1 (11.08) to year 9 (2.93). Further, unmarried mothers who were not living with extended kin, nor in mothers' own homes (Panel 3), were significantly more likely to be living with friends or homeless (i.e., living in shelters or on the street), incarcerated, or in treatment facilities. Given the specification of these variables, it is beyond the scope of this paper to pinpoint exactly where these unmarried mothers were living at years $1,3,5$, and 9.

Mothers who were romantically partnered were less likely to live with extended kin, particularly in extended kin homes. In fact, the odds of mothers who were married to new partners living with extended kin in extended kin households (Panel 2) were 95\% lower in year 1 and $80 \%$ lower in year 9 than they were for mothers who were not married to new partners; whereas, by year 9, mothers who were cohabiting with biological or social fathers were significantly less likely (56\% and 62\%, respectively) to live with extended kin in extended kin households (versus not living with extended kin, but in their own home) than were mothers who were are not partnered. Interestingly, the odds of extended kin living in the homes of cohabiting mothers, both with biological and social fathers, increased over time; however, the association was only moderately significant for mothers living with biological fathers. Turning to Panel 3, the odds that romantically partnered mothers were not living with extended kin, nor in their own 
homes (i.e., homeless or living with friends) versus not living with extended kin, but in their own homes, were lower for unmarried mothers. Indeed, mothers cohabiting with biological fathers were significantly less likely $(.43, p<.5)$ to be homeless or living with friends, as were mothers married to new partners $(.38, p<.5)$.

\section{Multivariate}

Table 3 shows results from logistic regression (LR), random effects (RE), and fixed effects (FE) regression models predicting extended kin coresidence (yes/no) by mothers' relationship status changes. Results from the baseline model (Model 1), which includes only mother's relationship status and no covariates, suggests that a significant relationship exists between mothers' relationship status and extended kin coresidence ( $p$ $\leq 0.001$ ) between the birth of a child and 9 years later. Beginning with the LR results, mothers who were not married (versus married) to biological fathers were significantly more likely (3.92) to coreside with extended kin over the observation period. Results from the RE (6.12) and the FE (2.94) analyses were similar; however, once the sample drops down to those who only change on relationship status and resident status in the FE models, the magnitude of the OR is smaller. This suggests that even in the most conservative estimates, when mothers experience changes in their romantic relationships, they are close to 3 times more likely to coreside with extended kin. Turning to partnered mothers, the results from the LR analyses showed that mothers who were living with biological fathers, or who were cohabiting with or married to a new partner were significantly less likely to live with family members $(.47, .31$, and .24 , respectively).

Results were consistent in the RE $(.40, .16$, and .12) and FE $(.24, .12$, and .14) analyses. 
After controlling for time-varying covariates (Model 2), mothers' relationship status changes remained significantly associated with extended kin coresidence.

However, the inclusion of covariates attenuated the size (but not the significance) of the ORs for unmarried mothers in both the LR and RE models. On the other hand, the size of the OR for unmarried mothers in the FE models increased; thus, unobserved characteristics may be driving the association between mothers' relationship status and extended kin coresidence.

Turning now to associations between covariates and coresiding with kin in Model 2 and starting with mothers' fertility, there was a negative, but significant association (LR .84 , RE .82) between mothers' parity (total number of children) and her coresidence with extended kin — a relationship that is not significant in the FE models. Multipartnered fertility also decreased mothers' chances of living with extended kin —an association that is significant in the FE models and moderately significant in the RE models. This suggests that change over time for individual mothers is more important than changes between mothers. Mothers' income-to-poverty ratios are significant in both the LR and RE models, but not in the FE models. Given the fact that fixed effects models account for within-individual change over time, it is not an economic factor that is driving mothers' reliance on extended kin, but may be unobserved differences over time.

Turning to Model 3, which adds time-invariant covariates to Model 2, and controls for both education and demographic characteristics. The addition of education, race, and whether or not mothers lived with both biological parents at age 15 slightly increased the magnitude of the ORs for unmarried mothers in both the LR and RE models, with little to no effect on the ORs for partnered mothers. Although higher levels 
of education were associated with lower odds of living with family, education was, surprisingly, not significantly associated with mothers' co-residence with extended kin. Moving on to race, compared to white mothers, black, Hispanic, and mothers who selfidentify as "other" were more likely to live with family members; however, the associations were only significant for Hispanic $(p \leq 0.001)$ and "other" $(p \leq 0.001)$ mothers. Unexpectedly, living with both biological parents at age 15 (versus not living with both biological parents at age 15) increased mothers' chances of living with extended kin by $12 \%$ in the LR models and $13 \%$ in the RE models.

\section{Discussion}

This study provides new evidence that extended kin offer "temporary refuge" to mothers (Edin and Kefalas 2005: 67) who experience relationship changes over time. Studies that have examined the correlates of "doubling up" have focused on the economic factors that may drive these associations (see Pilkauskas et al. 2014). Only one study (to my knowledge) examines how relationship status changes may influence extended kin coresidence - a study that limited the analysis of maternal relationship status to the period when the focal child was born, rather than account for relationship status variation across time (Pilkauskas 2012). The present study, therefore, intentionally measured relationship status change and its association with extended kin coresidence over a 9-year period. Knowing that relationship status changes are frequent among fragile families (McLanahan 2011), it is important to determine where mothers and their children seek refuge as they "regroup" (Edin and Kefalas 2005: 67). Specifically, Pilkauskas (2012) found that relationship status at the birth of a child is associated with a family's 
subsequent living arrangements. Evidence from the present study suggests that mothers' relationship status changes across time significantly factor into where and with whom they live. Even after controlling for a host of variables that past research has shown to be correlated with extended kin involvement, the association between mothers' relationship statuses and extended kin coresidence remains robust. Understanding that instability is associated with changes in both partnerships and residences, it is not surprising that mothers rely on those to which they are linked-families.

Beginning with descriptive statistics, around $20 \%$ of mothers report that they were sharing a residence with extended family members during the first few years of their child's life—a finding that is consistent with past research (Pilkauskas et al. 2014). A greater percentage of mothers report living in their own homes than living in extended family member's homes across the 9-year period, which may be attributed to the fact that around half of mothers report being married to biological fathers during the same time period. Multinomial regression analyses showed that partnered mothers were significantly less likely to live with extended kin, so the descriptive and bivariate results are consistent. Examining the changes in mothers who reported cohabiting with biological fathers (22.9\% at baseline versus $5.5 \%$ in year 9), cohabiting with a new partner (2.0\% at year 1 versus $9.1 \%$ at year 9$)$, and being married to a new partner (.3\% in year 1 versus $6.7 \%$ at year 9), it is evident that a significant proportion of mothers in this sample break-up and re-partner similarly to mothers in other fragile families studies (see Tach et al. 2010).

Although research suggests that mothers "partner up" after a break-up (Tach et al. 2010: 200), results from this study seem to deviate from this finding. Indeed, as the 
percentage of mothers who report new partnerships increased, their income-to-poverty ratios decreased. Perhaps this is attributed to assortative mating, where women and men partner based on educational homogamy (Schwartz and Mare 2005). Given that more than $60 \%$ of mothers reported having only a high school degree or less, the propensity for them to partner with similarly situated men is high; thus, mothers' partner selection is limited to men who are likely earning less than college graduates. Moreover, education may contribute to the increase in multipartnered fertility (MPF) reported by mothers. Indeed, Carlson and Furstenberg (2006) found that fathers who have earned less than a college degree are $66 \%$ more likely to have children with more than one partner. Further, the authors found that $59 \%$ of unmarried parents have children with more than one partner, while 21\% of married parents do (Carlson and Furstenberg 2006) —which may explain why the number of mothers reporting MPF coincides with the increased rates of cohabitation with and marriage to new partners.

Turning to multivariate results, analyses from multinomial regression models suggest that mothers' relationship status is associated with extended kin coresidence. Also, mothers, to an extent, experience residential instability. Put differently, mothers who experience relationship status changes are also experiencing changes in where and with whom they live. Being unmarried is especially salient in terms of coresidence with extended kin or being homeless. Thus, deviating from the "normal" sequence of events, shows that families truly are dynamic and susceptible to changes in the new generation's behaviors that provoke shifts in cultural norms (e.g., greater acceptance of nonmarital childbearing) - all of which work in tandem to alter developmental stages. The odds of unmarried mothers living in their own homes or in extended kin homes decreased 
drastically from year 1 to year 9; however, the odds of mothers living elsewhere (e.g., temporary shelter) remained significant. As aforementioned, mothers tend to coreside with extended kin when their children are young (Pilkauskas et al. 2014). Thus, as children (and mothers) age, mothers may seek help outside of their family networks. Further, mothers who have more children, especially with new partners, may believe that they have less access to support networks due to "network fatigue" (Harknett and Knab 2007: 246); thus, mothers may seek refuge in temporary shelters or with friends to avoid accruing more "debt" that may never be repaid (Mazelis and Mykyta 2011). Relying on family members too often may, indeed, disrupt the family system's equilibrium. Perhaps family systems can only deal with so many "shocks" before they are no longer able to recalibrate (Pilkauskas 2012).

Two seminal ethnographic studies examined reciprocal relationships among lowincome families, All Our Kin: Strategies for Survival in a Black Community and Promises I can Keep: Why Poor Women Put Motherhood Before Marriage. Stack (1974) found that race heavily influenced reciprocal relationships within black extended kin networks; whereas Edin and Kefalas (2005) found that class was a more important predictor of extended kin relationships than race - a finding that the authors attribute to the white participants in their study living within impoverished, rather than mixedincome, areas (Edin and Kefalas 2005: 14). In other words, the white, black, and Hispanic participants were all experiencing resource deprivation and similar neighborhood characteristics (e.g., drugs); thus, class emerged as a more salient predictor than race. In the present study, class was significant in the logistic regression and random effects models, but not in the fixed effects model. Fixed effects models are more rigorous 
than the other statistical methods used; therefore, economic factors do not appear to be the reason why mothers turn to family members when they experience a break-up. What about race? Compared to whites, blacks, Hispanics, and mothers who self-identified as other, are all more likely to rely on family members during transitional times. Edin and Kefalas (2005) may have been right when they said that it was a "rare opportunity" to collect data on racially-diverse families living in "similar ... social contexts" (14). Perhaps the white mothers within this study were segregated from the most impoverished neighborhoods and, therefore, had access to better resources than their black, Hispanic, and other race counterparts; thus, making class less of a factor.

Although findings suggest that black mothers are more likely than white mothers to seek refuge with family, the magnitude of the ORs is small and the relationship is not significant. Thus, this study provides evidence that black extended kin networks may have "weakened" (Collins 2000: 66) and is consistent with Martin and Martin's (1978) claim that "urban life is less conducive to the maintenance of the extended family structure than is rural or small-town life" (85). Also consistent with prior research, Hispanic and mothers who identified as other races were significantly more likely to live with extended kin during relationship changes (Pilkauskas 2012; Dunifon et al. 2014). Research shows that Hispanic families take a more "integrated family approach" (both male and female kin participate in exchange networks) (Haxton and Harknett 2009: 1035), so this finding is not surprising. In terms of other races, few studies explicitly discuss race beyond black, white, and Hispanic families. However, Dunifon et al. (2014) noted that Asian families are more likely to live in multigenerational households. Although white families (and black families to some extent) are less susceptible to life 
course diversions back home, the fact that Hispanic and mothers who identify as other races often go home during transitional times appears to support my claim that life course theory is biased toward white families — or families that may be better able to maintain their own nuclear subsystems. Thus, it appears that race is more significantly associated with extended kin coresidence than class. It should be noted that life course theory may also be biased toward family in general, as many families by year 9 are living outside their own homes and extended kin homes.

Overall, the hypothesis that mothers who experience relationship status changes will turn to extended kin during transitional times is supported, particularly when their children are young. Further, there is evidence that mothers live with extended kin in both their own homes and extended kin households, with the latter being more often the case. This study provides evidence that family cycling today is different from family cycling of the 1970s. Mothers who return to the family system demonstrate that exits from their base households may be impermanent. However, knowing that the percentage of mothers who do seek temporary refuge with extended kin decreases by year 9 , it is possible that diversions back home are too much for mothers to bear. Perhaps the gains in autonomy by initially moving out of family systems are hard to give up. In other words, mothers who move back home during transitional times may need to relinquish their power to the elder generation, which may exacerbate the effects of change. Further, maybe life course theorists' assumptions that paths are linear are correct, at least in terms of freedom. In other words, once freedom from the family system is achieved, it is likely hard to overcome. If mothers' individual agency is often connected to their partnership statuses, 
then their retreats home are likely linked to a loss of agency — an outcome that many people would find problematic.

Findings from this study are important because they suggest that the examination of economic factors overlooks the fact that when we, as humans, are hurting, we often turn to the people who have always been in our lives-our families. Yes, in some cases, mothers may "partner-up” following a break-up (e.g., Tach et al. 2010: 2000), but our relationships with family are not based on economics. Usually, families offer love, support, and shelter. It makes sense, then, that when mothers break-up with partners, they seek "temporary refuge" with people who (likely) have always nurtured them (Edin and Kefalas 2005: 67).

\section{Limitations}

This study is limited in several ways. First, the study only relies on maternal reports of extended kin coresidence. Given the time between waves of data was sometimes lengthy, particularly the four-year period between the fourth and fifth waves, mothers may have underreported their coresidency with extended kin due to recall issues. Extended kin, then, may report greater frequency of coresidency than mothers. Also, mothers were not asked where they lived, only with whom they lived, at baseline. Thus, it was not possible to determine if mothers lived in their own homes versus extended kin homes at the beginning of the study; therefore, some of the findings presented in this study may be underestimates.

Further, the study is limited in that it does not include mothers' siblings as extended kin co-residents. Martin and Martin (1978) argue that both the extended family 
base household (read here as household of origin) and sub-extended households (households that are established by siblings) may bring family members in need into their homes. Although research does suggest that young families do sometimes establish their own residences (see Edin and Kefalas 2005), for the purposes of this study, I limited analyses to those that would be considered multigenerational (mothers' generation versus her parents', grandparents', aunts/uncles').

Lastly, this study is limited in that it only examined coresidence between mothers and their extended kin. As research suggests, partnered mothers may be relying more on friends than family members for residential support (Pilkaukas et al. 2014). Given that this paper was framed within a life course theoretical approach, the analyses were limited to estimate the life course diversions among mothers who experience relationship status changes.

\section{Conclusion}

As Edin and Kefalas (2005) argued, families today face significant instability. Results from this study corroborate this finding, along with other studies (e.g., Osborne and McLanahan 2007; McLanahan 2011). Desmond et al. (2015) found that disadvantaged families experience significant residential instability, mostly related to economic factors. The current study extends Desmond's work, suggesting that socioeconomic factors interact with relationship status to not only create family instability, but residential instability. If networks become "fatigued" over time, but mothers continue to break-up and repartner, the rates of residential instability are likely to increase. Homeless shelters, if available, often have a time limit, as Edin and Shaefer 
(2015) so poignantly demonstrate with Jennifer's lived experience in \$2.00 a Day.

Mothers cannot sustain their families if they cannot establish subsystems, yet it appears that going home may not always be an option, as the "base household" can be overwhelmed (Martin and Martin 1978).

As I have speculated, family cycling today is different than when Elder theorized the life course (1977). Adult children may move in and out of their "base households" many times throughout their lifetimes, which is particularly true for mothers who have engaged in nonmarital childbearing. Leaving home to form independent families outside a marital context does appear to be associated with impermanent departures from family systems. Further, nonmarital childbearing does not only set mothers, fathers, and children on a nonlinear trajectory, but due to the linked nature of families, extended kin often become enmeshed and responsible for helping to re-stabilize the family after disruptions. Thus, it could be argued that establishing a family outside of marriage may be an impediment to life course development for unmarried mothers and fathers. Many of the mothers in this study do not seem to experience only life course path diversions, as an increased number of them are homeless or living elsewhere by the time their children are 9-years-old. Life course diversion implies purpose, or following a non-normative pathway, which may be an alternate path toward betterment. Multiple partnership dissolutions and homelessness, rather, imply substantial instability and indicate that these mothers' trajectories are bumpy, certainly not linear. This also means that children and extended kin experience mothers' setbacks. Findings suggest that these mothers are disadvantaged, which likely means they are linked to disadvantaged extended kin. Thus, in order to address mothers' needs, policy efforts need to be directed toward housing 
solutions. Perhaps extended kin could apply for temporary housing grants to assist with the associated expenses of taking in mothers and their children. Yes, mothers may not be moving in with extended kin out of economic necessity, but that does not mean that they are not depleting the resources of their kin in the process. Temporary shelter grants would need to be easily accessible and could be time-limited, perhaps renewable based on need. Grants also could be coordinated to match time limits imposed by local homeless shelters (e.g., with maybe three-month time limits). Offering grants to families could alleviate some of the financial pressures on extended kin and certainly free up space in homeless shelters for people who truly have nowhere to go.

Future research will examine why extended kin move into mothers' homes, or the mechanisms underlying the associations found in this study. Research shows that extended kin usually move in with married parents to meet their own needs (Dunifon et al. 2014); thus, it may not be explicitly known as to why extended kin move in with single mothers. Extended kin may move in with mothers to offer child care assistance or as emotional support mechanisms - both of which will be explored in future papers. Further, future analyses will tease apart extended kin (and will include siblings in the analyses) to determine if mothers who do retreat to kin homes rely on the same family member(s) at each time period. If mothers rely on the same family member, they may be contributing to "network fatigue" (Harknett and Knab 2007); however, if mothers coreside with multiple family members, this may indicate substantial precariousness and instability within family systems.

This research filled a gap in the research by examining where and with whom mothers reside during romantic partnership dissolutions. This study contributes a more 
nuanced understanding of multigenerational households (to the literature), expressing how lives are linked for more reasons than economic need. 
Table 1 Descriptive statistics for mothers relationship status, fertility, education, demographics, and personal characterisitcs across five waves.

\begin{tabular}{|c|c|c|c|c|c|}
\hline Mean $(\mathrm{SD})$ or $\%$ & Baseline & YR 1 & YR 3 & YR 5 & YR 9 \\
\hline Extended kin in household (yes/no) & 18.4 & 21.2 & 15.6 & 11.1 & 11.8 \\
\hline Mothers live in own homes & & 77.5 & 82.3 & 87.1 & 90.5 \\
\hline Mothers live in extended kin homes & & 21.1 & 16.3 & 11.5 & 8.8 \\
\hline \multicolumn{6}{|l|}{ Relationship status } \\
\hline Married to bio. father (yes/no) & 52.3 & 54.8 & 55.5 & 51.1 & 50.3 \\
\hline Lives with bio. father (yes/no)* & 22.9 & 22.1 & 15.6 & 10.5 & 5.5 \\
\hline Cohabits with new partner (yes/no) & & 2.0 & 5.0 & 8.8 & 9.1 \\
\hline Married to new partner (yes/no) & & .3 & .7 & 2.4 & 6.7 \\
\hline \multicolumn{6}{|l|}{ Fertility } \\
\hline Total number of children & 1.1 (1.3) & $2.1 \quad(1.3)$ & $2.4 \quad(1.4)$ & $2.7 \quad(1.3)$ & $3.0 \quad(1.5)$ \\
\hline Multipartnered fertility & & 1.3 & 4.8 & 4.0 & 7.0 \\
\hline Income to poverty ratio (range $=0-69)$ & $3.1 \quad(3.3)$ & $2.8 \quad(3.7)$ & $3.1 \quad(4.8)$ & $2.7 \quad(3.4)$ & $2.9 \quad(4.0)$ \\
\hline \multicolumn{6}{|l|}{ Education } \\
\hline Less than high school (ref) & 28.8 & & & & \\
\hline High school degree & 32.1 & & & & \\
\hline Some college & 19.4 & & & & \\
\hline College degree or more & 19.7 & & & & \\
\hline \multicolumn{6}{|l|}{ Demographic characteristics } \\
\hline White (ref) & 29.3 & & & & \\
\hline African American & 34.4 & & & & \\
\hline Latino/Hispanic & 29.6 & & & & \\
\hline Other & 6.4 & & & & \\
\hline Age & $27.0(6.2)$ & $28.2(6.2)$ & $29.9(6.2)$ & $32.1(6.2)$ & $36.4(6.2)$ \\
\hline
\end{tabular}

Lived with both bio. parents at age 15 (yes/no) 53.3

All figures are weighted by mother's sampling weights $(N=2,886) . N$ is unweighted.

*Percentage of unmarried mothers living with biological fathers at baseline. 
Table 2. Results from multinomial regression analyses predicting where mothers live by their relationship statuses. $(N=2,886)$

\begin{tabular}{|c|c|c|c|c|}
\hline & Year 1 & Year 3 & Year 5 & Year 9 \\
\hline & OR & OR & OR & OR \\
\hline
\end{tabular}

Panel 1: Outcome Contrast: Mothers' live with extended kin in their own homes versus mothers who do not live with extended kin, but in their own homes

Mothers are not married to biological fathers

Mothers cohabit with, but not married to bio fathers

Mothers cohabit with new partners

Mothers married to new partners

$\begin{array}{cccc}2.06 * * * & 1.71 * * & .98 & .86 \\ .59 * * & .69 \dagger & .68 & 1.84 \dagger \\ .46 & .29 * * & .57 & 1.02 \\ .0 & .72 & .30 & .53\end{array}$

Mothers married to biological dads (reference)

Panel 2: Outcome Contrast: Mothers live with extended kin in extended kin homes versus mothers who do not live with extended kin, but in their own homes.

Mothers cohabit with, but not married to bio fathers

Mothers cohabit with new partners

Mothers married to biological dads (reference)
Mothers are not married to biological fathers

Mothers married to new partners

$\begin{array}{rrrr}11.08 * * * & 9.36 * * * & 4.55 * * * & 2.93 * * * \\ .26 * * * & .28 * * * & .31 * * * & .44 * \\ .29 * * * & .27 * * * & .25 * * * & .38 * * \\ .05 * * & .08 * * * & .36 * & .20 * * *\end{array}$

Panel 3: Outcome Contrast: Mothers do not live with extended kin, nor their own homes versus mothers who do not live with extended kin, but in their own homes.

Mothers are not married to biological fathers

Mothers cohabit with, but not married to bio fathers

Mothers cohabit with new partners

Mothers married to new partners

$\begin{array}{lccc}5.00 * * * & 3.55 * * * & 4.02 * * * & 4.47 * * * \\ .53 * * * & .66 * * & .77 & .43 * \\ .82 & 1.24 & .90 & .73 \\ .38 & .49 & .30 * & .38 *\end{array}$

Mothers married to biological dads (reference)

$\dagger p<.10 * p<.05 * * p<.01 * * * p<.001$ 
Table 3. Results from logistic, random effects, and fixed effects regression models predicting extended kin coresidence by mothers' relationship statuses and covariates (odds ratios) $(N=2,886)$.

\begin{tabular}{|c|c|c|c|c|c|c|c|c|}
\hline & \multicolumn{3}{|c|}{ Model 1} & \multicolumn{3}{|c|}{ Model 2} & \multicolumn{2}{|c|}{ Model 3} \\
\hline & LR & $\mathrm{RE}$ & $\mathrm{FE}$ & LR & $\mathrm{RE}$ & FE & LR & $\mathrm{RE}$ \\
\hline \multicolumn{9}{|l|}{ Relationship status } \\
\hline Married to bio. father (yes/no) & $3.92 * * *$ & $6.12 * * *$ & $2.94 * * *$ & $2.92^{* * *}$ & $4.36 * * *$ & $3.30 * * *$ & $3.23^{* * *}$ & $4.75 * * *$ \\
\hline Lives with bio. father (yes/no) & $.47 * * *$ & $.40^{* * *}$ & $.58 * * *$ & $.41 * * *$ & $.31 * * *$ & $.41 * * *$ & $.39 * * *$ & $.30 * * *$ \\
\hline Cohabits with new partner (yes/no) & $.31 * * *$ & $.16^{* * *}$ & $.16^{* * *}$ & $.31 * * *$ & $.19 * * *$ & $.22 * * *$ & $.31^{* * *}$ & $.19 * * *$ \\
\hline Married to new partner (yes/no) & $.24 * * *$ & $.12 * * *$ & $.14 * * *$ & $.29 * * *$ & $.21 * * *$ & $.28 * * *$ & $.29 * * *$ & $.21 * * *$ \\
\hline \multicolumn{9}{|l|}{ Fertility } \\
\hline Total number of children & & & & $.84^{* * *}$ & $.82 * * *$ & .98 & $.84^{* * *}$ & $.83^{* * *}$ \\
\hline Multipartnered fertility & & & & .88 & $.75^{\dagger}$ & $.69^{*}$ & .87 & $.75 \dagger$ \\
\hline Income to poverty ratio & & & & $.94 * *$ & $.93 * * *$ & .97 & $.96^{*}$ & $.94^{*}$ \\
\hline Age & & & & $.93^{* * *}$ & $.90 * * *$ & $.89 * * *$ & $.93^{* * *}$ & $.90 * * *$ \\
\hline \multicolumn{9}{|l|}{ Education } \\
\hline \multicolumn{9}{|l|}{ Less than high school (ref) } \\
\hline High school degree & & & & & & & .98 & .97 \\
\hline Some college & & & & & & & .95 & .92 \\
\hline College degree or more & & & & & & & .83 & .75 \\
\hline \multicolumn{9}{|l|}{ Demographic characteristics } \\
\hline \multicolumn{9}{|l|}{ White (ref) } \\
\hline African American & & & & & & & 1.06 & 1.11 \\
\hline Latino/Hispanic & & & & & & & $1.36^{* * *}$ & $1.58 * * *$ \\
\hline Other & & & & & & & $2.19 * * *$ & $3.39 * * *$ \\
\hline Lived with both bio. parents at age 15 & (yes/no) & & & & & & $1.24 * * *$ & $1.29 * *$ \\
\hline
\end{tabular}

${ }^{\dagger} p \leq .10 * p \leq .05 * * p \leq .01 * * * p \leq .001$ 


\section{CHAPTER IV: \\ NEST EFFECTS: HOW CHILDREN FARE WHEN CHANGES OCCUR WITHIN THEIR MESOSYSTEMS ${ }^{3}$}

\section{Introduction}

Studies have shown that family structure transitions negatively affect child wellbeing (e.g., Cooper et al. 2011; Lee and McLanahan 2015). However, most studies focus on the parental bond as the transitioning unit, but do not delve into how extended family involvement potentially influences outcomes for biological children when parental relationships dissolve. Research suggests that grandparents (particularly maternal) often have higher contact with and assume parent-like behaviors in the lives of their grandchildren during times of distress (e.g., Cherlin and Furstenberg 1986). DeLeire and Kalil (2002), for example, found that junior high school-aged children benefit from grandparent coresidence, which may be attributed to increased resources and attention (Baydar and Brooks-Gunn 1998).

Maternal grandmothers' co-residence may also exacerbate mothers' levels of stress and depression, both of which are associated positively with children's externalizing behaviors (Jackson 1998). Jackson argues that grandmothers promote adequate parenting, but are often "sources of distress," because they compete with and undermine single mothers' authority to parent their children (Wakschlag and Chase-

\footnotetext{
${ }^{3}$ Acknowledgements/Funding: Thank you to the Columbia Population Research Center for its support of this study (FFCWS Study \# 5R01HD03699916, FFCWS Workshop \# 5R25HD074544; CPRC \# P2CHD058486).
} 
Landsdale 1996; Jackson 1998: 376; Jackson et al. 2013: 137). Thus, single parents may oscillate into extended family residences for many reasons, including childcare needs, but may transition out to regain independence. Either way, the presence of grandparents, particularly in a coresidential context, is likely to affect children whose parents are transitioning into or out of relationships and into new ones.

Using data from the Fragile Families and Child Wellbeing Study, this paper explores the following research questions: Does extended family coresidence mediate the association between family structure transitions and child wellbeing, measured by internalizing (i.e., withdrawing from others) and externalizing (i.e., fighting, skipping school) behaviors? Do race and education moderate the association between family structure transitions, extended family coresidence, and child wellbeing?

\section{Theoretical Framework and Background}

\section{Ecological Theory}

Ecological theorists posit that individual-, group-, institutional-, and ideologicallevel systems form the ecology of human development (Bronfenbrenner 1977). Changes within systems, including new memberships, will disturb the equilibrium of a given system and require a period of adjustment or adaptation. Indeed, research suggests that family structure transitions have destabilizing effects on children (e.g., Fomby and Cherlin 2007), which may idle for as long as seven years (Sweeney 2010). Yet, transitions out of high conflict relationships (e.g., volatile marriages) may improve the living conditions for children and subsequently their education, behavioral, and/or other outcomes (Amato 2000). Ecological theory, however, argues against only analyzing the 
“immediate situation containing the subject" (Bronfenbrenner 1977: 514). Rather, we might better understand childhood outcomes through investigating multiple, interacting social contexts. For example, research shows that parental relationship dissolutions, followed by the formation of new partnerships, are common among low-income families (Bzostek et al. 2012; Lee and McLanahan 2015).

Therefore, to investigate a child's "immediate situation" may not account for the circumstances that led to the current family structure and contributed to child wellbeing. Fomby and Cherlin (2007) argue that multiple family structure transitions have a cumulative effect on children. Thus, examining family structure transitions over time without consideration for the larger set of social systems in which children are embedded, limits the extent to which different, intersecting social contexts interact with time to influence child outcomes. Therefore, a multilevel analysis that accounts for the overlapping contexts (i.e., microsystems and mesosystems) in which children experience transitions over time, is important.

As an analytical tool, ecological theory situates individual interactions within four systems - the micro-, meso-, exo-, and macrosystems. Microsystems are interactions and outcomes for individuals. Mesosystems are the combined microsystems in which a person interacts (e.g., mother's home with maternal grandmother coresidence). Exosystems are institutional-level systems, such as the workplace, the educational system, and the judicial system. Macrosystems represent societal beliefs and prescribe normative behaviors (i.e., nonmartial childbirth is indicative of engaging in premarital sex, which has long been considered deviant). 
Arguably, family instability increases the likelihood that a child will not live within one stable household, but will oscillate between and within multiple family structures (i.e., mesosystems). This family instability increases the risk of deleterious outcomes for children (Shanahan 2000) and risky adolescent behaviors (DeLeire and Kalil 2002; Högnäs and Carlson 2012). This study only examines the micro- and mesosystems in which children live and interact. The mesosystem, importantly, is likely influenced by the exosystem (i.e., labor market, educational system) and the macrosystem (i.e., norms, such as marriage is a better context to rear children); although data limitations do not allow for examining all system levels. Microsystems vary in their definition. Here, the microsystem level is defined as child wellbeing, or children's internalizing and externalizing behaviors.

\section{Family Structure Transitions and Child Wellbeing}

Family structure transitions are important predictors of child wellbeing. Indeed, transitioning out of a two-parent household, whether married or cohabiting, appears to negatively affect children's internalizing and externalizing behaviors (Lee and McLanahan 2015). Research suggests that lower versus higher educated parents are at a greater risk of experiencing partnership transitions (McLanahan 2011); and changes at the exosystem level (e.g., loss of a job, loss of government benefits) may reduce their ability to think clearly (i.e., cognitive functioning) when either conflict or other seemingly insurmountable financial problems arise (Fomby and Cherlin 2007). With respect to child wellbeing, the implications may be that lower educated parents may be 
heavily burdened financially, may be forced to work more than one job, and thus, spend less time with, and have fewer resources to invest in, their children.

Lower educated, or socioeconomically disadvantaged, parents may enter into new relationships quickly after dissolving old ones; and, studies show that the likelihood of repartnering after a breakup is common (Bzostek et al. 2012; Sweeney 2010). Moreover, many mothers repartner due to economic necessity, especially if the biological father does not pay child support (Cancian et al. 2011). In some cases, fathers reduce or stop paying informal child support when mothers start new partnerships or have more children (Meyer and Cancian 2012). Often, mothers "partner up," meaning that new versus old partners earn more (Bzostek et al. 2012; Tach et al. 2010). Qualitative research shows that mothers do enforce "pay to stay" policies with boyfriends (Edin and Lein 1997); thus, this may mean that mesosystem membership is contingent on a partner's ability to maintain their position within the exosystem (e.g., formal employment)—which is often difficult for young, disadvantaged men to do (Smeeding et al. 2011).

Family structure instability also appears to be transmitted over generations, as more couples procreate and partner according to their own parental models (McLanahan 2011). Indeed, family structure homogamy among couples fosters the formation of relationships, but often is indicative of ephemeral, tenuous unions (Högnäs and Thomas 2016). Research shows that mothers who were reared in unstable households are more likely to give birth outside the marital context (Fomby and Cherlin 2007). Fathers who grew up in similar households are at a greater risk to engage in nonmarital childbearing, multi-partnered fertility, and nonresidential fathering - patterns which appear to hold 
constant across generations (Högnäs and Carlson 2012) and increase the likelihood of changing children's ecological systems at multiple levels.

Studies have examined with whom and why mothers repartner (Bzostek et al. 2012), the likelihood of multi-partnered fertility (Cancian et al. 2011), the effects of household membership changes (i.e., father exits, extended family members enter, mom and child[ren] change residences), and repartnering types (i.e., cohabiting, dating, single) on child wellbeing (Magnuson and Berger 2009; Cooper et al. 2011; Mitchell et al. 2014; Mitchell et al. 2015). Indeed, children who experience family structure transitions are much more likely to do worse in school and misbehave than children who are reared in a stable, two-parent household (Magnuson and Berger 2009). Increases in antisocial behaviors (i.e., breaking rules) follow the departure of the biological father from the household; whereas the opposite effects are true when fathers move into the household (Mitchell et al. 2015). The authors speculate that the negative association between fathers' coresidence and children's antisocial behavior is attributed to an increase in household resources.

Overall, family structure transitions may compromise the wellbeing of children as financial strain and the formation of new relationships may mean less time, and less money invested in children.

\section{Transitions, Extended Family Coresidence, and Child Wellbeing}

Although research shows a negative association between family instability and child wellbeing, no study exists (to my knowledge) that explores the influence of both the types of parental partnership transitions, and extended family coresidence (over time) on 
child wellbeing. This seems a glaring omission, given that 1) demographers have found that extended family members' support is activated during times of distress (Stack 1975; Lee and McLanahan 2015); and, 2) scholars have made the assertion that the strength of these relationships will increase (Cherlin 2010), meaning that as instability becomes more likely, extended kin relationships will become more necessary to meet the needs of fragile families. Indeed, research shows that coresidence with extended kin has increased over the last decade or so (Dunifon et al. 2014).

Findings from the limited extant literature emphasizing extended family coresidence and child wellbeing have largely been mixed. For example, Mollborn, Fomby, and Dennis (2011) find that young children, who coreside with grandparents (and mothers), have lower cognitive and behavioral outcomes. On the other hand, when black and Hispanic versus white children coreside with grandparents, their cognitive scores improve. Kalil and Deleire (2002) find that children who live both with a single parent and with extended kin have better educational and behavioral outcomes, compared to children who live only with a single parent. Even so, other studies show negative outcomes for children who live in three-generational homes (see Dunifon et al. 2014). Overall, parental relationship quality and economic circumstances have been underscored as factors driving the increase in both family instability and extended family coresidence. Yet, studies have not explicitly explored how children fare when extended kin coreside with them in the context of multiple family structure transitions (i.e., when their parents dissolve romantic partnerships and form new ones). It may be that during transitional periods, the presence of a familiar loved one, a family member, may reduce 
the potentially negative impact of parental relationship changes on children, and thus decrease the likelihood of internalizing and externalizing behaviors.

\section{Confounding Factors}

Considering that race, education, parents' backgrounds, maternal health and age, multipartnered fertility (MPF), and incarceration all affect the resources contributing to and the maintenance of mesosystems, these variables are all explored as potential confounding factors. Beginning with race, family structure transitions may distress white children more than black children (Fomby and Cherlin 2007; Lee and McLanahan 2015).

One explanation is that black children have traditionally had well-established connections with extended kin, which benefit them (Fomby and Cherlin 2007). These coresidential relationships with extended kin mean that additional family members share parenting responsibilities and reduce maternal stress associated with money and caregiving roles (McLanahan and Bumpass 1988).

On the other hand, black children are at greater risk for decreased cognitive functioning when they transition out of a two-parent household (Lee and McLanahan 2015). Although Lee and McLanahan (2015) argue that transitioning into a two-parent home is less detrimental to children, they did find that the opposite effect is true for Hispanic children. Hispanic children experience decreased ability to interact with others, which may be attributed to an increased number of people in the household. Therefore, they may be learning to navigate new relationships and potentially new boundaries with their biological parent (Lee and McLanahan 2015). 
Turning now to MPF, research shows that a high proportion of unmarried parents (i.e., 60\%) have children with more than one partner (Cherlin 2010)—a proportion that may be "higher once completed fertility is observed" (Smeeding et al. 2011: 12). Multipartnered fertility affects mothers and fathers differently. One study, for example, found that mothers" MPF may lead them to "settle" with the father of a new baby, as their economic needs are likely greater and their odds of repartnering after multiple children weaker (Bzostek et al. 2012: 829). Father involvement may be reduced because of mothers' MPF and investments in new families (Tach et al. 2010). Further, fathers' new partners may limit their interaction with previous biological children, as ongoing interaction may lead to attachments or romantic involvement with former partners (Reed 2006).

Importantly, MPF may disrupt child development. Children's relations with their residing parent suffer from "second-order effects" or outcomes that follow an initial change in the household (e.g., entrance of a new partner) (Bronfenbrenner 1977). Second order effects of MPF emerge from changes in the "proximal processes" of the parentchild bond (Bronfenbrenner 1995: 620), as evidenced through changes in the biological parent's level of involvement with different children. To demonstrate the magnitude of effects caused by MPF, Cancian et al. (2011) found that within the first decade of a child's life, their parents' MPF could potentially link them to "at least five adults who are either their parents or the parents of half-siblings" (977). This finding demonstrates the substantial number of adults the child may interact with, but does not indicate the number of children (which could be much greater than five) with which they will have to share resources. New children, then, force both biological parents and focal children to 
renegotiate their roles, while simultaneously building relationships with new members of the mesosystem. Thus, MPF often indicates that children of unmarried parents will face substantial instability and will become part of multiple mesosystems during their childhood.

Further, spells of paternal incarceration affect the wellbeing of children, particularly for male children (Geller et al. 2012). Indeed, researchers found that children with incarcerated fathers display more externalizing behaviors by the age of 5 than children whose parents are not incarcerated (Geller et al. 2012). The researchers also found that, like education, incarceration tends to bring people together (Geller et al. 2012). In other words, fathers who have spent time incarcerated tend to form relationships with women who have faced incarceration. There is no question that children whose parents are in jail or prison will experience a mesosystem disruption.

\section{The Current Study}

Bronfenbrenner $(1974,1977)$ argues for an intersectional analysis of all ecosystems and their organisms to better measure the breadth of factors contributing to developmental outcomes. Delving into the various, interacting ecological systems reduces the potential for missed periods of development (and investigating only baseline and year 9 may not capture effects [or system interactions] at years 1,3 , and 5 that are contributing to childhood outcomes, such as extended kin coresidence). Therefore, this study draws on Bronfenbrenner's ecological systems model to extend the extant literature to include an exploration of the association between family structure transitions and 
extended kin coresidence (i.e., mesosystems) and child wellbeing in terms of internalizing and externalizing behaviors (i.e., microsystems).

I hypothesize that 1) most unmarried mothers' baseline relationships will not remain stable over the first 9 years of their child's life, and this instability negatively influences child wellbeing; 2) family structure transitions increase biological children's risk of internalizing and externalizing behaviors; and 3) extended family coresidence mediates the association between family structure transitions and child wellbeing outcomes.

\section{Methods}

\section{Dataset}

The study employs a quantitative, deductive approach, using data from the Fragile Families and Child Wellbeing Study (FFCWS). The FFCWS is a longitudinal birth cohort study, conducted in 20 cities (with populations > 200,000) in 75 hospitals. Baseline data were collected between 1998 and 2000 at the birth of the focal child, with follow-up surveys conducted at years 1, 3,5, and 9 following birth. The study oversampled nonmarital births ( $N=4,897$ total 3,710 to unmarried parents and 1,187 to married parents). Both mothers and fathers were interviewed. By year $9,76 \%$ of mothers still participated. Fathers were more difficult to locate at baseline, and retention rates were not as high as mothers', but $88 \%$ of fathers participated at least once. Because I am interested in mothers' residential patterns, reports from mothers will be used for this study. 
The analytic sample was restricted to mothers who live with focal children at least half the time at all waves, as I rely on mothers' reports of child wellbeing. At baseline, mothers reported living with focal children if they answered yes to either the question "is respondent married to [baby's father]?” or “will the baby live with mother?” Beginning in year 1, mothers were asked, "How much of the time does (child) live with you?" Those children who lived with mothers all or half of the time were coded as living with mothers. Mothers who reported that their children lived with them some or none of the time were coded as not living with their children.

\section{Measures}

Independent Variables. Mothers' relationship transition types are included as independent variables. At each wave, mothers were asked about their relationships with biological fathers and new partners. From these two questions, five categories were created: married to biological father, cohabiting with biological father, married to social dad, cohabiting with social dad, and single. These five categories were used to code for 14 possible transitions, which were then collapsed into 11 categories to ease interpretation of the output. The eleven transition types are as follows: married to married, married to biological father to single, married to biological father to cohabiting

with or married to new partner, cohabiting with biological father to married to biological father, cohabiting with biological father to cohabiting with or married to new partner, cohabiting to cohabiting with same partner, cohabiting with biological father or social father to single, single to cohabiting with or marrying biological father, single to cohabiting with new partner, single to married to new partner, and single to single. 
Individual dummy variables were created for the eleven relationship transition types, with each individual transition coded as 1 and all other transitions coded as other (0).

Extended kin coresidence was determined using the household roster from baseline to year 9. Mothers were asked "who currently lives in your household?" Mothers were coded as living with extended kin if they reported that they lived with their mothers, fathers, grandmother, grandfather, aunts, uncles, and partner's parents. All other categories (i.e., spouse, partner, bio/adopted child, stepchild, sibling, cousin, non-relative adult, non-relative kid, niece/nephew, unknown related adult) were coded as zero.

Dependent Variables. Using mother reports, this study examined two indicators of child wellbeing, internalizing and externalizing behaviors. Beginning in Year 3, mothers were asked a series of questions regarding internalizing and externalizing behaviors, which were based on Achenbach's (1992) Child Behavior Checklist. All questions were measured on a 3-point Likert scale, ranging from 0 (not true) to 2 (very true or often true). Scores were averaged to calculate the anxious/depressive and withdrawn subscale (referred to as internalizing behaviors) and the aggressive and destructive subscale (referred to as externalizing behaviors). Internalizing behaviors include 28 different indicators, for example, child avoids looking other in the eye, child cries a lot, child clings to adults or is too dependent, among others. Externalizing behaviors include 42 different indicators, for example, child can't concentrate, can't pay attention for long, child is cruel to animals, child is defiant, child's demands must be met immediately, among others (see Appendix I for the full list of internalizing and externalizing behaviors). Alpha reliability scores for both measures at all waves were always above .60 (from internalizing, $\alpha_{3}=.71, \alpha_{5}=.65, \alpha_{9}=.84$; and externalizing $\alpha_{3}=.86, \alpha_{5}=.82, \alpha_{9}=$ 
.91). I combined all the internalizing variables into one composite variable, averaging their scores; and combined all the externalizing variables into one composite variable, averaging their scores. Both composite measures ranged from 0-2.

\section{Covariates}

I controlled for a host of covariates, which may confound the relationship between parental partnership changes, extended kin coresidence, and child wellbeing. I included mother's age (measured in years). I created a dummy variable to determine if the mother lived with both biological parents at age 15 . Dummy variables were constructed for Whites (reference category), African-Americans, Hispanics, and others, as race has been shown to influence the types of partnerships and the duration of partnerships in which people engage (Fitch and Ruggles 2000) and child wellbeing outcomes. Understanding that education is strongly associated with nonmarital births and partnership decisions (e.g., Musick et al. 2010), I included mothers' education, recoded as four dummy variables, less than high school (reference category), high school, some college, and a college degree or more. Mother's income-to-poverty ratio, measured at all waves, was included. Mothers' health was also included. Respondents were asked "in general, how is your health?," measured using a range from $1=$ Excellent to $5=$ Poor. This variable was reverse coded, so that higher numbers indicated better health. To explore how the exosystem (i.e., judicial system) influences the mesosystem and its changes, I included fathers' incarceration and child support orders, each of which were measured using dummy variables. 
I also controlled for child characteristics. Because this study is situated within ecological theory, I controlled for whether a child visits her/his father, as membership within another mesosystem may exacerbate potential negative outcomes. Beginning in year 1, mothers (in 18 cities) were asked "Since child's birth, has child ever stayed overnight with father (yes or no)?" A dummy variable was constructed for overnight stays as yes (1) and no (0) responses. Further, I included a dummy indicator for gender, as research suggests that boys tend to have a harder time adjusting to parental separation and, therefore, express more externalizing and internalizing behaviors than girls (Lee and McLanahan 2015).

\section{Analytic Strategy}

I started with descriptive statistics for characteristics of the analytic sample. Then, I estimated a series of bivariate multilevel regression models, predicting children's internalizing and externalizing behaviors by mothers' relationship transition types, and in separate models extended kin coresidence predicted child wellbeing outcomes. This study also employed multilevel modeling, which explores waves nested within subjects. Multilevel modeling was ideal for this study, as I wanted to understand how changes in parental partnerships and (potential) changes in residences or household members influence changes in child wellbeing over the first nine years of focal children's lives. These models do not assume independence, but rather account for nonindependence; therefore, they "allow researchers to adjust for and model" the nonindependent nature of mothers and children over time (McCoach 2010). Using multilevel modeling provides a broader analysis of the social contexts in which children are born and reared than simple 
regression models, as these models test cross-level interactions. In this study, mothers' relationship transition types and extended kin coresidence interact with time to predict childhood outcomes. All models were estimated using Stata SE, version 14.2. To account for missing data, I multiply imputed 5 datasets using the ICE command in Stata. To provide unbiased results, unimputed dependent variables were used for all analyses.

Due to the longitudinal nature of the data, Level 1 consists of the waves of data and time-varying covariates and Level 2 consists of mothers' reports of children (or clusters) and time-invariant covariates (Rabe-Hesketh and Skrondal 2012: 227). Data from baseline through year 9 were pooled, and covariates and independent variables were measured at each wave, but child wellbeing was measured only at 3, 5, and 9 (and thus primary analyses emphasize mesosystems measured over the full observation period, and microsystems measured at years 3, 5, and 9).

In terms of multilevel models, I estimated separate models for children's internalizing and externalizing behaviors (separately) by mothers' relationship transition types and the time-varying covariates. This step was to determine if changes in family structure are associated with childhood outcomes, net of demographic characteristics (e.g., maternal race, education). Next, internalizing and externalizing behaviors were regressed (separately) on extended kin coresidence and the time-varying covariates to determine whether living with family members accounted for child outcomes (net of demographic characteristics). Then, internalizing and externalizing behaviors were regressed (separately) on mothers' relationship transition types, extended kin coresidence, and the time-varying covariates to determine whether extended kin mediates the association between mothers' relationship transitions and child wellbeing over time. 
Mothers who were stably married to biological fathers served as the reference group for all multilevel models reported in this study.

Level 1 models internalizing and externalizing behaviors over three waves of data (years 3, 5, and 9) as a linear function of time:

$$
Y_{i t}=\beta_{0 j}+\beta_{1 j} \alpha_{i j}+\epsilon_{t i}
$$

Where $Y_{i t}$ represents internalizing and externalizing behaviors for the $i$ th mother at time $t$, $\alpha_{i j}$ is time at each measurement occasion for the $i$ th mother, $\beta_{0 j}$ is the intercept for the $i$ th mother, $\beta_{1}$ is the slope for the $i$ th mother, and $\epsilon_{t i}$, represents error for the $i$ th mother at time t. Adding in the independent variables (relationship transition types and extended kin coresidence) and time-varying variables expands the equation:

$$
Y_{i t}=\beta_{0 j}+\beta_{1 j} \alpha_{i j}+\beta_{2 i} \alpha_{2 t i}+\epsilon_{t i}
$$

Where $\beta_{2 i} \alpha_{2 t i}$ represents the added variables. Level 2 models incorporate the subjects and the time-constant covariates — or variables that differ among subjects, but are static over time (e.g., race). Thus, the intercepts and slopes vary between mothers, but the timeinvariant characteristics are idiosyncratic to individual mothers. The Level 2 equation is:

$$
\beta_{0 j}=\gamma_{00}+\gamma_{01} X_{1 i}+\gamma_{02} X_{i}+\gamma_{03} X_{i}+\gamma_{04} X_{i}+\gamma_{05} X_{i}+r_{i j}
$$

Where $X$ s represent the time-constant variables. 
Lastly, two multilevel interaction models were estimated to explore whether education and race moderate the association between family structure transitions, extended kin coresidence, and child wellbeing. To begin, I constructed a three-way interaction term between mothers' relationship transition types, race, and extended kin coresidence to predict internalizing and externalizing behaviors (Table 4). White mothers who were not living with extended kin and who had not experienced relationship transitions served as the reference group. Then, I constructed a three-way interaction term between mothers' relationship transition types, education, and extended kin coresidence to predict children's internalizing and externalizing behaviors (Table 5). Mothers who had some college education or were college educated (coded as having higher education), who were not living with extended kin, and who had not experienced relationship transitions served as the reference group.

\section{Results}

\section{Descriptive Statistics}

Table 1 shows the weighted descriptive statistics for the analytic sample. Internalizing and externalizing behaviors $(D V s)$. Beginning with year 3 (the first year these measures were collected via the in-home survey), on a scale from $0-2$, children expressed an average of .3 internalizing and .5 externalizing behaviors. By year 5 , children expressed the same number of internalizing behaviors, but externalizing behaviors decreased to .3. Both internalizing and externalizing behaviors decreased to .2 by year 9 . 
Relationship transition types and extended kin coresidence (IVs). From baseline to year $1,52 \%$ of mothers stayed married to biological fathers. This number increased to $53.3 \%$ by year 3 , but decreased to $50.6 \%$ in year 5 , and $49.3 \%$ in year 9 . From baseline to year $1,1.3 \%$ of mothers who were married to biological fathers at baseline transitioned to single. This number increased to $2.2 \%$ in year 3 and $5.0 \%$ in year 5 , and decreased to $3.4 \%$ in year 9. The number of mothers who were married to biological fathers at baseline, but transitioned to cohabiting with or marring a new partner was .1\% at year 1, $.2 \%$ at year $3, .8 \%$ at year 5 , and $1.4 \%$ at year 9 . The number of mothers who reported cohabiting with biological fathers at baseline to marrying them at year 1 was $3.5 \%$. This number steadily decreased from $2.8 \%$ in year 3 to $2.5 \%$ in years 5 and 9 . The number of mothers who reported being in cohabiting relationships at baseline to being married to new partners at year 1 was . $3 \%$. This number increased over time, with .4\% at year 3, $.9 \%$ at year 5 , and $1.0 \%$ at year 9 . In year $1,13.9 \%$ of mothers reported being in consistent cohabiting unions. This number decreased to $11.1 \%$ in year 3 , to $7.8 \%$ in year 5 , and $4.4 \%$ in year 9 .

The number of mothers who reported transitioning from cohabiting relationships to being single was $4.2 \%$ in year $1,4.0 \%$ in year $3,2.8 \%$ in year 5 , and $1.8 \%$ in year 9 . The number of mothers who reported being single at baseline to cohabiting with or marrying the biological fathers was $8.4 \%$ in year 1 . By year 3, $4.9 \%$ of mothers reported this transition type, a number that decreased to $2.9 \%$ in years 5 and 9 . The number of mothers who reported being single at baseline to cohabiting with a new partner was $1.7 \%$ at year $1,3.7 \%$ at year 3,5.4\% at year 5, and $7.0 \%$ at year 9 ; whereas the number of mothers who reported being single at baseline to marrying new partners was .1\% at year 
$1, .5 \%$ at year $3,2.1 \%$ at year 5 , and $5.8 \%$ at year 9. And, for mothers who reported being single at baseline, $14.5 \%$ reported being single at year 1 . This number steadily increased to $16.9 \%$ at year $3,19.3 \%$ at year 5 , and $20.6 \%$ at year 9 .

At baseline, $17.8 \%$ of mothers reported living with extended kin. This number increased to $22.0 \%$ by year 1 . However, the number decreased to $15.5 \%$ by year 3 and $11.3 \%$ in year 5 . There was a slight increase in extended kin coresidence at year 9, $11.7 \%$

Time-varying covariates. Mothers' average income-to-poverty ratio was consistently around 3 from baseline to year 9. Mothers' reported that they were in good health, with an average of 4.0 (out of 5) at baseline to 3.8 at year 9. Multipartnered fertility increased from $1.1 \%$ of mothers reporting new children with new partners in year 1 to $6.9 \%$ in year 9 . The number of fathers who were incarcerated increased from $1.9 \%$ at baseline to $3.5 \%$ at year 9 . The number of fathers paying formal child support increased dramatically from $13.8 \%$ in year 1 to $32.8 \%$ in year 9 . And, the number of children who visit their fathers increased from $46.6 \%$ in year 1 to $75.7 \%$ in year 9 .

Time-invariant covariates. More than half of the mothers in this sample had a high school diploma or less $(56.9 \%)$, while $21.2 \%$ had some college, and $22.0 \%$ had a college degree or more. Combining mothers' educational attainment with their poverty status, the sample, overall, is disadvantaged. In terms of race, the sample is $32.0 \%$ white, $33.6 \%$ black, $27 \%$ Hispanic, and 7.3\% self-identified as other. At baseline, mothers were on average 27-years-old. More than half of the mothers in this sample reported having lived with both biological parents at age 15 (54.2\%). And more than half of the mothers reported that their focal child was a boy (56.6\%). 
Table 2 shows results from multilevel bivariate regression models, where mothers' relationship transition types and extended kin coresidence (estimated separately) predicted children's internalizing and externalizing behaviors. Beginning with mothers' relationship transitions, there is strong evidence that changes in family structure negatively (in most cases) and significantly influenced child wellbeing. In other words, many of the associations between mothers' relationship transitions and children's behaviors improved over time. In other words, the size of the coefficients decreased across the waves. Therefore, early transitions appear to affect children more than later transitions.

Two transitions, however, produced larger effects on children at year 9 versus years 3 or 5 - mothers who were married to biological fathers and became single (Internalizing Y1 $-b=.04, p<.05 ; \mathrm{Y} 3-b=.03, p<.05 ; \mathrm{Y} 9-b=.08, p<.001$, and Externalizing Y1 $-b=.04, p<.10 ; \mathrm{Y} 3-b=.06, p<.01 ; \mathrm{Y} 9-b=.11, p<.001)$ and mothers who were married to biological fathers and transitioned into cohabiting or marital unions with new partners (Internalizing Y1 $-b=-.04, N S ; \mathrm{Y} 3-b=-.09, p<.01$; Y9 $-b=.13, p<.001$, and Externalizing Y1 $-b=.04, N S ; \mathrm{Y} 3-b=.04, N S ; \mathrm{Y} 9-b=.15$, $p<.001)$. Thus, mothers' transitions out of marriages with biological fathers increased negative child outcomes over time.

Transitioning from cohabiting relationships, with both biological fathers and new partners, to marriage had the largest impacts on children at year 3 versus years 5 and 9. In fact, transitioning from cohabiting to marrying biological fathers produced larger, positive effects on children's internalizing (reported first) and externalizing behaviors at year $3(b=.10, p<.001 ; b=.19 p<.001)$ than at years $5(b=.02, N S ; b=.09, p<.001)$ 
and $9(b=.03, p<.01 ; b=.04, p<.01)$. Transitioning from cohabiting to marrying new partners produced larger, positive effects on children's internalizing (reported first) and externalizing behaviors at year $3(b=.10, p<.01 ; b=.25, p<.001)$ than at years $5(b=$ $.03, N S ; b=.08, p<.01)$ and $9(b=-.00, N S ; b=.04, p<.05)$. In other words, at age 3 , children experience more internalizing and externalizing behaviors when mothers transition from cohabiting to marital unions than children at ages 5 and 9.

Extended kin coresidence increased children's internalizing $(b=.03, p<.001)$ and externalizing $(b=.03, p<.01)$ behaviors at year 3 . At year 9 , extended kin coresidence was positively and significantly associated with children's externalizing behaviors $(b=.01, p<.05)$.

Table 3 shows results from the multilevel models predicting internalizing and externalizing behaviors by mothers' relationship transition types and whether or not they lived with extended kin, net of demographic characteristics. Models 1 and 4 predict internalizing and externalizing behaviors by mothers' relationship transition types and time-varying covariates; Models 2 and 5 predict internalizing and externalizing behaviors by extended kin coresidence and time-varying covariates; and Models 3 and 6 predict internalizing and externalizing behaviors by mothers' relationship transition types, extended kin coresidence and time-varying covariates. Mothers who were continuously married to biological fathers served as the reference group for all models.

Beginning with internalizing behaviors (Model 1), mothers who transitioned from cohabiting with the biological father to marrying him reported higher levels of internalizing behaviors among their children than mothers who were stably married to biological fathers $(b=.04, p<.01)$. Mothers who were consistently cohabiting, whether 
to the biological father or to a new social father, also reported higher levels of internalizing behaviors among their children $(b=.08, p<.001)$. In addition, mothers who transitioned from cohabiting to single and single to cohabiting or marrying the biological father also reported higher levels of internalizing behaviors among their children, $(b=$ $.05, p<.01$ and $b=.07, p<.001$, respectively).

Results from Model 2 show that extended kin coresidence is positively and significantly associated with increases in children's internalizing behaviors $(b=.02, p<$ $.05)$. Does this association hold after including mothers' relationship transition types in Model 3? After including both mothers' relationship transition types and extended kin coresidence in the model, the magnitude of extended kin coresidence remains the same ( $b$ $=.02, p<.10)$, but the significance decreased. In terms of mothers' relationship transitions, the association between mothers who transitioned from cohabiting with to marrying the biological fathers and children's internalizing behaviors was unchanged from Model 1 to Model $3(b=.04, p<.001)$ when accounting for extended kin coresidence. The same was true for mothers who reported they consistently cohabited (either with biological fathers or social fathers). Extended kin coresidence did not mediate the associations or significance between mothers who transitioned from cohabiting to being single, although the size of the coefficient decreased by 1 percent. Among mothers who transitioned from being single to cohabiting with or marrying biological fathers $(b=.07, p<.001)$, there was no change.

Mothers' income-to-poverty ratios and self-reported health were significantly associated with internalizing behaviors across Models 1-3. Therefore, as mothers' income-to-poverty ratios increased, they reported fewer internalizing behaviors among 
their children (Model 1: $b=-.01, p<.001$; Model 2: $b=-.01, p<.001$; and, Model 3: $b=$ $-.01, p<.001)$; whereas mothers who reported better health, also reported fewer internalizing behaviors among their children (Model 1: $b=-.02, p<.001$; Model 2: $b=$ $.02, p<.001$; and, Model 3: $b=-.02, p<.001$ ). Mothers who engaged in new (meaning after the focal child's birth) multipartnered fertility reported increases in internalizing behaviors among their children (Model 1: $b=.04, p<.001$; Model 2: $b=.02, p<.10$; and, Model 3: $b=.04, p<.001)$. Note that when only accounting for extended kin coresidence (Model 2), the magnitude of the coefficient for multipartnered fertility decreased, as did the significance.

Moving on to externalizing behaviors, compared to mothers who remained married to biological fathers over the 9-year period, mothers who transitioned from cohabiting with to marrying the biological father reported an increase in externalizing behaviors $(b=.12, p<.001)$ (Model 4). Mothers who consistently cohabited, transitioned from cohabiting with biological fathers or social fathers to being single, transitioned from being single to cohabiting with or marrying biological fathers, and those who remained consistently single all reported increases in externalizing behaviors among their children $(b=.11, p<.001 ; b=.10, p<.001 ; b=.14, p<.001 ;$ and $b=.05, p<.01$ respectively). Interestingly, the largest increases in externalizing behaviors occur when mothers change their statuses with biological fathers, from cohabiting with to marrying biological fathers or transitioning from being single to moving in with or marrying biological fathers. Mothers who transitioned from being single to marrying a new partner reported decreases in externalizing problems among their children $(b=-.08, p<.01)$. 
Results from Model 5 show that extended kin coresidence is positively and significantly associated with increases in children's externalizing behaviors $(b=.02, p<$ .05). Does this association hold after including mothers' relationship transition types in Model 6? After including both mothers' relationship transition types and extended kin coresidence in the model, the magnitude of extended kin coresidence remains the same ( $b$ $=.02, p<.10)$, but the significance decreased. In terms of mothers' relationship transitions, the association between mothers who transitioned from cohabiting with to marrying the biological fathers and children's externalizing behaviors was unchanged from Model 4 to Model $6(b=.12, p<.001)$ when accounting for extended kin coresidence. Further, for mothers who reported consistently cohabiting (either with biological fathers or social fathers) and mothers who reported transitioning from being single to cohabiting with or marrying biological fathers, adding extended kin coresidence to the model did not change the magnitudes of the coefficients or the significance levels $(b=.11, p<.001 ; b=.14, p<.001)$. Coresiding with extended kin did attenuate the effects of mothers' relationship transitions on children's externalizing behaviors for mothers who transitioned from cohabiting relationships to being single $(b=.09, p<.001)$ and for mothers who reported being consistently single $(b=.04, p<.05)$, but only by 1 percent. However, extended kin coresidence exacerbated the association between mothers who transitioned from being single to marrying a new partner, but only by 1 percent $(b=$ $-.07, p<.01)$.

Mothers' income-to-poverty ratios and self-reported health were significantly associated with externalizing behaviors across Models 4-6. Therefore, as mothers' income-to-poverty ratios increase, they also report fewer externalizing behaviors (Model 
4: $b=-.01, p<.01 ;$ Model 5: $b=-.01, p<.001$; and, Model 6: $b=-.01, p<.01)$; whereas mothers who report better health, also report fewer externalizing behaviors (Model 4: $b=$ $-.01, p<.01 ;$ Model 5: $b=-.01, p<.01 ;$ and, Model 6: $b=-.01, p<.01)$. Further, mothers who reported that their children's fathers were in jail also reported increases in externalizing behaviors compared to children whose fathers were not incarcerated (Model 4: $b=.05, p<.01$; Model 5: $b=.04, p<.05$; and, Model 6: $b=.05, p<.01)$. Results from Model 5 suggest that there is evidence that living with extended kin does slightly (a $1 \%$ decrease) mediate the association between fathers' incarceration and children's externalizing behaviors $(b=.04, p<.05)$. Mothers who reported new multipartnered fertility also reported significant increases in children's externalizing behaviors ((Model 4: $b=.10, p<.001$; Model 5: $b=.06, p<.001$; and, Model 6: $b=.10, p<.001)$. Again, there is evidence from Model 5 that living with extended kin mediates the effects of new multipartnered fertility on children's externalizing behaviors.

Table 4 shows results from the three-way interaction models between mothers' relationship transitions, extended kin coresidence, and race, predicting internalizing and externalizing behaviors. Specifically, findings presented in Table 4 show whether the associations between children's internalizing and externalizing behaviors and mothers' relationship transitions and extended kin coresidence depend on mothers' race. Compared to white mothers who do not live with extended kin and who have not experienced a relationship transition, all other combinations increased internalizing behaviors. Beginning with white mothers, those who do not live with extended kin, but who have experienced a relationship transition, internalizing behaviors increased among their children $(b=.05, p<.01)$; while white mothers who do live with extended kin and who 
have experienced a relationship transition also reported increased internalizing behaviors $(b=.06, p<.05)$. Turning to non-white mothers, all interactions between non-white mothers, extended kin coresidence, and transitions positively and significantly increased children's internalizing behaviors. Non-white mothers who do not live with extended kin and who have not experienced a transition report that their children display internalizing behaviors $(b=.03, p<.05)$. When mothers reported living with extended kin but no transitions, the magnitude of the coefficient increased, but the significance of the association decreased $(b=.04, p<.10)$. When mothers reported a transition but did not live with extended kin, the magnitude of the coefficient increased, as did the significance ( $b=.05, p<.001)$. And, when non-white mothers who reported living with extended kin and a transition, the magnitude of the coefficient increased $(b=.07, p<.001)$. Thus, in terms of internalizing behaviors, race moderated the association between mothers' transitions and extended kin coresidence. Specifically, overall, non-white mothers reported more internalizing behaviors than white mothers.

Turning to externalizing behaviors, compared to white mothers who did not live with extended kin and who did not report a transition, white mothers who reported a transition (but did not live with extended kin), also reported increased externalizing behaviors among their children $(b=.07, p<.01)$, which is two percentage points higher than for non-white mothers. When white mothers reported both living with extended kin and a transition, the magnitude of the coefficient increased $(b=.08, p<.05)$. Non-white mothers who live with extended kin and who have experienced a transition report similar externalizing behaviors as their white counterparts; however, the significance level is higher for non-whites. Thus, in terms of externalizing behaviors, overall, race moderated 
the association between mothers' transitions and extended kin coresidence. Specifically, non-white mothers reported more externalizing behaviors than white mothers.

Table 5 shows results from the three-way interaction models between mothers' relationship transitions, extended kin coresidence, and education, predicting internalizing and externalizing behaviors. Compared to mothers with higher education (i.e., some college or a college degree) who did not live with extended kin and who have not experienced a transition, coresiding with extended kin or experiencing a relationship transition positively influenced internalizing behaviors. For internalizing behaviors, there appeared to be no significant differences between higher educated mothers by extended kin coresidence. On the other hand, there were differences among the lower educated groups. Indeed, not having any college education (and not living with extended kin or experiencing a transition) increased internalizing behaviors among children by $4 \%$ ( $p<$ $.01)$. Coresiding with extended kin exacerbated this effect $(b=.06, p<.05)$, as did experiencing a transition $(b=.07, p<.001)$. For mothers who coresided with extended kin and reported experiencing a transition, not having any college education significantly moderated the association between mothers' relationship and living situations and children's internalizing behaviors.

In terms of externalizing behaviors, the associations between mothers' relationship transitions, extended kin coresidence, and education are all positive, except for educated mothers who coreside with extended kin, but who have not experienced a transition. Thus, when educated mothers live with extended kin, but have not experienced a transition, children's externalizing behaviors decreased $(b=-.02, N S)$. Educated mothers who experienced a transition (but do not coreside with extended kin) and 
educated mothers who both lived with extended kin and reported a transition, also reported increased externalizing behaviors among their children $(b=.03, N S ; b=.09, p<$ $.01)$. As was the case with internalizing behaviors, the coefficients are larger for mothers with a high school diploma or less; externalizing behaviors among children increased by $2 \%(N S)$ for mothers who did not have any college education and who reported not living with extended kin or experiencing a relationship transition. For less educated mothers, experiencing a transition increased children's externalizing behaviors $(b=.09, p<.001)$; while coresiding with extended kin and experiencing a relationship transition increased children's externalizing behaviors $(b=.10, p<.001)$. Thus, mothers' education levels do moderate the association between extended kin coresidence and relationship transitions and children's wellbeing.

\section{Discussion}

This study contributes new information about how the changes within households disturb the equilibrium of a family's ecological system, and increase the risk of children's internalizing and externalizing behaviors during mothers' relationship transitions. Indeed, the associations between mothers' relationship transitions and child wellbeing are strong across time, even after accounting for extended kin coresidence—or the entrance of children's loved ones, or people who are familiar to children, into their family system.

Beginning with descriptive statistics, around half of the sample remains consistently married to biological fathers across time. However, for the other half of the sample, there is significant variation in mothers' relationship transitions. The transitions with the largest increases over the 9-year period transition from being single to 
cohabiting with or marrying a new partner and mothers who report being single from wave to wave - which supports past research that finds that single mothers transition frequently, with “only $15 \%$ report[ing] no change in relationship status" by children's fifth birthday (McLanahan 2011: 119). However, 20.6\% of mothers report being consistently single at year 9, which may be associated with fathers' child support payments. Indeed, nearly $33 \%$ of fathers pay child support by year 9 . Even though the sample is disadvantaged, mothers who receive formal child support may be better able to delay new partnerships than mothers who do not receive support (Cancian et al. 2011). On the other hand, the increases in mothers transitioning from being single to new partnerships may be associated with economic need and may account for the nearly $66 \%$ of biological fathers not paying child support. There was a dramatic increase in multipartnered fertility, from $1.1 \%$ in year 1 to $6.9 \%$ in year 9 ; thus, mothers may be "settling" with new partners to meet financial needs (Bzostek et al. 2012) — which may, subsequently, discourage biological fathers from sustaining their obligations to their children (Tach et al. 2010). Further, the decrease in extended kin coresidence, particularly from years 1-9, may be attributed to increases in multipartnered fertility. In other words, as mothers have more children, they may concurrently deplete their resources, including access to kin support (Harknett and Knab 2007).

Bivariate, multilevel results show strong associations between mothers' relationship transitions and children's internalizing and externalizing behaviors over the 9 year observation period. Thus, findings support McLanahan's (2011) research that suggests childhood outcomes are contingent on family instability. Unexpectedly, extended kin coresidence was positively associated with both internalizing and 
externalizing behaviors; however, the magnitude of the coefficients were small. Extended kin coresidence may exacerbate children's behaviors because the presence of kin could influence mothers' parenting and stress levels (Jackson 1998). McLanahan (2011), for example, found that relationship transitions may temporarily decrease maternal mental health, though surmountable as long as there were no "additional stressors" (e.g., extended kin) (McLanahan 2011: 124). Therefore, if extended kin coresidence coincides with mothers' relationship changes, the stress may be overwhelming and, subsequently, influence child wellbeing negatively.

Moving to results from the multivariate multilevel models, net of covariates, there were significant associations between mothers' relationship transitions and children's internalizing and externalizing behaviors; and there are positive, significant associations between extended kin coresidence and children's behavioral outcomes. In terms of internalizing behaviors, extended kin coresidence mediated the associations among mothers who consistently cohabit, mothers who transition from cohabiting unions to being single, and mothers who report being consistently single (the last of which is not significant). As Brown (2005) found, cohabitation is common among low-income families, which means they often dissolve more quickly and more frequently than marriages; thus, extended kin who coreside with cohabiting families conceivably contribute resources to the family. More resources may lead to better outcomes for children.

In terms of externalizing behaviors, extended kin coresidence mediates the associations between transitions and child behavior among mothers who transition from cohabiting unions to being single, being single to marrying a new partner, and who report 
being consistently single. I hypothesized that if, for example, mothers' relationship transitions increase the likelihood of harsh parenting (McLanahan 2011), living with extended kin following mothers' partnership transitions, and subsequently being single, may benefit children. Research shows that mothers' parenting authority is often in abeyance while living with extended kin (Wakschlag and Chase-Landsdale 1996), but it may also mean that extended kin care for children during adjustment periods for mothers. The idea that mothers may concede some parental authority while coresiding with their family may account for the increase in externalizing behaviors as mothers transition from being single to marrying a new partner. Who is in charge? Extended kin may intervene more when mothers transition into new relationships, as they may perceive mothers new relationships as diversions from parenting. And, when mothers remain consistently single over time, extended kin may provide needed child care as mothers try to fulfill all parental roles. This may influence children's behavior negatively as parenting from their mother may be what they need or want.

Extended kin coresidence appears to mediate the association between multipartnered fertility (and father incarceration) and child wellbeing outcomes. Multipartnered fertility is strongly associated with children's internalizing and externalizing behaviors; however, extended kin coresidence attenuates the association. In terms of Bronfenbrenner's "first- and second-order effects," perhaps the presence of extended kin does mediate the influence of new partners' (i.e., first-order effects) relationships with mothers and child wellbeing (i.e., second-order effects), as extended kin may offer attention to a child that he or she is not getting from either biological parent. The consequences of first- and second-order effects may be understated, as they 
consider only the outcomes associated with individual households and their members. In other words, considering only the child's household context ignores the potential influence of nonresident family members (e.g., biological fathers), in terms of direct decisions made about a child's wellbeing. Indeed, research suggests that mothers often marginalize biological fathers to protect resources that are associated with new partnerships and children (Tach et al. 2010). Thus, it is possible that changes within one mesosystem affect the parent-child relationships within another system. In addition, the presence of new members within a child's mesosystem may even sever ties with biological parents outside of that system — a decision that likely is not made by either the nonresident parent or the child. Cooper et al. (2009), for example, found that ongoing relationships with nonresident biological fathers is directly (and positively) associated with mothers' stress levels. Fathers' incarceration is also an important influence on children, and extended kin coresidence may attenuate any associated negative consequences for children. Extended kin, then, may provide much-needed resources (e.g., attention) during periods of forced separation from a parent, or periods when mothers' attention is elsewhere (e.g., investments in new partnerships). Extended kin coresidnece during paternal incarceration may be particularly beneficial to male children, as they tend to be more aggressive (i.e., externalizing behaviors) than female children (Geller et al. 2012).

There is evidence that changes within the mesosystem (i.e., the child's home), or where the child most frequently interacts, are the most destabilizing for children (Fomby and Cherlin 2007). In many cases, mothers' relationship changes cause distress, indicated by children withdrawing or acting out. Findings from the present study suggest that 
interactions between mesosystems, for example children living in one home and biological fathers in another, may not be as detrimental to children as prior research suggests. Children who visit their fathers show fewer internalizing and externalizing behaviors. Although these associations were not significant, from an ecological perspective, the findings seem, in some ways, counterintuitive. In other words, children who visit their fathers and, therefore, oscillate into and out of multiple mesosystems, could experience stressful and confusing, ongoing adjustments, particularly if mothers (or even nonresident fathers) repartner multiple times. However, results from this study are consistent with past research, which suggests that engagement with nonresident fathers is beneficial to children (e.g., Amato and Gilbreth 1999). Indeed, the authors argue that nonresident fathers who adopt or engage in authoritative parenting provide stability for their children (Amato and Gilbreth 1999).

Amato and Gilbreth (1999) also found that fathers' child support payments are positively associated with children's outcomes, particularly externalizing behaviors; thus, when fathers pay child support, children fare better. Findings from this study show that by year 9 , the highest proportion of dads make child support payments (32.8\%) and children's internalizing and externalizing behaviors are the lowest (i.e., .2). Moreover, at year $9,75.7 \%$ of children visit their fathers, suggesting ongoing father-child relationships. Even so, I did not control for fathers' multipartnered fertility or their new romantic relationships, which may interfere with father-child relationships over time. Further, as previous research suggests, father involvement is often contingent on fathers' ability to get along with the mothers, so in these circumstances, children may spend more time with their nonresident biological fathers (e.g., McLanahan 2011). In other words, if 
biological mothers and fathers support each other's parenting, and each live in stable households, children may not have to navigate hostile relationships in overlapping mesosystems, and adjustments within both households may be smoother.

Understanding that changes within systems, including new memberships, disturb the system's equilibrium and require a period of adjustment or adaptation, we could argue that absent members also generate similar effects. In other words, when biological fathers are incarcerated and, therefore, absent from mesosystems, analyses on child wellbeing should include their potential interactions with other systems (e.g., the exosystem, or influential institutional interactions). Children who visit incarcerated fathers may become embedded within the exosystem (e.g., the penal system) as they interact with staff and bureaucratic procedures. Research suggests that mothers sometimes serve as gatekeepers between non-resident fathers and their children to protect their resources and childrenwhich leads to less father involvement (Sano et al. 2008). It is possible to consider the penal system a gatekeeper between fathers and children, restricting father involvement to short, scheduled visits. Understanding that children benefit from visiting their fathers, limiting their visitation may lead to increases in children's internalizing and externalizing behaviors. Although extended kin mediate the association between paternal incarceration and child wellbeing, they may not completely compensate for absent fathers.

Further, fathers' interaction with the exosystem (e.g., prison) may potentially affect children's wellbeing and their mesosystems, as fathers with formal child support orders will likely not be able to fulfill their financial obligations. Subsequently, mothers' cognitive functioning may decrease due to a reduction in resources (Fomby and Cherlin 2007) — which could encourage mothers to seek out new partnerships. Thus, new 
partnerships could lead to new multipartnered fertility. Taken together, children may temporarily lose one parent to the exosystem (i.e., prison), while simultaneously learning to negotiate new members both outside (e.g., correctional officers) and within their mesosystems (e.g., new social fathers, new siblings).

Thus, how do children's interactions with the penal system influence macrosystems? It may be possible that early interactions with the penal system desensitizes children to, and therefore normalizes engagement with, both the judicial and penal systems. Is it possible, then, that family instability, as a result of incarceration, could be transmitted intergenerationally—similar to the ways in which younger generations' partnering and parenting behaviors (e.g., nonmarital childbearing, multipartnered fertility) are linked to family instability (Fomby and Cherlin 2007; Högnäs and Carlson 2012)? Understanding that children's externalizing behaviors increase when fathers leave households (Mitchell et al. 2015), it is possible that children may engage in activities that could lead to their own legal trouble, or their own involvement in the exosystem.

In addition to multivariate multilevel modes, I explored whether maternal race and education moderated the association between mothers' relationship transitions and child wellbeing. Although race appears to moderate the aforementioned associations, transitions appear to be a more important in one scenario-when mothers experience transitions, but not extended kin coresidence. In these contexts, child wellbeing outcomes are identical for both white and non-white mothers. Scholars have noted that race differences in extended kin social support have shifted over time, with more white families benefitting from family networks than black families today (see Roschelle 1997), 
and results from this study suggest that non-white mothers' coresidence with extended kin (with transitions) increases children's internalizing and externalizing behaviors. Collins (2000) argues that black family networks are not as prominent as they once were due to "shrinking opportunities" that led young women into motherhood and inundated older women with more familial obligations (66). Indeed, she argues that some black women may view "their daughters' pregnancies as one more responsibility for them to bear" (Collins 2000: 71). Thus, mothers may feel judged as parents, which could exacerbate their stress levels and, subsequently, increase negative child outcomes. Interestingly, living with extended kin (with no transitions) is not associated with nonwhite children's externalizing behaviors. Fomby and Cherlin (2007) argue that black children may not be as affected by family structure transitions for two reasons: 1) they tend to be more enmeshed in family systems than white children and, therefore, kin may "ease the emotional strain" and additional child care responsibilities placed on the residing parent once the other parent leaves the system; and 2) they often live in "family and neighborhood environments where a greater number of stressful events occur...[thus], the relative effect of the added stress of a partnership change would be lower" (Fomby and Cherlin 2007: 185).

In addition to race, education also moderates the associations between mothers' transitions, extended kin coresidence, and child wellbeing. Children with mothers with a high school degree or less display more internalizing and externalizing behaviors than children whose mothers are more educated, whether they live with extended kin or not and whether they experience transitions or not. Transitions may have deleterious effects on mothers and their children (Osborne et al. 2012), but for low-income women, 
relationship changes often lead to short-lived (mostly) spells of doubling up (Pilkauskas et al. 2014) — contributing to greater instability, including residential (Desmond 2016). Further, race and education may interact, which is beyond the scope of this paper, as research shows that mothers' lack of education is associated with their children's externalizing behaviors (Fomby and Cherlin 2007). More educated mothers, on the other hand, often have more agency and financial independence when it comes to relationship changes; thus, the economic and emotional consequences may not be as severe for educated mothers, regardless of race, as they would be for less educated mothers (Cooper et al. 2009).

The hypothesis that extended kin coresidence moderates the associations between mothers' relationship transitions and children's internalizing and externalizing behaviors is supported for particular transition types: mothers who consistently cohabit, mothers who transition from cohabiting to being single, and mothers who are consistently single. For all other transition types, extended kin coresidence has little influence on child wellbeing outcomes. However, extended kin coresidence does appear to mediate the association between multipartnered fertility and father incarceration and child wellbeing (respectively). Thus, extended kin do, in some ways, buffer children from family instability, but they may also make some situations worse. Along these lines, three decades ago Cherlin and Furstenberg (1986) found that middle-class, married parents are protected by "norms of non-interference," meaning that marriage provides an invisible barrier around their family systems, where decisions made about, and for, family members were guarded from outsiders. Low-income families, on the other hand, often rely on extended kin to make ends meet, which could be inviting interference, not only 
into their households, but also as co-parents in some cases. It makes sense, then, that as mothers cope with partnership changes, that their stress levels increase if they have others (e.g., extended kin) telling them how to adjust and how to parent. Although extended kin are likely trying to help mothers, their involvement may be both requested and viewed as interference. Unfortunately, children, regardless of age, tend to pick up on related tensions, and the results of the current study suggest that they may subsequently fare worse.

\section{Limitations}

This study is limited in several ways. First, the study is limited to mothers who report living with their children at least half or most of the time; thus, children's internalizing and externalizing behaviors may be downwardly biased with the exclusion of those who live with mothers less than half-time. Second, this study relies on maternal reports of child wellbeing. To the extent that involved fathers may have a different view of children's behaviors, the results may be biased. Third, although child reports are available for year 9, maternal reports from years 3, 5, and 9 were used in an effort to be consistent across waves. Fourth, given the duration of time between the fourth and fifth waves of data collection, children's internalizing and externalizing behaviors may be underestimates of the behaviors at each given wave, or they may be exaggerated in the absence of knowing how children were doing between waves.

Fifth, the complexity of interacting three categorical variables (i.e., transitions, race and education, and kin coresidence) in my three-way interaction models meant that I had to give up information about specific differences between race and education groups. 
This limits my ability to report on specific races and educational differences in terms of associations between mothers' transitions and extended kin coresidence and child wellbeing outcomes. Although I can report that non-whites and children with lower educated mothers fare less well compared to whites and children with higher educated parents, I cannot tease apart differences between black, Hispanic, and mothers who selfidentify as other; nor can I tease apart differences between mothers with less than a high school degree, a high school degree, some college, or a college degree.

Lastly, the study is limited in that multilevel modeling using longitudinal data requires that time (i.e., waves) be nested in subjects, rather than social contexts (e.g., households). Thus, I was not able to determine who exactly in specific households influences child wellbeing over time; however, it was possible to capture how time affects child wellbeing outcomes.

\section{Conclusion}

McLanahan (2011) argues that "it is not marital status at birth that promotes children's long-term well-being but rather the fact that marital status at birth is a pretty good proxy for children's long-term family structure" (131). In other words, children who are born to married parents are more likely to live in stable, nuclear families, with fewer interruptions in their households (Cherlin and Furstenberg 1986). Stability begets stability, meaning that children who live in secure households are more likely to fare better in other contexts, including the exosystem (e.g., school); their attention is less likely to be diverted by their parents' new partners, new children, extended kin, or even parents' incarceration. 
Past research suggests that mothers' relationship transitions are difficult for them and their children, as these changes increase the likelihood of maternal depression and parenting stress (see Cooper et al. 2009; Osborne et al. 2012). This study extends this literature, suggesting that extended kin coresidence mediates the associations between family structure transitions and child wellbeing. It appears that extended kin may exacerbate the influence of many transition types, but may attenuate the influence of specific household changes (e.g., where there is multipartnered fertility, fathers' incarceration) that may turn mothers' attention away from children.

As I have speculated, change within children's households disturbs the equilibrium of the household and necessitates a period of adjustment and negotiation with new members. Thus, mothers' relationship changes permeate the family system, and underscore the enmeshed and interdependent nature of households. Further, it is plausible that mothers' authority is compromised when living with extended kin during transitional times. Perhaps the concomitant effects of a relationship change and losing some control over their children is too much for mothers and too much for children. Finding ways to limit the number of household changes that mothers and children experience is important. As Fomby and Cherlin (2007) note, there is a cumulative effect for children experiencing multiple transitions, but this means that there is likely a cumulative effect for mothers and other members of family systems, too. It is important to find ways to minimize negative child wellbeing outcomes associated with increasing family instability, and will require that policy makers think differently about how to improve the contexts in which children are reared. 
Rather than marriage promotion in contexts where marriage may be viewed as unattainable (e.g., Edin and Kefalas 2005), policy makers could focus more on resources that may improve the life chances of children who live in unstable contexts. A good place to begin would be to invest more in housing for parents (mothers and fathers) regardless of who has custody of their children. If policy makers considered and addressed the overlapping mesosystems in which children are embedded, this might improve the household conditions that children live in both full- and part-time (and may even increase the likelihood that children spend more time with nonresident fathers). Of course, addressing housing issues is not likely to solve the problems children face when their parents dissolve and begin new romantic partnerships, but at least it would reduce the likelihood that children would have to move in with extended kin if (and when) their parents experience a breakup. Memberships within children's ecological systems may change, but permanent, affordable housing could improve children's outcomes immensely.

In terms of future research, extensions to this work will include an exploration of child wellbeing outcomes for children who do not live with mothers. Although mothers' parenting changes following the dissolution of - or entrance into-a romantic relationship (McLanahan 2011), remaining with mothers may be more beneficial to children than alternative arrangements (e.g., living with extended kin alone). It might also be interesting to explore the (potential) differences between children who visit fathers and children who visit mothers. Further, in my future research, I intend to examine children's reports of their wellbeing. 
This research filled a gap in the literature by examining whether extended kin coresidence mediates the association between mothers' relationship transitions and child wellbeing. The study contributes to the literature a better understanding of when extended kin may matter (e.g., including fathers' incarceration) and when kin may make children's circumstances worse. Yes, extended kin may serve as protective barriers against the potentially negative effects of change, but they may also contribute to the destabilization of a child's ecological system. 
Table 1. Descriptive statistics for mothers relationship status, fertility, education, demographics, and personal characterisitcs across five waves.

\begin{tabular}{|c|c|c|c|c|c|c|c|c|c|}
\hline \multirow{2}{*}{$\begin{array}{l}\text { Mean (SD) or \% } \\
\text { Children's Behaviors }\end{array}$} & Base & \multirow{2}{*}{\multicolumn{2}{|c|}{ YR 1}} & \multicolumn{2}{|l|}{ YR 3} & \multicolumn{2}{|l|}{ YR 5} & \multicolumn{2}{|c|}{ YR 9} \\
\hline & & & & & & & & & \\
\hline Internalizing Behaviors (range $=0-2$ ) & & & & .3 & $(.3)$ & .3 & $(.3)$ & .2 & $(.2)$ \\
\hline Externalizing Behaviors (range $=0-2$ ) & & & & .5 & $(.3)$ & .3 & $(.3)$ & .2 & $(.2)$ \\
\hline \multicolumn{10}{|l|}{ Relationship Transition Types } \\
\hline Consistently married to bio. dad (yes/no) (ref) & & 52.0 & & 53.3 & & 50.6 & & 49.3 & \\
\hline Married to bio dad to single & & 1.3 & & 2.2 & & 5.0 & & 3.4 & \\
\hline Married to cohab/married to new partner & & .1 & & .2 & & .8 & & 1.4 & \\
\hline Cohabiting to married to bio dad & & 3.5 & & 2.8 & & 2.5 & & 2.5 & \\
\hline Cohabiting to married to new partner & & .3 & & .4 & & .9 & & 1.0 & \\
\hline Cohabiting to cohabiting & & 13.9 & & 11.1 & & 7.8 & & 4.4 & \\
\hline Cohabiting to single & & 4.2 & & 4.0 & & 2.8 & & 1.8 & \\
\hline Single to cohab/married to bio dad & & 8.4 & & 4.9 & & 2.9 & & 2.9 & \\
\hline Single to cohab with a new partner & & 1.7 & & 3.7 & & 5.4 & & 7.0 & \\
\hline Single to married to a new partner & & .1 & & .5 & & 2.1 & & 5.8 & \\
\hline Consistently single & & 14.5 & & 16.9 & & 19.3 & & 20.6 & \\
\hline Extended kin coresidence (yes/no) & 17.8 & 22.0 & & 15.5 & & 11.3 & & 11.7 & \\
\hline \multicolumn{10}{|l|}{ Covariates } \\
\hline Income to poverty ratio $($ range $=0-69)$ & $3.3(3.3)$ & 2.9 & (3.4) & 3.2 & $(5.1)$ & 2.8 & (3.5) & 3.0 & $(4.1)$ \\
\hline Maternal health & $4.0 \quad(.9)$ & 3.8 & $(1.1)$ & 3.9 & $(1.0)$ & 3.7 & $(1.0)$ & 3.8 & (1.1) \\
\hline Multipartnered fertility & & 1.1 & & 4.1 & & 3.4 & & 6.9 & \\
\hline Father incarcerated (yes/no) & 1.9 & 3.2 & & 3.4 & & 3.0 & & 3.5 & \\
\hline Father pays child support (yes/no) & & 13.8 & & 19.3 & & 28.1 & & 32.8 & \\
\hline Child visits father (yes/no) & & 46.6 & & 60.2 & & 63.0 & & 75.7 & \\
\hline \multicolumn{10}{|l|}{ Education } \\
\hline Less than high school (ref) & 23.5 & & & & & & & & \\
\hline High school degree & 33.4 & & & & & & & & \\
\hline Some college & 21.2 & & & & & & & & \\
\hline College degree or more & 22.0 & & & & & & & & \\
\hline \multicolumn{10}{|l|}{ Demographic characteristics } \\
\hline White (ref) & 32.0 & & & & & & & & \\
\hline African American & 33.6 & & & & & & & & \\
\hline Latino/Hispanic & 27.0 & & & & & & & & \\
\hline Other & 7.3 & & & & & & & & \\
\hline Age (range $15-43$ ) & $27.3(6.1)$ & & & & & & & & \\
\hline Lived with both bio. parents at age 15 (yes/no) & 54.2 & & & & & & & & \\
\hline Focal children's gender (boy/girl) & 56.6 & & & & & & & & \\
\hline
\end{tabular}


Table 2. Bivariate Statistics. Mothers' Relationship Transition Types and Extended Kin Coresidence Predicting Children's Internalizing and Externalizing Behaviors at Years 3, 5, and 9 (Internalizing Models $N=1,908$; Externalizing Models $N=2,201$ ).

\begin{tabular}{|c|c|c|c|c|c|c|c|c|c|c|}
\hline \multicolumn{5}{|c|}{ Internalizing Behaviors } & \multicolumn{6}{|c|}{ Externalizing Behaviors } \\
\hline Year 3 & & & & & & & & Year 5 & & Year 9 \\
\hline$S E$ & $\beta$ & $S E$ & $\beta$ & $S E$ & $\beta$ & $S E$ & $\beta$ & & $S E$ & $S E$ \\
\hline
\end{tabular}

Relationship Transition Type ${ }^{1}$

Married to bio dad (ref)

Married to bio dad to single

$\begin{array}{lllllllllllll}.04 * & .02 & .03 * & .01 & .08 * * * & .01 & .04 \dagger & .02 & .06 * * & .02 & .11 * * * & .01\end{array}$

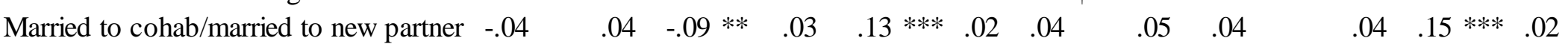

Cohabiting to married to bio dad

$\begin{array}{llllllllllllll}.10 * * * & .01 & .02 & .01 & .03 * * & .01 & .19 * * * & .02 & .09 * * * & .02 & .04 * * & .01\end{array}$

Cohabiting to married to new partner

Cohabiting to cohabiting

$\begin{array}{llllllllllllll}.10 * * & .03 & .03 & .02 & -.00 & .02 & .25 * * * & .04 & .08 * & .03 & .04 * & .02\end{array}$

Cohabiting to single

$\begin{array}{llllllllllllll}.11 * * * & .01 & .06 * * * & .01 & .04 * * * & .01 & .08 * * * & .01 & .03 * * & .01 & .04 * * * & .01\end{array}$

$\begin{array}{lllllllllllll}.07 * * * & .01 & .04 * * & .01 & .00 & .01 & .10 * * * & .01 & .05 * * & .01 & .05 * * * & .01\end{array}$

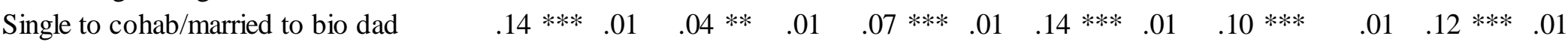

Single to cohab with a new partner

$\begin{array}{llllllllllllll}.10 * * * & .01 & .02 * & .01 & .02 * * & .01 & .14 * * * & .01 & .13 * * * & .01 & .07 * * * & .01\end{array}$

Single to married to a new partner

Single to single

$\begin{array}{llllllllllllll}.11 * * * & .02 & .05 * * * & .01 & .04 * * * & .01 & .18 * * * & .01 & .05 * * & .02 & .07 * * * & .01\end{array}$

$\begin{array}{lllllllllllll}.12 * * * & .01 & .01 \dagger & .01 & .02 * * * & .00 & .11 * * * & .01 & .10 * * * & .01 & .06 * * * & .00\end{array}$

\section{Extended Kin Coresidence}

Extended kin coresidence (yes/no)

$\begin{array}{llllllllll}.03 * * * & .01 & .01 & .01 & .01 & & .01 & .03 * * & .01 & -.00\end{array}$

$.01 \quad .01 * \quad .01$

$' \dagger \mathrm{p}<.10, * \mathrm{p}<.05, * * \mathrm{p}<.01, * * *<.001$.

${ }^{1}$ Separate bivariate models were estimated predicting children's internalizing and externalizing behaviors by mothers' relationship transition types and extended kin coresidence. 
Table 3. Multilevel models predicting internalizing and externalizing behaviors by mothers' relationship transition types and extended kin coresidence (Internalizing Models $N=1,908$; Externalizing Models $N=2,201$ ).

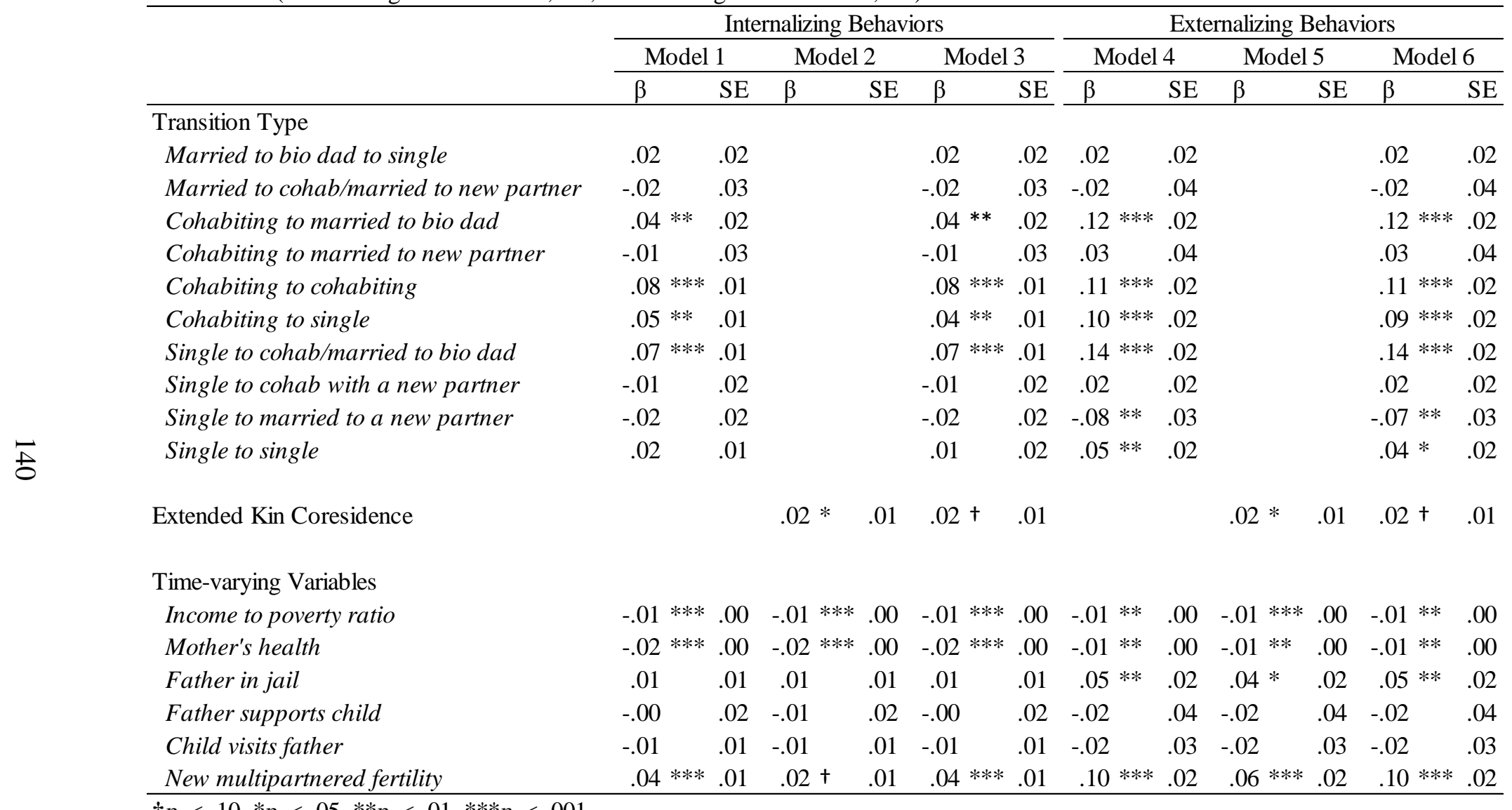

$\dagger p<.10 . * p<.05 . * * p<.01 . * * * p<.001$

Note: Models 1 and 4 include only the mothers' relationship transition types and time-varying covariates. Models 2 and 5 include extended kin coresidence and time-varying covariates. Models 3 and 6 include mothers' relationship transition types, extended kin coresidence and time-varying covariates. Models also control for mother's age, race, education, whether or not the mother lived with her biological parents at age 15 , and child's gender. 
Table 4. Results from Multilevel Models Predicting Internalizing and Externalizing Behaviors by ThreeWay Interactions between Mothers' Relationship Transitions, Extended Kin Coresidence, and Race (Internalizing Models $N=1,908$; Externalizing Models $N=2,201$ ).

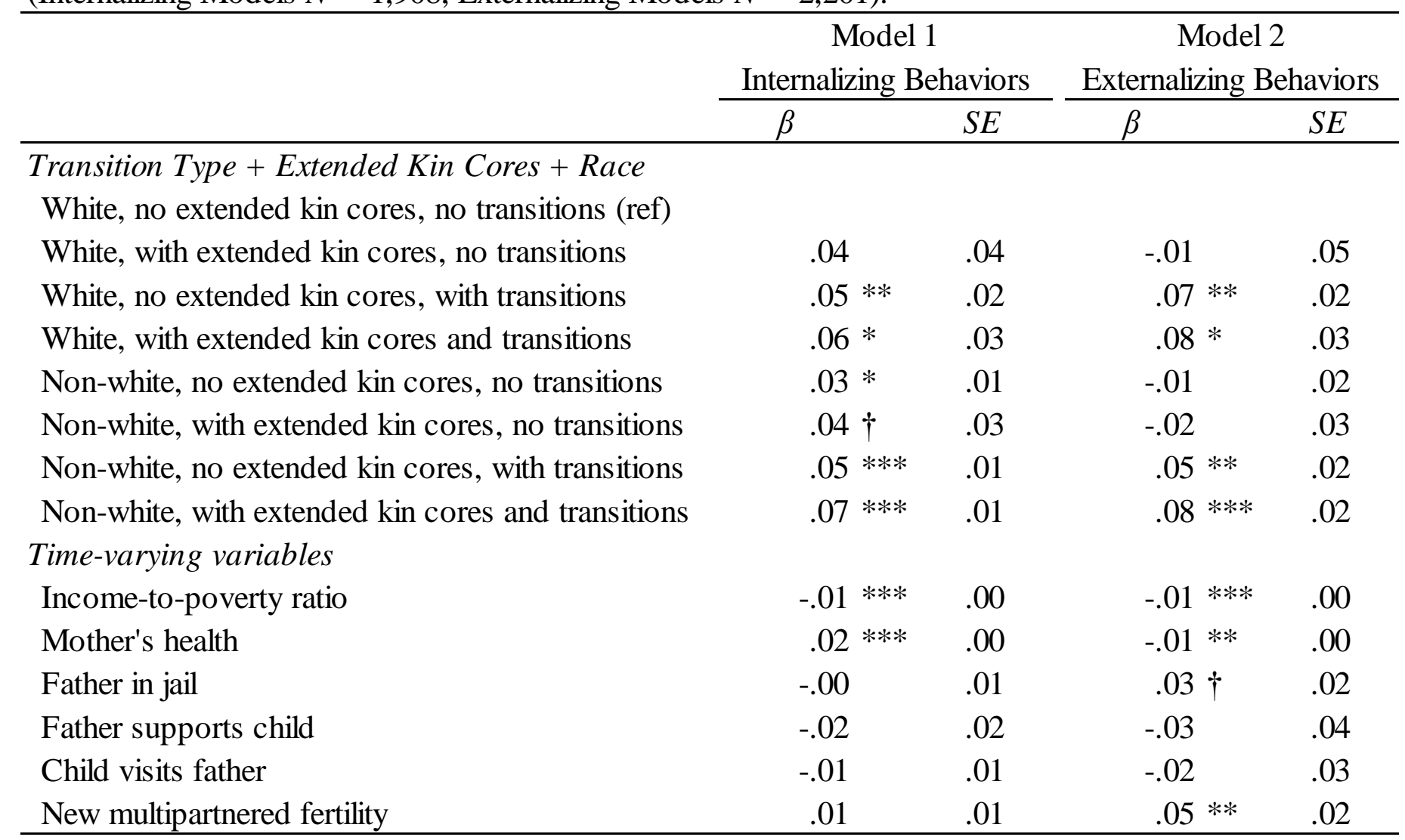

$\dagger p<.10, * p<.05, * * p<.01, * * *<.001$.

Note: Dummy variables for mothers' relationship transition types, extended kin coresidence, and race were combined into one three-way interaction term. 
Table 5. Results from Multilevel Models Predicting Internalizing and Externalizing Behaviors by Three-Way Interactions between Mothers' Relationship Transitions, Extended Kin Coresidence, and Education

(Internalizing Models $N=1,908$; Externalizing Models $N=2,201$ ).

\begin{tabular}{|c|c|c|c|c|}
\hline & \multicolumn{2}{|c|}{$\begin{array}{c}\text { Model } 1 \\
\text { Internalizing Behaviors }\end{array}$} & \multicolumn{2}{|c|}{$\begin{array}{c}\text { Model } 2 \\
\text { Externalizing Behaviors }\end{array}$} \\
\hline & $\beta$ & $S E$ & $\beta$ & $S E$ \\
\hline \multirow{2}{*}{\multicolumn{5}{|c|}{$\begin{array}{l}\text { Transition Type }+ \text { Extended Kin Cores }+ \text { Education } \\
\text { Higher ed, no extended kin cores, no transitions (ref) }\end{array}$}} \\
\hline & & & & \\
\hline Higher ed, with extended kin cores, no transitions & .02 & .03 & -.02 & .04 \\
\hline Higher ed, no extended kin cores, with transitions & .01 & .01 & .03 & .02 \\
\hline Higher ed, with extended kin cores and transitions & .03 & .02 & $.09 * *$ & .03 \\
\hline No higher ed, no extended kin cores, no transitions & $.04 * *$ & .01 & .02 & .02 \\
\hline No higher ed, with extended kin cores, no transitions & $.06 *$ & .03 & .01 & .04 \\
\hline No higher ed, no extended kin cores, with transitions & $.07 * * *$ & .01 & $.09 * * *$ & .01 \\
\hline No higher ed, with extended kin cores and transitions & $.08 * * *$ & .01 & $.10 * * *$ & .02 \\
\hline \multicolumn{5}{|l|}{ Time-varying variables } \\
\hline Income-to-poverty ratio & $-.00 * *$ & .00 & $-.01 * *$ & .00 \\
\hline Mother's health & $-.02 * * *$ & .00 & $-.01 * *$ & .00 \\
\hline Father in jail & -.01 & .01 & .03 & .02 \\
\hline Father support child & -.01 & .02 & -.03 & .04 \\
\hline Child visits father & -.01 & .02 & -.02 & .03 \\
\hline New multipartnered fertility & .01 & .01 & $.05 * *$ & .02 \\
\hline
\end{tabular}

$\dagger p<.10, * p<.05, * * p<.01, * * *<.001$.

Note: Dummy variables for mothers' relationship transition types, extended kin coresidence, and education were combined into one three-way interaction term. Mothers who had some college or college degrees were coded as having higher education. Mothers with a high school diploma or less were coded as 0 . 


\section{CHAPTER V: ROUND AND ROUND AND ROUND IN THE FAMILY GAME ${ }^{4}$}

Scholars argue that there is a "new package deal," where children precede parental commitment (Tach et al. 2010). The "new package deal," then, signifies a deviation from the traditional life course-i.e., marriage, then children-which begs the question, how does a life course path diversion influence the development of social subsystems and interactions within Bronfenbrenner's mesosystems? In other words, when unmarried parents (i.e., fragile families) enter parenthood outside of marriage (what many consider to be a more secure union), what is the likelihood that parents will eventually rely on others (e.g., extended kin) for resource support, coparenting, etc.? Although research suggests that more than $80 \%$ of fragile families are together at the births of their children (50\% are cohabiting and 32\% are "romantically involved"), around $66 \%$ break up within five years (McLanahan 2011: 111).

Understanding that break-ups often require a residential move, especially for cohabitors, it is important to ask where families go during transitional times. And, knowing that moving is expensive, coupled with the fact that many fragile families are socioeconomically disadvantaged, it is also important to explore where they go and if they enact support from extended kin in the process. And, finally, considering that family members are interdependent, parents who are disadvantaged are likely linked to extended

\footnotetext{
${ }^{4}$ The title of Chapter Five is a play on lyrics by Joni Mitchell. Words taken from the song "The Circle Game."
} 
kin in similar socioeconomic stratum; thus, hardships (e.g., residential instability) associated with partnership dissolutions among fragile families likely generate hardships for entire family systems — an implication that needs consideration. To explore these connections, this dissertation examined the associations between coparenting relationships and parental commitment; mothers' relationship statuses and extended kin coresidence; and mothers' transitional types and extended kin coresidence, and child wellbeing.

\section{Major Findings from the Three Quantitative Chapters}

Findings from chapter two, "For us or the children: Exploring the association between coparenting trajectories and parental commitment," suggest that coparenting relationships among unmarried parents are strong across the first five years of their children's lives. Coparenting relationships appear to influence parental commitment at Year 5. Therefore, supportive coparenting among unmarried, cohabiting parents (i.e., less committed than married parents) increases the strength of parental relationships.

Moving on to findings from chapter three, "Maternal partnership transitions and coresidence with extended kin." Findings from this chapter suggest that unmarried mothers versus married mothers are significantly more likely to coreside with extended kin, especially early in their children's lives. In other words, mothers often seek “temporary refuge" with extended kin during relationship changes. The majority of mothers lived in their own homes versus extended kin homes; however, this finding is likely attributed to the fact that more than half of the mothers in the sample were married. When examining unmarried mothers alone, they are significantly more likely to live in 
extended kin homes than their own homes. However, by year 9, unmarried mothers are significantly more likely to live elsewhere — either with friends or in temporary shelters. Thus, reliance on extended kin appears to weaken over time, which may be the result of mothers experiencing more stress when living with family, or it may be because mothers have exhausted the resources available to them from extended kin. Race is a more significant predictor of extended kin coresidence than socioeconomic status, with significant associations between Hispanic and mothers who self-identify as "other" races and extended kin coresidence. Importantly, this study finds that money is not the only significant factor among families who double up; rather, mothers turn to family members during transitional times.

Turning to findings from chapter four, "Nest effects: How children fare when changes occur within their mesosystems," extended kin mediate the association between mothers' relationship transitions when mothers consistently cohabit, when they transition from cohabiting relationships to being single, and when they are consistently single. Although extended kin coresidence appears to increase both internalizing and externalizing behaviors, they do buffer children from instability caused by fathers' incarceration or mothers' new multipartnered fertility. In other words, extended kin may offer resources (e.g., attention) to children when their parents are distracted or absent.

Children who interact with nonresident fathers show fewer internalizing and externalizing behaviors. Indeed, children who visit fathers and who benefit from fathers' child support payments fare better than children who do not. Race and education appear to moderate the association between family structure transitions and child wellbeing. For nonwhite children, living with extended kin and mothers' relationship transitions increase 
children's internalizing and externalizing behaviors. On the other hand, if nonwhite children live with extended kin, but their parents do not experience a transition, extended kin do not influence externalizing behaviors. Mothers' education levels influence child wellbeing; however, for the lowest educated mothers with no transitions, extended kin coresidence appears to buffer children from externalizing, but not internalizing behaviors. Overall, the children of mothers with less education, net of extended kin coresidence and transitions, are more likely than higher educated mothers to show internalizing and externalizing behaviors.

What do these findings mean in terms of policy recommendations? First, given that there is evidence of a "new package deal," policymakers should focus their efforts on the coparental relationship, rather than the parental bond. Findings from Chapter II suggest that parents—-both mothers and fathers—are committed to their children. However, understanding that fragile families are at a greater risk of breaking up, efforts to ensure that parents can continue to coparent their shared children if they experience a break up may be more beneficial to child wellbeing, particularly given that research suggests that positive coparenting is good for children.

Turning to parents who do experience a break up, findings from Chapters III and IV suggest that secure, stable, affordable housing may lead to better outcomes for both parents and children. Findings show that mothers reduce their reliance on extended kin, but increase their likelihood to live "elsewhere" (e.g., temporary shelters, with friends) by the time their children are age 9-outcomes that are likely linked to both mothers experiencing more stress and depression when they coreside with extended kin (Osborne et al. 2012) and children's increased expression of internalizing and externalizing 
behaviors. Although mothers may not remain in stable partnerships, offering mothers and their children stable housing will decrease the magnitude of change they experience when mothers begin and end new partnerships. Moving, in general, is stressful. However, moving in with extended kin, friends, or into temporary shelters will require families to make adjustments as they concurrently adapt to other changes (e.g., the loss of a social father or partner, loss of neighborhood connections if the family had to move); whereas mothers and children who can remain in their own homes will only need to adjust to system exits (e.g., a social father moving out). Further, offering housing assistance to mothers and their children will likely decrease the strain on both family and friends that are linked to families in transition. As Harknett and Knab (2007) pointed out, it is possible that families experience "network fatigue"; thus, policies that fall short of helping families meet their needs are: 1) assuming that personal safety networks exist and are available, and 2) exacerbating mothers' and children's instability by forcing them to find refuge that may be short-term and unsafe.

Further, there are possibilities of Type I errors in all three papers. In other words, there is a chance that significant findings between my independent and dependent variables are not true relationships. However, given that previous research shows that the coparental relationship is often contingent on the parental bond (Cooper et al. 2015), I feel confident that the findings in Chapter II showing a relationship between coparenting and parental commitment are replicable. In terms of Chapter III, doubling up scholarship focuses on economic factors; however, families in transition are likely to rely on their extended kin networks for more than financial help. Research suggests that extended kin may offer families "temporary refuge" (Edin and Kefalas 2005), particularly after a 
"shock" (Pilkauskas 2012). Relationship transitions may be considered "shocks" that necessitate temporary housing. Lastly, findings from Chapter IV suggest that extended kin coresidence exacerbates child wellbeing outcomes. Understanding that previous research shows that mothers who experience a break up experience greater material hardship and psychological distress (Osborne et al. 2012). Further, research suggest that mothers who live, even temporarily, with extended kin adopt harsher parenting (McLanahan 2011) —all of which put children at risk of faring worse within these contexts. Therefore, I am confident that my findings could be replicated given the overall consistency with prior theory and empirical research.

\section{Connections between the Papers}

Consistent with prior research, relationship status is an important indicator for coparenting relationships (see Fagan and Palkovitz 2011), doubling up (Pilkauskas et al. 2014), and child outcomes (Lee and McLanahan 2015). There is evidence that a "new package deal" exists. Parents appear to be more dedicated to their children than to each other; however, the coparental relationship influences parental commitment for coresiding parents five years after the children's births. Perhaps, then, parents who maintain relationships for their children (and not initially for each other) may not be as romantically engaged as parents who were intentionally dedicated (i.e., committed) to each other from the start of the relationship. This may explain why children's internalizing and externalizing behaviors increase when mothers move in with, or marry, biological fathers-extended kin's presence does not mediate these associations. Children 
may be aware of the insecure relationship bond between their parents, despite their strong coparental bond.

On the other hand, parents who live together for coparenting reasons, rather than out of dedication to each other, may centralize children within families, or put their needs first. What happens if parents do become committed to each other? Research suggests when mothers and nonresident fathers transition into romantic relationships, the coparenting relationship often suffers, as fathers no longer have to negotiate access to their children (Fagan and Palkovitz 2011). Therefore, parents may prioritize their relationship, even briefly, over the children's needs, which may cause children to withdraw or act badly. Interestingly, children's externalizing behaviors significantly decrease when mothers transition into marriages with new partners. Extended kin coresidence, however, does attenuate the association between mothers' new marriages and children's externalizing behaviors; thus, suggesting that as mothers commit to new relationships, extended kin may be there for children in ways that mothers may not be. McLanahan (2004) argues that children reared in stable, two-parent households fare better than children reared in other contexts, and this argument is supported by the findings in this dissertation. But, findings from all three of the quantitative studies provide evidence that McLanahan's (2004) argument holds for parents and their extended families. In other words, marriage protects parents, their relationships with each other, and relationships with others (e.g., extended kin). For instance, commitment among married couples is not likely continuously evaluated, as commitment is implied by the marriage itself. Yes, married parents are likely to have hiccups; however, their commitment to each other is often formed prior to the birth of children and, therefore, 
their other shared relationships (e.g., coparental) are not contingent on their ability to get along. However, commitment between unmarried parents is tenuous and, based on findings in Chapter Two, appears to be derived from their shared children. In other words, their partnerships are linked to their coparental relationships-which often means that if parents break up, one parent (typically fathers) is at risk of losing both relationships. Marriage, then, offers protected access to children.

Also, previous research suggests that marriage protects spouses from interfering family members (Cherlin and Furstenberg 1986). Even so, mothers turn to extended kin during transitional times, particularly when their children are young (Pilkauskas et al. 2014). Over time, this may strain mothers' relationships with extended kin, particularly when they experience multiple transitions (i.e., they may seek support more frequently). When extended kin interfere in mothers' relationships, it may be that they are protecting themselves (in addition to their children and grandchildren) from giving more support. In other words, if mothers' partnerships provide support to them, this may also reduce the likelihood that mothers will seek support from extended kin. Thus, extended kin may also benefit when mothers have supportive partners.

However, extended kin interference (or presence) does matter when significant changes occur within children's mesosytems. For example, when fathers are incarcerated or when mothers engage in new multipartnered fertility, children benefit from extended kin coresidence. Again, this finding is likely linked to resources, such as attention given to children. However, this finding may be connected to financial hardship. It is possible that mothers who are married to incarcerated men, especially recently incarcerated men, need to supplement lost income. Extended kin coresidence may mean more child care for 
mothers, or that older children may be less likely to engage in risky behaviors when more adults (e.g., maternal grandmothers) are present. Children may benefit from sustained interaction with extended kin. That is, children may be less likely to get depressed or experience anxiety when their mothers are absent (e.g., working or spending time with new romantic partners). But, when mothers have another child, existing children may also experience an increase in financial hardship, as resources would be distributed across more members within the family system. Extended kin may also provide financial support during these times, particularly if mothers are strapped financially with the birth of a new child.

\section{Contribution to the literature}

The three quantitative papers within this dissertation contribute to family scholarship, particularly fragile family literature. Chapter two provides information about unmarried parents from a perspective that is not often explored (if explored at all). That is, rather than investigating what happens after parents break up, chapter two examines why unmarried parents stay together. Understanding why parents break up is important, but analyzing why parents stay together could inform policies that could help other families stay together. The other two papers examine family instability; however, each paper investigates the prevalence of extended kin involvement, which Cherlin (2010) argues may become more important over time. Importantly, both papers on extended kin involvement show that extended kin appear to make things worse-which could have serious long-term implications for families. Residential instability is a serious social problem (Desmond 2016), coupled with the possibility that extended kin networks are 
weakening and sometimes problematic for child wellbeing, findings from these two papers underscore the importance of affordable housing. Over time patterns of family formation and parenting have changed dramatically, and it may be that these changes have influenced (potentially negatively) the composition and availability of informal social safety nets (e.g., personal supportive networks). Findings from these studies suggest that real policy efforts need to be developed in order to address the needs of changing families.

\section{Overarching limitations}

The Fragile Families and Child Wellbeing Study focuses on unmarried couples who live in cities. Although these data enriched our understanding of the prevalence and hardships of urban fragile families, the data do not capture potential variation between urban and rural fragile families. Fragile families, regardless of geography, are likely facing similar circumstances (e.g., loss of industries within their local communities). However, because my research interest focuses on extended kin involvement/coresidence, limiting data collection to only urban areas may underestimate the importance of extended kin within fragile families. Martin and Martin (1978) warned decades ago that cities may break down extended kin networks. In other words, cities tend to be too large and complicated to maintain extended kin networks (e.g., people often leave extended family to move to cities); thus, relationships with other network members (e.g., fictive kin/friends), and in many ways, replace family members (McDonald and Armstrong 2001). Geographic isolation in rural areas often means that people rely exclusively on their kin, as they may be the only accessible relationships. 
The dissertation is further limited in that each chapter relies on maternal reports of coparenting, parental commitment, extended kin coresidence, and child wellbeing. Although, I did do sensitivity analyses to examine whether fathers' reports of coparenting and parental commitment were consistent with mothers', and they were. Excluding father reports from analyses may not necessarily bias the results in these studies. Even so, due to social desirability, mothers may exaggerate the strength of both the coparenting relationship and parental commitment, as they may think that researchers who study families assume that these relationships are vitally important for child outcomes. In addition, mothers may under-report children's internalizing and externalizing behaviors, as mothers may interpret these behaviors as reflecting poorly on their parenting. Further, extended kin coresidence may be underreported, as mothers may feel that successful mothering is linked to their ability to maintain independent households.

Also, extended kin coresidence may be temporary given that, even amid transitions between partnerships, kin coresidence may increase mothers' stress. The difference between changes in extended kin coresidence and changes in partnership coresidence is that extended kin may be more likely to return to the household. Along similar lines, another limitation is that those who report being homeless may not actually be homeless, and they may coreside with extended kin. Indeed, in another project (Williams 2016), I find that mothers often consider themselves to be homeless when, in fact, they live with extended kin. To the extent that this is true, findings in this dissertation may underestimate mothers' coresidence with extended kin. 


\section{Future Research}

My future research will include using the Fragile Families and Child Wellbeing Study to extend my work on mothers' relationship transitions, extended kin involvement/coresidence, and child wellbeing. Specifically, I want to investigate the association between mothers' social support (e.g., support from both extended and fictive kin) and coparental trajectories. If mothers' extended kin are more likely to meddle in their romantic partnerships, and this places those partnerships at risk (e.g., Högnäs and Carlson 2010), then the coparenting relationship may also be at risk.

Further, I want to explore the mechanisms underlying the movement of extended kin into mothers' homes, and the prevalence of mothers moving in with friends. Perhaps extended kin move into mothers' homes to provide child care or as emotional support mechanisms. Moreover, I would like to examine more closely different specific kin ties, including siblings, as lateral extended kin networks may be increasingly common (Mollborn et al. 2011). If extended kin networks weaken over time (Collins 2000), which was supported by findings in chapters two and three, it is important to determine if others step in. In addition, I want to explore child wellbeing within the context of father-headed households. I am particularly interested in the (potential) differences between children visiting mothers versus children visiting fathers.

Lastly, I am interested in exploring the associations between mothers' relationship transitions, extended kin coresidence, and child wellbeing using data from the children themselves. Although the codebook for the 15-year data has not been released, the FFCWS website does indicate that teens were asked about their family relationships 
(http://www.fragilefamilies.princeton.edu/documentation/year15). Exploring the data from the perspective of teen-age children is an exciting prospect.

\section{Exploring Fragile Families in Rural Settings}

While emphasis on urban fragile families has significantly improved our understanding of disadvantaged families, the extant literature has not addressed nonmarital childbearing in geographically-isolated areas. Therefore, my long-term research goal is to broaden analyses of fragile families to rural areas. Rural families face unique challenges—-limited access to valuable resources (e.g., healthcare, education)— that increase their reliance on extended kin to meet their needs. Indeed, since 2006, the number of grandmothers who serve as primary caregivers of children in West Virginia (WV) increased by 25\% (Pratt et al. 2013). Further, rural families are often enmeshed in and reliant upon family networks for caregiving, particularly when drugs are involved (Barnard 2003; Bigbee et al. 2010; Lee et al. 2016) —a finding that suggests extended kin networks serve more purposes than simply "doubling up" out of economic necessity (Pilkauskas et al. 2014).

Specifically, I would focus my research efforts on McDowell County, WV, an area that has suffered significant economic loss over the last half-century due to coal mining closures. Nearly three-fourths of the county's school-aged children are reared in households with no consistent income — an artifact of both the collapsed industry and, arguably, parental substance abuse. Indeed, West Virginia ranks third for the most prescribed opioids in the country (http://www.cdc.gov/vitalsigns/opioidprescribing/index.html), with McDowell County leading "the nation in overdose deaths 
from narcotic pain medications" (www.ReconnectingMcDowell.org). Further, rural versus urban families are much more likely to share prescribed drugs with "nonmedical users," including children (Keyes et al. 2014). Children in rural areas, then, are vulnerable to the drug culture, due to easy access and the lack of alternate means of recreation - all of which increases the propensity for children to experiment with harsher drugs (e.g., heroin), drop out of high school, and engage in risky behaviors (e.g., early entrance into sexual activity) (Keyes et al. 2014; Pilkauskas et al. 2014). Understanding that McDowell County had 29 teacher vacancies during the 2011-12 academic year, the likelihood that students will not finish high school is high, which may, in turn, increase these risk factors.

High rates of unemployment and substance abuse in McDowell County likely contribute to the increase in grandparents serving as primary caregivers to their grandchildren - a phenomenon that merits investigation. Research shows that grandparents who assume grand-childrearing roles buffer the effects of instability caused by parental drug use on child wellbeing (Barnard 2003). However, Barnard (2003) found that Scottish grandparents who provide instant, around-the-clock care for grandchildren may (unintentionally) encourage parental drug use - an outcome that would be worth exploring in rural areas of the United States. Further, grand-caregiving roles often mean that grandparents experience more financial hardships and diminished physical and mental health (Bigbee et al. 2010), as their care likely operates outside formal care networks and without financial assistance associated with welfare programs (Pilkauskas et al. 2014). 
As is the case for urban fragile families, I suspect that rural families face significant instability, where marcrolevel factors (e.g., loss of industry, languishing educational system) influence microlevel processes (e.g., nonmarital childbearing, extended kin networks, drug dependency). As a result, there are likely: 1) significant rates of nonmarital childbearing in rural areas; and 2) grandparents engaged in sustained care or "care churning," meaning that grandparents care for children during parents' bouts with substance abuse, the criminal justice system, and recovery—all of which are subject to repetition. These caring relationships may necessitate grandparents to be available with little to no negotiation. Given that age at mortality in McDowell County is the lowest in the nation for men (64 versus 82 years) and second to last for women (73 versus 85 years) (Wang et al. 2013), children may lose both their parents and other stable caregivers at an early age — which could exacerbate their own long-term financial hardships and (potential) drug dependency. Thus, it is important to explore the mechanisms that hinder these families and provide data to policymakers that may address the specific needs of rural families. Examining how rural fragile families differ from urban fragile families will not only expand my knowledge of disadvantaged families, but stands to make a unique contribution to the literature. 


\section{REFERENCES}

Acock, Alan C. 2013. Discovering Structural Equation Modeling Using Stata. Revised ed. College Station, TX: A Stata Press Publication.

Allison, Paul D. 2003. "Missing data techniques for structural equation modeling." Journal of Abnormal Psychology 112(4): 545-557.

Amato, Paul R. 2000. "The consequences of divorce for adults and children." Journal of Marriage and Family 62 (4): 1269-1287.

Amato, Paul R. and Joan G. Gilbreth. 1999. "Nonresident fathers and children's wellbeing: A meta-analysis." Journal of Marriage and Family 61(3): 557-573.

Amato, Paul R. 2005. "The impact of family formation change on the cognitive, social, and emotional well-being of the next generation." The Future of Children 15 (2): 75-96.

Aquilino, William S. 1990. "The likelihood of parent-adult child coresidence: Effects of family structure and parental characteristics." Journal of Marriage and Family 52: 405-419.

Barnard, Marina. 2003. "Between a rock and a hard place: The role of relatives in protecting children from the effects of parental drug problems." Child and Family Social Work 8: 291-299.

Baydar, Nazli and Jeanne Brooks-Gunn. 1998. "Profiles of Grandmothers who help care for their grandchildren in the United States." Family Relations 47 (4): 385-393.

Belsky, Jay and Kuang-Hua Hsieh. 1998. "Patterns of marital change during the early childhood years: Parent personality, coparenting, and division-of-labor correlates." Journal of Family Psychology 12 (4): 511-528.

Bengston, Vern L. and Katherine R. Allen. 1993. "The Life Course Perspective applied to families over time." Pp. 469-498 in Sourcebook of Family Theories and Methods: A Contextual Approach, edited by P.G. Boss, W.J. Doherty, R. LaRossa, W.R. Schumm, and S.K. Steinmetz. New York, NY: Springer.

Bigbee, Jeri L, Carol Musil, and Diane Kenski. 2010. "The health of caregiving grandmothers: A rural-urban comparison.” The Journal of Rural Health 27: 289296.

Bonds, Darya D. and Dawn M. Gondoli. 2007. "Examining the process by which marital adjustment affects maternal warmth: The role of coparenting support as a mediator." Journal of Family Psychology 21 (2): 288-296.

Bronfenbrenner, Urie. 1974. "Developmental research, public policy, and the ecology of childhood." Child Development 45 (1): 1-5.

Bronfenbrenner, Urie. 1977. "Toward an experimental ecology of human development." American Psychologist 32(7): 513-531. 
Bronfenbrenner, Urie. 1995. "Developmental ecology through space and time: A future perspective." Pp. 619-647 in Examining Lives in Context: Perspectives on the Ecology of Human Development, edited by P. Moen, G.H. Elder, Jr., and K. Lüscher. Washington, DC: American Psychological Association.Bronte-Tinkew, Jacinta and Allison Horowitz. 2010. "Factors associated with unmarried, nonresident fathers' perceptions of their coparenting." Journal of Family Issues 31 (1): 31-65.

Bronte-Tinkew, Jacinta and Allison Horowitz. 2010. "Factors associated with unmarried, nonresident fathers' perceptions of their coparenting." Journal of Family Issues 31 (1): 31-65.

Brown, Susan I. 2005. "How cohabitation is reshaping American families." Contexts 4 (3): 33-37).

Bumpass, Larry L. 1990. "What's happening to the family? Interactions between demographic and institutional change." Demography 27 (4): 483-498).

Bzostek, Sharon H., Sara S. McLanahan, and Marcia J. Carlson. 2012. "Mothers' repartnering after a nonmarital birth." Social Forces 90 (3): 817-841.

Byrne, Barbara M. 2010. Structural Equation Modeling with AMOS: Basic Concepts, Applications, and Programming. $2^{\text {nd }}$ ed. New York, NY: Routledge.

Cancian, Maria, Daniel Meyer, and Eunhee Han. 2011. "Child support: Responsible fatherhood and the quid pro quo." The ANNALS of the American Academy of Political and Social Science 635: 140-62.

Cancian, Maria, Daniel R. Meyer, and Steven T. Cook. 2011. "The evolution of family complexity from the perspective of nonmarital children." Demography 48: 957982.

Carlson, Marcia J. and Frank F. Furstenberg, Jr. 2006. "The prevalence and correlates of multipartnered fertility among urban U.S. parents." Journal of Marriage and Family 68: 718-732.

Carlson, Marcia J., Sara S. McLanahan, and Jeanne Brooks-Gunn. 2008. “Coparenting and nonresident fathers' involvement with young children after a nonmarital birth." Demography 45 (2): 461-488.

Carlson, Marcia J. and Sara S. McLanahan. 2010. "Fathers in fragile families." Pp. 241269 in M. E. Lamb (Ed.), The role of the father in child development $\left(5^{\text {th }} \mathrm{ed}\right.$.). New York: Wiley \& Sons.

Carlson, Marcia and Paula England. 2011. Social Class and Changing Families in an Unequal America. Stanford, CA: Stanford University Press.

Casper, Lynne M. and Suzanne M. Bianchi. 2002. Continuity \& Change in the American Family. Thousand Oaks, CA: Sage.

Centers for Disease Control and Prevention. 2016. "Opioid Painkiller Prescribing." Retrieved November 22, 2016 (http://www.cdc.gov/vitalsigns/opioidprescribing/index.html).

Cherlin, Andrew J. and Frank F. Furstenberg, Jr. 1986. The New American Grandparent: A Place in the Family, A Life Apart. Cambridge, Massachusetts: Harvard University Press.

Cherlin, Andrew J. 2009. The Marriage-Go-Round: The State of Marriage and the Family in America Today. New York, NY: Vintage Books. 
Cherlin, Andrew J. 2010. "Demographic trends in the United States: A review of research in the 2000s." Journal of Marriage and Family 72: 403-419.

Choi, Jeong-Kyun and Ho-Soon Pyun. 2013. "Nonresident fathers' financial support, informal instrumental support, mother's parenting, and child development in single-mother families with low-income.” Family Issues 35 (4): 526-546.

Christopher, Caroline, Tomo Umemura, Tanya Mann, Deborah Jacobvitz, and Nancy Hazen. 2015. "Marital quality over the transition to parenthood as a predictor of coparenting." Journal of Child Family Studies 24: 3636-3651.

Collins, Patricia Hill. 2000. Black Feminist Thought. New York, NY: Routledge.

Cooper, Carey E., Audrey N. Beck, Robin S. Högnäs, and Jodi Swanson. 2015. "Mothers' partnership instability and coparenting among fragile families." Social Science Quarterly 96 (4): 1103-1116.

Cooper, Carey E., Sara S. McLanahan, Sarah O. Meadows, and Jeanne Brooks-Gunn. 2009. "Family Structure Transitions and Maternal Parenting Stress." Journal of Marriage and Family 71: 558-574.

Cooper, Carey E., Cynthia A. Osborne, Audrey N. Beck, and Sara S. McLanahan. 2011. "Partnership instability, school readiness, and gender disparities." Sociology of Education 84(3): 246-259.

Crosnoe, Robert and Glen H. Elder, Jr. 2002. "Life Course Transitions, the generational stake, and grandparent-grandchild relationships." Journal of Marriage and Family 64: 1089-1096.

DeLeire, Thomas and Ariel Kalil. 2002. "Good things come in threes: Single-parent multigenerational family structure and adolescent adjustment." Demography 39(2): 393-413.

Desmond, Matthew. 2016. Evicted: Poverty and Profit in the American City. New York, NY: Crown Publishers.

Desmond, Matthew, Carl Gershenson, and Barbara Kiviat. 2015. "Forced relocation and residential instability among urban renters." Social Service Review 89 (2): 227262.

Dunifon, Rachel E., Kathleen M. Ziol-Guest, and Kimberly Kopko. 2014. "Grandparent coresidence and family well-being: Implications for research and policy." The ANNALS of the American Academy of Political and Social Science 654: 110-126.

Edin, Kathryn and Laura Lein. 1997. Making Ends Meet: How Single Mothers Survive Welfare and Low-Wage Work. New York, NY: Russell Sage Foundation.

Edin, Kathryn and Maria Kefalas. 2005. Promises I Can Keep: Why Poor Women Put Motherhood before Marriage. Berkeley, CA: University of California Press.

Edin, Kathryn and Timothy J. Nelson. 2013. Doing the Best I Can: Fatherhood in the Inner City. Berkeley, CA: University of California Press.

Edin, Kathryn J. and H. Luke Shaefer. 2015. \$2.00 a Day: Living on almost nothing in America." New York, NY: Houghton Mifflin Harcourt.

Elder, Glen H., Jr. 1977. "Family History and the Life Course." Journal of Family History 2 (4): 279-304.

Elder, Glen H., Jr. 1998. "The Life Course as developmental theory.” Child Development 69 (1): 1-12. 
Elder, Jr., Glen H., Monica Kirkpatrick Johnson, and Robert Crosnoe. 2003. "The emergence and development of life course theory." Handbook of the life course," edited by J.T. Mortimer \& M.J. Shanaha. New York, NY: 3-19.

Fagan, Jay and Rob Palkovitz. 2011. "Coparenting and relationship quality effects on father engagement: Variations by residence, romance." Journal of Marriage and Family 73: 637-653.

Fitch, Catherine A. and Steven Ruggles. 2000. "Historical trends in marriage formation: The United States 1850-1990.” Pp. 59-88 in The Ties that Bind: Perspectives on Marriage and Cohabitation, edited by L.J. Waite, C. Bachrach, M. Hindin, E. Thomson, and A. Thornton. New York, NY: Aldine de Gruyter.

Fomby, Pamela and Andrew J. Cherlin. 2007. "Family Instability and Child Well-Being." American Sociological Review 72 (2): 181-204.

Fragile Families and Child Wellbeing Study. 2017. "About the Fragile Families and Child Wellbeing Study." Retrieved on March 31, 2017 :

(http://www.fragilefamilies.princeton.edu/about).

Fragile Families and Child Wellbeing Study. 2017. "General Documentation.” Retrieved on March 31, 2017: (http://www.fragilefamilies.princeton.edu/documentation/general).

Fragile Families and Child Wellbeing Study. 2017. "Funders." Retrieved on March 31, 2017: (http://fragilefamilies.princeton.edu/about/funders).

Fragile Families and Child Wellbeing Study. 2017. "Year 15.” Retrieved April 3, 2017 (http://www.fragilefamilies.princeton.edu/documentation/year15).

Furstenberg, Frank F., Jr. 2003. "Teenage childbearing as a public issue and private concern." Annual Review of Sociology 29: 23-39.

Geller, Amanda, Carey E. Cooper, Irwin Garfinkel, Ofira Schwartz-Soicher, and Ronald B. Mincy. 2012. "Beyond absenteeism: Farther incarceration and child development." Demography 49: 49-76.

Gibson-Davis, Christina M., Kathryn Edin, and Sara McLanahan. 2005. "High hopes but even higher expectations: The retreat from marriage among low-income couples." Journal of Marriage and Family 67(5): 1301-1312.

Goldberg, Julia S. 2015. "Coparenting and nonresident fathers' monetary contributions to their children." Journal of Marriage and Family 77: 612-627.

Goldberg, Julia S. and Marcia J. Carlson. 2015. "Patterns and predictors of coparenting after unmarried parents part." American Psychological Association 29 (3): 416426.

Harknett, Kristen and Jean Knab. 2007. "More kin, less support: Multipartnered fertility and perceived support among mothers." Journal of Marriage and Family 69: 237253.

Harknett, Kristen S. and Caroline Sten Hartnett. 2011. "Who lacks support and why? An examination of mothers' personal safety nets." Journal of Marriage and Family 73: 861-875.

Haxton, Clarisse L. and Kristen Harknett. 2009. "Racial and gender differences in kin support: A mixed-methods study of African American and Hispanic Couples." Journal of Family Issues 30 (8): 1019-1040.

Herzog, Melissa J., Adriana J. Umana-Taylor, Debra A. Madden-Derdich, and Stacie A. Leonard. 2007. “Adolescent mothers' perceptions of fathers' paternal 
involvement: Satisfaction and desire for involvement." Family Relations 56: 244257.

Högnäs, Robin. 2010. "A mechanism describing how low-income women exchange support in their personal networks." Sociological Focus 43 (4): 330-348.

Högnäs, Robin and Marcia Carlson. 2010. "Intergenerational relationships and union stability in fragile families." Journal of Marriage and Family 72 (1220-1233).

Högnäs, Robin and Marcia Carlson. 2012. "Like parent, like child?: The intergenerational transmission of nonmarital childbearing." Social Science Research 41: 14801494.

Högnäs, Robin and Jason R. Thomas. 2016. "Birds of a feather have babies together?: Family structure homogamy and union stability among cohabiting parents." Journal of Family Issues 37 (1): 29-52.

Jackson, Aurora P. 1998. "The Role of Social Support in Parenting for Low-Income, Single, Black Mothers.” Social Service Review 72 (3): 365-378.

Jackson, Aurora P., Kathleen S. J. Preston, and Crystal A. Thomas. 2013. "Single Mothers, Nonresident Fathers, and Preschoolers' Socioemotional Development: Social Support, Psychological Well-Being, and Parenting Quality." Journal of Social Service Research 39: 129-140.

Jones, Deborah J. and Kristin M. Lindahl. 2011. "Coparenting in extended kinship systems: African American, Hispanic, Asian Heritage, and Native American Families." Pp. 61-80 in Coparenting: A conceptual and clinical examination of family systems, edited by J.P. McHale and K.M. Lindahl. Washington, D.C.: American Psychological Association.

Kamp Dush, Claire M., Letitia E. Kotila, and Sarah J. Schoppe-Sullivan. 2011. "Predictors of supportive coparenting after relationship dissolution among at-risk parents." American Psychological Association 25 (3): 356-365.

Keyes, Katherine M., Magdalena Cerda, Joanne E. Brady, Jennifer R. Havens, and Sandro Galea. 2014. "Understanding the rural-urban differences in nonmedical prescription opioid use and abuse in the United States." American Journal of Public Health 4 (2): e52-e59.

Lee, Dohoon and Sara McLanahan. 2015. "Family structure transitions and child development: Instability, selection, and population heterogeneity." American Sociological Review 80(4): 738-763.

Lee, Eunju, Michael Clarkson-Hendrix, and Yeonggeul Lee. 2016. "Parenting stress of grandparents and other kin as informal kinship caregivers: A mixed methods study." Children and Youth Services Review 69: 29-38.

Lindahl, Kristin M., Mari Clements, and Howard Markman. 1997. "Predicting marital and parent functioning in dyads and triads: A longitudinal investigation of marital processes." Journal of Family Psychology 11 (2): 139-151.

Magnuson, Katherine and Lawrence M. Berger. 2009. "Family structure states and transitions: Associations with children's well-being during middle childhood." Journal of Marriage and Family 71(3): 575-591.

Mangelsdorf, Sarah C., Daniel J. Laxman, and Allison Jessee. 2011. "Coparenting in two-parent nuclear families." Pp. 39-59 in Coparenting: A conceptual and clinical examination of family systems, edited by J.P. McHale and K.M. Lindahl. Washington, DC: American Psychological Association. 
Manning, Wendy and Pamela J. Smock. 2000. "'Swapping' families: Serial partnering and economic support for children." Journal of Marriage and Family 62: 111122.

Mare, Robert D. 1991. "Five decades of assortative mating." American Sociological Review 56 (1): 15-32.

Margolin, Gayla, Elana B. Gordis, and Richard S. John. 2001. "Coparenting: A link between marital conflict and parenting in two-parent families." Journal of Family Psychology 15 (1): 3-21.

Martin, Elmer P. and Joanne Mitchell Martin. 1978. The Black Extended Family. Chicago, IL: The University of Chicago Press.

Martin, Joyce A., Brady E. Hamilton, Michelle J.K. Osterman, Sally C. Curtin, and T.J. Mathews. 2013. "Births: Final Data for 2012." National Vital Statistics Reports 62 (9): 1-87.

Martin, Anne, Rebecca M. Ryan, Elizabeth M. Riina, and Jeanne Brooks-Gunn. 2015. "Coresidential father transitions and biological parents' coparenting quality in early and middle childhood." Journal of Family Issues.

Mazelis, Joan Maya and Laryssa Mykyta. 2011. "Relationship status and activated kin support: The role of need and norms." Journal of Marriage and Family 73: 430445.

McCoach, D. Betsy. 2010. "Hierarchical Linear Modeling." Pp. 123-140 in The Reviewer's Guide to Quantitative Methods in the Social Sciences, GR Hancock \& RO Mueller. New York, NY: Routledge.

McDonald, Katrina Bell and Elizabeth M. Armstrong. 2001. "De-Romanticizing Black Intergenerational Support: The Questionable Expectations of Welfare Reform." Journal of Marriage and Family 63: 213-223.

McHale, James P. and Karina Irace. 2012. "Coparenting in diverse family systems." Pp. 15-38 in Coparenting: A conceptual and clinical examination of family systems, edited by J.P. McHale and K.M. Lindahl. Washington, D.C.: American Psychological Association.

McLanahan, Sara and Larry Bumpass. 1988. "Intergenerational consequences of family disruption." American Journal of Sociology 94 (1): 130-152.

McLanahan, Sara. 2004. "Diverging destinies: How children are faring under the second demographic transition.” Demography 41(4): 607-627.

McLanahan, Sara. 2011. "Family instability and complexity after a nonmarital birth: Outcomes for children in fragile families." Pp. 108-133 in Social Class and Changing Families in an Unequal America, edited by M.J. Carlson and P. England. Stanford, CA: Stanford University Press.

Meadows, Sarah O. 2011. "The association between perceptions of social support and maternal mental health: A cumulative perspective." Journal of Family Issues 32 (2): 181-208.

Merrifield, Kami A. and Wendy C. Gamble. 2012. "Associations among marital qualities, supportive and undermining coparenting, and parenting self-efficacy: Testing spillover and stress-buffering processes." Journal of Family Issues 34 (4): 510533. 
Meyer, Daniel and Maria Cancian. 2012. "'I'm not supporting his kids': Nonresident fathers' contributions given mothers' new fertility." Journal of Marriage and Family 74 (1): 132-151.

Mitchell, Colter, John Hobcraft, Sara S. McLanahan, Susan Rutherford Siegel, Arthur Berg, Jeanne Brooks-Gunn, Irwin Garfinkel, and Daniel Notterman. 2014. "Social disadvantage, genetic sensitivity, and children's telomere length." Proceedings of the National Academy of Science 111(16): 5944-5949.

Mitchell, Colter, Sara McLanahan, John Hobcraft, Jeanne Brooks-Gunn, Irvin Garfinkel, and Daniel Notterman. 2015. "Family instability, Genetic sensitivity, and child well-being." American Journal of Sociology 120(4): 1-31.

Mitchell, Joni. 1968. “The Circle Game.” New York, NY: Elektra Records.

Mitchell, Joni. 1971. "A Case of You.” Burbank, California: Reprise Records.

Mollborn, Stefanie, Paula Fomby, and Jeff A. Davis. 2011. "Who matters for Children's early development? Race/Ethnicity and extended household structures in the United States." Child Indicators Research 4 (3): 389-411.

Musick, Kelly, Paula England, Sarah Edgington, and Nicole Kangas. 2010. "Education differences in intended and unintended fertility." Social Forces 88 (2): 543-572.

Nepomnyaschy, Lenna and Julien Teitler. 2013. "Cyclical cohabitation among unmarried parents in fragile families." Journal of Marriage and Family 75 (5): 1248-1265.

Osborne, Cynthia and Sara McLanahan. 2007. "Partnership instability and child wellbeing." Journal of Marriage and Family 69 (4): 1065-83.

Osborne, Cynthia, Lawrence M. Berger, and Katherine Magnuson. 2012. "Family structure transitions and changes in maternal resources and well-being." Demography 49: 23-47.

Park, Jung Min, Teresa Ostler, and Angela Fertig. 2015. "Physical and Psychological Aggression Toward a Child Among Homeless, Doubled-Up, and Other LowIncome Families." Journal of Social Service Review 41: 413-423.

Pilkauskas, Natasha V. 2012. "Three-Generation Family Households: Differences By Family Structure at Birth.” Journal of Marriage and Family 74: 931-943.

Pilkauskas, Natasha V., Irwin Garfinkel, and Sara S. McLanahan. 2014. "The prevalence and economic value of doubling up." Demography 51: 1667-1676.

Pratt, Julie, Ted Boettner, Stuart Frazier, Stephen Smith, and Renate Pore. 2013. "Child Poverty in West Virginia: A growing and persistent problem." Retrieved November 15, 2016 (http://www.legis.state.wv.us/senate1/majority/poverty/WV\%20Child\%20Poverty \%20Report\%20February\%2019\%202013\%20WVCBP\%20$\% 20$ Ted\%20Boettner.pdf).

Rabe-Hesketh, Sophia and Anders Skrondal. 2012. Multilevel and Longitudinal Modeling Using Stata. Volume I: Continuous Responses. $3^{\text {rd }}$ ed. College Station, TX: Stata Press.

Radey, Melissa and Yolanda C. Padilla. 2009. "Kin financial support: Receipt and provision among unmarried mothers." Journal of Social Service Research 35: 336-351.

Reconnecting McDowell. "Reconnecting McDowell.” Retrieved on November 15, 2016. (www.ReconnectingMcDowell.org). 
Reed, Joanna M. 2006. "Not Crossing the 'Extra Line': How cohabitors with children view their unions." Journal of Marriage and Family 68: 1117-1131.

Reichman, Nancy, Julien Teitler, Irwin Garfinkel, and Sara McLanahan. 2001. "Fragile Families: Sample and Design." Children and Youth Services Review 23 (4/5): 303-326.

Rhoades, Galena K., Scott M. Stanley, and Howard J. Markman. 2010. "Should I stay or should I go?: Predicting dating relationship stability from four aspects of commitment." Journal of Family Psychology 24 (5): 543-550.

Roschelle, Anne R. (1997). No More Kin: Exploring Race, Class, and Gender in Family Networks. Thousand Oaks, CA: Sage Publications.

Sano, Y., Richards, L. N. \& Zvonkovic, A. M. (2008). Are mothers really 'gatekeepers' of children?: Rural mothers' perceptions of nonresident fathers' involvement in low-income families. Journal of Family Issues, 29, 1701-1723.

Sarkisian, Natalia and Naomi Gerstel. 2004. "Kin Support among Blacks and Whites: Race and Family Organization." American Sociological Review 69: 812-837.

Schminkey, Donna L., Timo von Oertzen, and Linda Bullock. 2016. "Handling missing data with multilevel structural equation modeling and full information maximum likelihood techniques." Research in Nursing \& Health 39 (4): 286-297.

Schoppe-Sullivan, Sarah J., Sarah C. Mangelsdorf, Cynthia A. Frosch, and Jean L. McHale. 2004. "Associations between coparenting and marital behavior from infancy to the preschool years." Journal of Family Psychology 18 (1): 194-207.

Schwartz, Christine R. and Robert D. Mare. 2005. "Trends in educational assortative marriage from 1940 to 2003." Demography 42: 621-646.

Seltzer, Judith. 2000. "Families formed outside of marriage.” Journal of Marriage and Family 62(4): 1247-1268.

Shanahan, Michael J. 2000. "Pathways to adulthood in changing societies: Variability and mechanisms in life course perspective." Annual Review of Sociology 26: 667692.

Sigle-Rushton, Wendy and Sara McLanahan. 2004. "Father absence and child wellbeing: A critical review." Pp. 116-155 in The Future of the Family, edited by D.P. Moynihan, T.M. Smeeding, and L. Rainwater. New York: NY: Russell Sage Foundation.

Smeeding, Timothy M. Irwin Garfinkel, and Ronald B. Mincy. 2011. "Young disadvantaged men: Fathers, families, poverty, and policy." The ANNALS of the American Academy of Political and Social Science 635: 6-21.

Smock, Pamela J. 2000. "Cohabitation in the United States: An appraisal of research themes, findings, and implications." Annual Review of Sociology 26: 1-20.

Smock, Pamela J., Wendy D. Manning, and Meredith Porter. 2005. "'Everything's there except money': How money shapes decisions to marry among cohabitors." Journal of Marriage and Family 67 (3): 680-696.

Smock, Pamela J. and Wendy Manning. 2010. "New couples, new families: The cohabitation revolution in the United States.” Pp. 131-139 in Families as They Really Are, edited by B.J. Risman. New York, NY: W.W. Norton \& Company.

Stack, Carol. 1975. All Our Kin: Strategies for survival in a black community. New York, NY: Harper Colophone Books. 
Stanley, Scott M. and Howard J. Markman. 1992. "Assessing commitment in personal relationships." Journal of Marriage and Family 54: 595-608.

Stanley, Scott M., Galena K. Rhoades, and Sarah W. Whitton. 2010. "Commitment: Functions, and the securing of romantic attachment." Journal of Theory \& Review 2 (4): 243-257.

Stanley, Scott M., Galena Kline Rhoades, and Howard J. Markman. 2006: "Sliding versus deciding: Inertia and the premarital cohabitation effect." Family Relations 55: 499-509.

Surra, Catherine A. and Debra K. Hughes. 1997. "Commitment processes in accounts of development of premarital relationships.” Journal of Marriage and Family 59: 521.

Sweeney, Megan. 2010. "Remarriage and stepfamilies: Strategic sites for family scholarship in the $21^{\text {st }}$ Century." Journal of Marriage and Family 72 (3): 667-684.

Tach, Laura, Ronald Mincy, and Kathryn Edin. 2010. 'Parenting as a 'Package Deal': Relationships, fertility, and nonresident father involvement among unmarried parents." Demography 47 (1): 181-204.

Uhlenberg, Peter and Margaret Mueller. 2003. "Family context and individual wellbeing: Patterns and mechanisms in life course perspective." Pp. 123-149 in Handbook of the life course, edited by JT Mortimer \& MJ Shanahan. New York, NY: Springer.

US Census Bureau. 2015. "How the Census Bureau Measures Poverty." Retrieved September 27, 2015 (https://www.census.gov/hhes/www/poverty/about/overview/measure.html).

Wakschlag, Lauren S. and P. Lindsay Chase-Lansdale. 1996. "Not just 'ghosts in the nursery': Contemporaneous intergenerational relationships and parenting in young African-American families." Child Development 67(5): 2131-2147.

Waller, Maureen R. 2012. "Cooperation, conflict, or disengagement? Coparenting styles and father involvement in fragile families." Family Process 51 (3): 325-342.

Wang, Haidong, Austin E. Schumacher, Carly E. Levitz, Ali H. Mokdad, and Christopher JL Murray. 2013. "Left behind: Widening disparities for males and females in US county life expectancy, 1985-2010.” Population Health Metrics 11 (8): 1-15.

Western, Bruce, Deirdre Bloome, and Christine Percheski. 2008. "Inequality among American families with children, 1975 to 2005." American Sociological Review 73: 903-920.

Williams, Heidi M. In Progress. "Conceptualizing support: An analysis of social support from residentially secure, low-income, single mothers."

Wilson, Edward O. 2000. Sociobiology: The New Synthesis. $25^{\text {th }}$ Anniversary ed. Cambridge, MA: The Belknap Press of Harvard University Press.

Wu, Lawrence. 2008. "Cohort estimates of nonmarital fertility for U.S. women." Demography 45 (1): 193-207. 


\section{APPENDIX I CHILD WELLBEING MEASURES}

Externalizing Behaviors

Child can't concentrate, can't pay attention for long

Child is cruel to animals

Child is defiant

Child's demands must be met immediately

Child destroys his/her own things

Child destroys things belonging to his/her family or other children

Child is disobedient

Child does not seem to feel guilty after misbehaving

Child gets in many fights

Child physically attacks people

Punishment doesn't change child's behavior

Child screams a lot

Child is stubborn, sullen, or irritable

Child has sudden changes in mood or feelings

Child sulks a lot

Child has temper tantrums or a hot temper

Child is unusually loud

Child is whiny

Child argues a lot

Child is disobedient at home

Child is disobedient at school or in childcare

Child hangs out with others who get in trouble

\section{Child lies or cheats}

Child prefers being with other kids

Child refuses to talk

Child runs away from home

Child sets fires

Child steals at home

Child steals outside the home

Child is suspicious

Child swears or uses obscene language

Child teases a lot

Child threatens people

Child vandalizes

Child drinks alcohol without parents' approval

Child is cruel, bullies, or shows meanness to others

Child demands a lot of attention

Child breaks rules at home, school, or elsewhere

Child has sexual problems

Child thinks about sex too much

Child smokes, chews, or sniffs tobacco

Child is truant, skips school

Child uses alcohol or drugs for nonmedical purposes

Internalizing Behaviors

Child avoids looking others in the eye

Child cries a lot

Child clings to adults or is too dependent

Child gets too upset when separated from parents

Child is nervous, high strung, or tense

Child is self-conscious or easily embarrassed

Child shows little interest in things around him/her

Child is too shy or timid

Child is too fearful or anxious

Child is under active, slow moving, or lacks energy

Child is unhappy, sad, or depressed

Child is withdrawn, doesn't get involved with others

Child fears that he/she might think or do something bad

Child feels he/she has to be perfect
Child feels or complains that no one loves him/her

Child would rather be alone than with others

Child feels too guilty

Child refuses to talk

Child is secretive, keeps things to self

Child worries

There is very little child enjoys

Child fears certain animals, situations, or places, other than school

Child fears going to school

Child fears he or she might think or do something bad

Child fears he or she has to be perfect

Child feels or complains that no one loves him or her

Child feels worthless or inferior

Child talks about killing self 


\title{
CURRICULUM VITAE
}

\author{
Heidi Michele Williams \\ Department of Sociology \\ 103 Lutz Hall \\ University of Louisville \\ Louisville, KY 40292 \\ $\mathrm{Ph}:$ (304) 208-0856 \\ Email: hmwill07@ louisville.edu
}

\section{EDUCATION}

Doctoral Candidate, Department of Sociology, University of Louisville Expected graduation date - May 2017

Dissertation: Embeddedness and Commitment: Tracing Patterns of Family Instability and Child Wellbeing over Time.

Committee: Robin Högnäs (Chair), Robert Carini, Karen Christopher, Lauren Heberle, Armon Perry

M.A., Sociology, Marshall University, 2003

B.A., Sociology, Marshall University, 2001

Minors: Women's Studies and French

\section{HONORS}

\author{
2015-present Mary Craik Scholarship \\ 2015 M. Celeste Professional Development Award \\ 2014 Outstanding Teaching Award, Department of Sociology, University of \\ Louisville \\ 2013-2016 Graduate Assistantship, Funded by the Department of Sociology and the \\ School for Interdisciplinary and Graduate Studies \\ 2012 Outstanding Women of Marshall Award, presented by the Marshall \\ University Women's Center and the Women's Studies Program
}




\section{TEACHING EXPERIENCE}

Part-time Lecturer, Department of Sociology, University of Louisville Spring 2017

Responsible for developing and teaching Social Problems (SOC 202) and Diversity \& Inequality (323)

Fall 2016

Responsible for developing and teaching Social Stratification (SOC 454), a writingintensive, distance education course; and Social Problems (SOC 202)

Spring 2016

Responsible for developing and teaching two sections (one distance education) of Diversity \& Inequality (323)

Graduate Teaching Assistant, Department of Sociology, University of Louisville Spring 2013-Fall 2015

Responsible for developing and teaching one course per semester, including one summer course.

Taught three sections of Social Theory (SOC 320, Spring 2015, Summer 2015, Fall 2015), two sections of Diversity \& Inequality (SOC 323, Summer and Fall 2014), three sections of Social Problems (SOC 202, Spring and Fall 2013, Spring 2014) and one section of Introduction to Sociology (SOC 201, Summer 2013)

Instructor, Department of Sociology \& Anthropology, Marshall University Academic Year 2011-2012

Developed and taught four sections per semester of Introduction to Sociology (SOC 200), a designated Critical Thinking course

Developed grading rubrics for all written assignments

Developed and administered written and oral examinations

Developed assignments to assess students' level of understanding throughout the semester, including a baseline evaluation

Demonstrated sociological concepts through media

Adjunct Professor, Introduction to Sociology (SOC 200), Marshall University Fall 2008, 2009, 2010, Spring 2011

Developed grading rubrics for all written assignments

Developed and administered written and oral examinations

Developed assignments to assess students' level of understanding throughout the semester, including a baseline evaluation at the beginning

Engaged students in weekly discourse to expand their understanding of the material by facilitating discussions on current events or topics of interest to the students Demonstrated sociological concepts through media 


\section{WORK EXPERIENCE}

Program Coordinator, MU-ADVANCE, Marshall University

2007-2012

Coordinated all activities of the grant, including research design, data collection and analysis, symposia, workshops, and networking events. In addition, wrote quarterly and annual reports to the National Science Foundation on all grant activities.

Disseminated program activities and findings through both the MU-ADVANCE newsletter and the Academic Affairs weekly newsletter. Managed the overall budget and individual faculty fellows' budgets. Served as a liaison and advocate for new female faculty. Interviewed potential female faculty for all open Science, Technology, Engineering and Mathematics positions. Worked collaboratively with the external evaluator to develop progress indicators, measure program outcomes, and implement recommended modifications to programs to ensure success.

Scheduled and prepared materials for all meetings. Supervised 1-3 graduate students per semester. Co-wrote the no-cost extension and renewal grant (both of which were awarded).

Administrative Assistant, Experimental Program to Stimulate Competitive Research (EPSCoR), Marshall University

2003-2007

Planned, wrote, and created all publicity materials. Organized and wrote progress reports. Planned and executed conferences and meetings. Organized a visiting scientist program. Assisted with the coordination of development opportunities for students and faculty. Maintained faculty budgets.

Graduate Assistant, Women's Center, Marshall University

2001-2003

Coordinated special events, recruited speakers, educated campus on women's issues by conducting dormitory programs and providing information tables on campus, and provided support to individual and/or groups on women's issues.

Research Assistant, Center for the Study of Ethnicity \& Gender in Appalachia, Marshall University 2002

Researched archives related to the 1974 Kanawha County (West Virginia) Textbook Controversy. 


\section{PAPERS}

\section{Journal Articles}

Högnäs, Robin .S. and Heidi Williams. Forthcoming. "Maternal Kinship Involvement and Father Identity in Fragile Families." Journal of Family and Economic Issues. Published online April 11, 2016. doi: 10.1007/s10834-016-9487-2.

Williams, Heidi and Robin S. Högnäs. In Review. "Exploring Postsecondary Educational Resident Programs for Low-Income Single-Parents in a Midwestern U.S. City: A Process Evaluation." Journal of Sociology and Social Welfare.

\section{In Progress}

Williams, Heidi. "For Us or the Children: Coparenting Associations in Parental Commitment."

Williams, Heidi. "Maternal Partnership Transitions and Coresidence with Extended Kin."

Williams, Heidi. “'Nest effects: How children fare when changes occur within their microsystems."

Högnäs, Robin S. and Heidi Williams. "Family Structure Transitions, Social Support, and Maternal Health."

Williams, Heidi M. "Conceptualizing support: An analysis of social support from residentially secure, low-income, single mothers."

\section{PRESENTATIONS}

Williams, Heidi M., Cheryl L. Crane, and Christa J. Moore. "Do Community Programs Make 'Better' Mothers?' Panel presentation at the Sociologists for Women in Society 2016 Annual Meeting, held February 4-7, in Memphis, Tennessee.

Högnäs, Robin S. and Heidi M. Williams. "Family Structure Transitions, Social Support, and Maternal Health." Paper presented at the Population Association of America 2015 Annual Meeting, held April 30-May 2, in San Diego, California.

Högnäs, Robin S. and Heidi M. Williams. "Is She the Boss of Us?: Maternal Grandmothers and Father Identity in Fragile Families." Paper presented (by Williams) at the Population Association of America 2014 Annual Meeting, held from May 1-3, 2014, in Boston, Massachusetts. 
Williams, Heidi M. "Corporate Power and The food Industry: Spam.” Paper presented at the 1st Annual Undergraduate Research and Creativity Conference, April 2001, Huntington, West Virginia.

\section{POSTER PRESENTATIONS}

Williams, Heidi M. "For Us or the Children: Dedication and Constraints in Parental Commitment." Poster presentation at the Southern Sociological Society's 2016 Annual Meeting, held April 13-16, 2016, in Atlanta, Georgia.

Harrison, Marcia A., Williams, Heidi M., Baker, Elaine, Delidow, Beverly, Logan, Patricia, \& Silver, Judith. Disseminating Successful Practices of MU-ADVANCE: Advancing Women in STEM (Science, Technology, Engineering, and Mathematics) at Marshall. Poster presented (by Williams) at the 9th Annual Institutional Transformation Principal Investigator's Meeting, Arlington, VA, October 2010.

Harrison, Marcia A., Williams, Heidi M., Baker, Elaine, Delidow, Beverly, Logan, Patricia, \& Silver, Judith. MU-ADVANCE: Developing Faculty-Administrator Partnerships to Drive Institutional Change. Poster presented (by Williams) at the 8th Annual Institutional Transformation Principal Investigator's Meeting, Arlington, VA, October 2009.

Harrison, Marcia A., Williams, Heidi M., Baker, Elaine, Delidow, Beverly, Logan, Patricia, \& Silver, Judith. MU-ADVANCE YR2: Successes and Challenges at an Appalachian Primarily Undergraduate Institution. Poster presented (by Williams) at the 31st Annual Appalachian Studies Association Conference, Huntington, W.V., March 2008.

Harrison, Marcia A., Cartwright, Tina J., Williams, Heidi M., Baker, Elaine, Miezio, Kathleen, \& Murray, Elizabeth. MU-ADVANCE YR1: Successes and Challenges at an

Appalachian Primarily Undergraduate Institution. Poster presented (by Williams) at the 6th Annual ADVANCE Institutional Transformation Principal Investigator's Meeting, Arlington, VA., June 2007.

\section{SERVICE}

2015-2016 President, Sociology Graduate Student Association

2014 Textbook Reviewer for Sage, Introduction to Sociology, 2nd ed. by George Ritzer (chapters 9-12)

2013-2015 Vice President, Sociology Graduate Student Association

2013-present Peer Mentor, Department of Sociology, University of Louisville 


\section{SERVICE continued}

Serve as a peer mentor for four female graduate students, two at the University of Louisville, one at Marshall University, and one at Governors State University

2012-13 Graduate Student Representative, Faculty Department Meetings, Department of Sociology, University of Louisville

2012 Textbook Reviewer for Pearson, The NYU Sociology Project (chapter reviews)

2012 Media Reviewer for Pearson, The Sociology Core Concepts Video Series

2011 Textbook Reviewer for Sage, Our Social World: Introduction to Sociology

2010-2012 Member, Advisory Board, Marshall University Women's Studies Program, Huntington, West Virginia.

2007-2009 Vice President, Board of Directors, CONTACT Rape Crisis Center, Nonprofit organization, Huntington, West Virginia.

2007 Member of the Board of Directors, CONTACT Rape Crisis Center, Nonprofit organization, Huntington, West Virginia.

2006 Series Editor Assistant, Ohio University Press, Athens, Ohio.

\section{AWARDS \& GRANTS}

Graduate Network in Arts \& Sciences

Title: For Us or the Children: Dedication and Constraints in Parental Commitment

Award: $\$ 100$

M. Celeste Nichols Professional Development Award

Title: Do Community Programs Make "Better" Mothers?

Award: $\$ 400$

Graduate Student Council Travel Award

Title: Do Community Programs Make "Better" Mothers?

Award: $\$ 300$

Department of Sociology Travel Award

Title: Do Community Programs Make "Better" Mothers?

Award: $\$ 300$ 


\section{AWARDS \& GRANTS continued}

Graduate Student Union Travel Award

Title: Is She the Boss of Us?: Maternal Grandmothers and Father Identity in Fragile Families Award: \$100

Graduate Student Council Travel Award

Title: Is She the Boss of Us?: Maternal Grandmothers and Father Identity in Fragile

Families Award: $\$ 300$

Department of Sociology Travel Award

Title: Is She the Boss of Us?: Maternal Grandmothers and Father Identity in Fragile

Families Award: \$100

\section{PROFESSIONAL ORGANIZATIONS}

Population Association of America, 2014-present

Sociologists for Women in Society, 2015-present

Southern Sociological Society, 2015-present

American Sociological Association, 2016-present

\section{PROFESSIONAL DEVELOPMENT}

"Fragile Families Summer Data Workshop 2016," hosted by the Columbia Population Research Center, June 15-17, 2016.

“Ack! My Dissertation Feels Like a Bloated Elephant," facilitated by Meggin McIntosh, March 4, 2016.

"The Publishing Academy," a semester-long series of workshops on how to be successful at publishing. Spring 2016 semester.

"Poised for Life...Poised for Success: Maintaining Balance and Equilibrium as a Woman In Academia," facilitated by Meggin McIntosh, Ph.D., February 28, 2008.

"Deputize...Then Delegate," facilitated by Meggin McIntosh, Ph.D., November 21, 2009.

"Publish and Flourish," facilitated by Tara Gray, Ph.D., June 28, 2010.

"Writing Across the Curriculum Training," facilitated by Shirley Lumpkin, Ph.D., October 15-16, 2011. 